University of Louisville ThinkIR: The University of Louisville's Institutional Repository

Electronic Theses and Dissertations

$12-2014$

\title{
An examination of the relationship between sense of coherence, engagement in health behaviors, and individual coping style.
}

Dean Todd Misener 1973-

University of Louisville

Follow this and additional works at: https://ir.library.louisville.edu/etd

Part of the Community Health and Preventive Medicine Commons, Preventive Medicine Commons, and the Public Health Education and Promotion Commons

\section{Recommended Citation}

Misener, Dean Todd 1973-, "An examination of the relationship between sense of coherence, engagement in health behaviors, and individual coping style." (2014). Electronic Theses and Dissertations. Paper 1750.

https://doi.org/10.18297/etd/1750

This Doctoral Dissertation is brought to you for free and open access by ThinkIR: The University of Louisville's Institutional Repository. It has been accepted for inclusion in Electronic Theses and Dissertations by an authorized administrator of ThinkIR: The University of Louisville's Institutional Repository. This title appears here courtesy of the author, who has retained all other copyrights. For more information, please contact thinkir@louisville.edu. 


\title{
AN EXAMINATION OF THE RELATIONSHIP BETWEEN SENSE OF COHERENCE, ENGAGEMENT IN HEALTH BEHAVIORS, AND INDIVIDUAL COPING STYLE
}

\author{
By \\ Dean Todd Misener \\ B.S.P.E, University of Saskatchewan, 1997 \\ M.P.H., Western Kentucky University, 2002

\begin{abstract}
A Dissertation
Submitted to the Faculty of the in Partial Fulfillment of the Requirements

for the Degree of

Doctor of Philosophy

Department of Health Promotion and Behavioral Science

University of Louisville

Louisville, Kentucky
\end{abstract} \\ School of Public Health and Information Sciences of the University of Louisville
}

December 2014 



\title{
AN EXAMINATION OF THE RELATIONSHIP BETWEEN SENSE OF COHERENCE, ENGAGEMENT IN HEALTH BEHAVIORS, AND INDIVIDUAL COPING STYLE
}

\author{
By \\ Dean Todd Misener \\ B.S.P.E., University of Saskatchewan, 1997 \\ M.P.H., Western Kentucky University, 2002 \\ A Dissertation Approved on
}

August 29, 2014

by the following Dissertation Committee

Richard Wilson, DHSc, MPH - Dissertation Director

A. Scott LaJoie, $\mathrm{PhD}$

Aaron Hughey, $\mathrm{PhD}$

Kristi King, $\mathrm{PhD}$ 


\section{ACKNOWLEDGMENTS}

There are many people that I need to thank for their part in helping me achieve this academic milestone. My parents, Don and Bonnie Misener laid the foundation of work ethic and drive into my upbringing and continue to provide a steady stream of unconditional love and support to me in all of my endeavors. For that and so much more I am immeasurably grateful. I could not have even begun this process were in not for the overwhelming support of my supervisor and colleagues at WKU, particularly those in the Health \& Fitness Lab (Alissa Arnold, Sabrina Pate, Lindsay Thomayer, and Jaroslava Voracova) who have routinely supported my efforts to better myself and who sheltered me from distractions when I needed to focus on my work. To all of them, I am tremendously grateful. To my friend and running partner Dr. Pitt Derryberry, thank you for your encouragement and advice while we logged those many miles and thank you to Dr. Bob Cobb for your blunt counsel and encouragement. To my committee chair Dr. Richard Wilson, who mentored me through my Masters and Doctoral programs, thank you for your calm leadership and encouragement, for that and much more I am very grateful. To my committee members, Dr. Aaron Hughey, Dr. Kristi King, and Dr. Scott La Joie, thank you for your expertise, encouragement, and time throughout this process. Finally, to my wife Jenny, thank you for loving me, supporting me, and enduring this endeavor. I never could have considered beginning this program without your support. You took on so much while I travelled to class each week, you allowed the kids to stay up a little later so I could tuck them in, you watched over and cared for our kids while I 
studied on weekends and evenings, you sacrificed so much of your time and energy so I could achieve this goal. My love and appreciation for all you do and all you did to support me is without end. In closing, to my kids (Alex, Mary, and Sarah) thank you for the hugs, kisses and unconditional love you give to me every day. No matter, how hard the days were, you always brought light and love to my world. 


\begin{abstract}
AN EXAMINATION OF THE RELATIONSHIP BETWEEN SENSE OF

COHERENCE, ENGAGEMENT IN HEALTH BEHAVIORS, AND INDIVIDUAL COPING STYLE
\end{abstract}

Dean Todd Misener

August 29, 2014

Stress is a pervasive issue among traditional college students; affecting their choice in health behaviors, and overall academic performance. What is not clear is why some students, despite the pervasiveness of stressors are able to do well in school and maintain/improve their health, while other students struggle to maintain their health and do poorly in school. Aaron Antonovsky theorized that when confronted with a stressor a person with a high sense of coherence (SOC) will be motivated to cope, believe the challenge is understood and that the necessary resources to cope with the stressor are available. Overall, Antonovsky theorized that SOC is a significant factor contributing to overall health. The purpose of this study was to measure sense of coherence (SOC) in a sample of traditional aged U.S. college students, measure its relationship to perceived stress, coping style, health behaviors, and grade point average, and determine if coping style serves as a mediator between SOC and the engagement in pro-health behaviors. A total of 380 college students aged 18-24 years of age completed a 59 item questionnaire measuring sense of coherence, dispositional coping, perceived stress, and health behavior 
engagement. Correlational, regression and mediation analyses were used to analyze the data. The results of this study revealed that within the study population, SOC had a statistically significant positive relationship with the engagement in pro-health behaviors, problem-focused coping, and GPA; and had a statistically significant negative correlation with perceived stress, and emotion-focused coping. The results of a multi-variable mediation analysis using a bootstrapping statistical resampling process showed that emotion-focused coping and problem-focused coping acted as a statistically significant mediator between SOC and the engagement in pro-health behaviors within the study population. Overall, within this study dispositional coping was a significant mediator in the relationship between SOC and health behavior engagement, students scoring higher in SOC used fewer emotion-focused coping styles, reported lower perceived stress and had significantly higher term and cumulative GPA's than those students who scored lower SOC. Limitations and implications of this study are discussed. 


\section{TABLE OF CONTENTS}

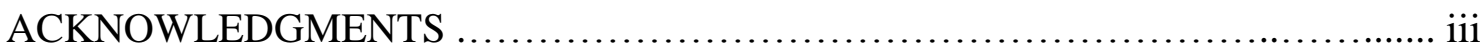

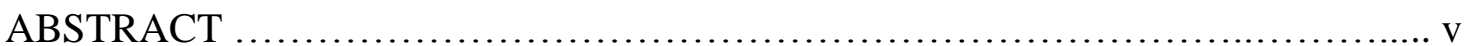

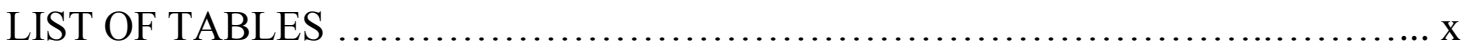

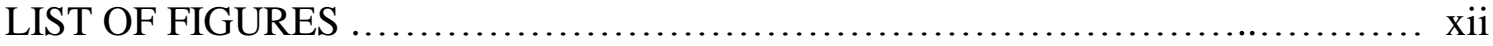

\section{CHAPTER 1: INTRODUCTION TO THE STUDY}

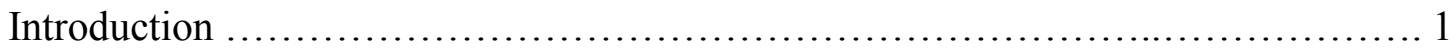

Statement of the Problem ................................................. 10

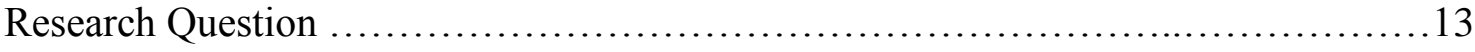

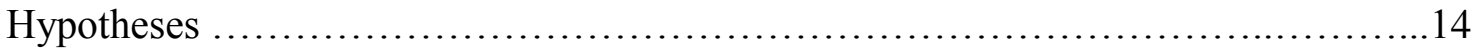

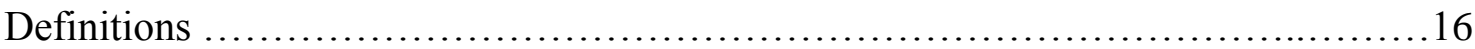

\section{CHAPTER 2: REVIEW OF LITERATURE}

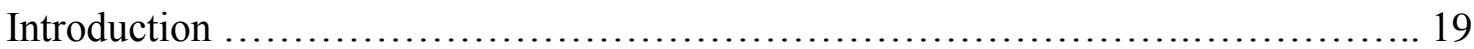

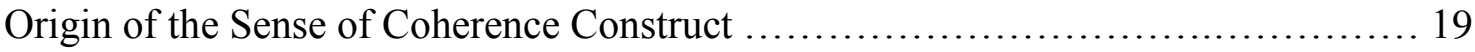

Generalized Resistance Resources .............................................20

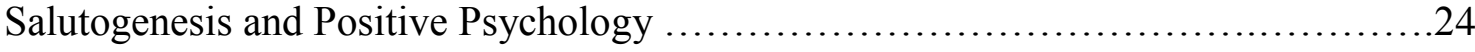

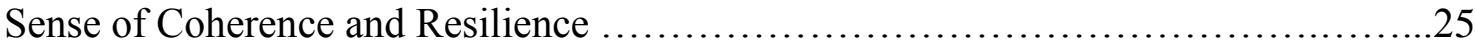

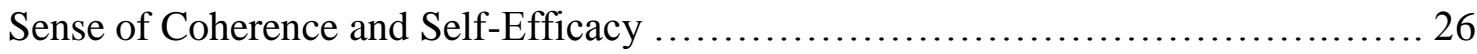

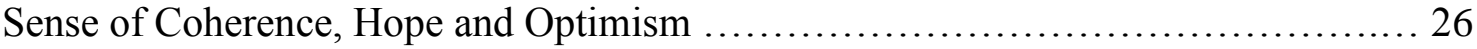

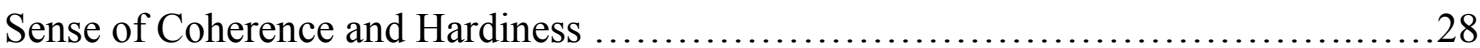

Validity and Reliability of the Sense of Coherence Construct ..................... 29

How Sense of Coherence Changes Over Time .................................. 31 


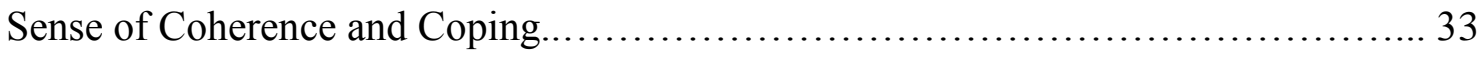

Sense of Coherence and Perceived Stress ...................................... 36

Sense of Coherence and Health Behaviors ....................................... 38

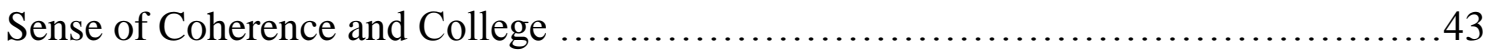

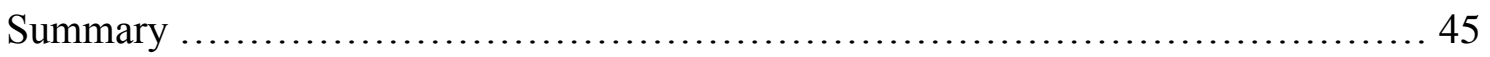

\section{CHAPTER 3: METHODOLOGY}

Introduction ...................................................................... 46

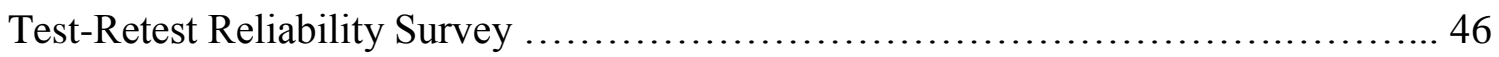

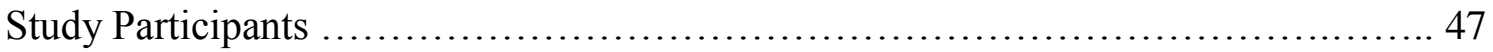

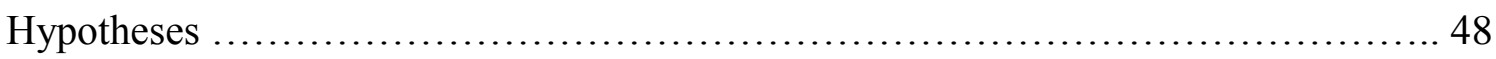

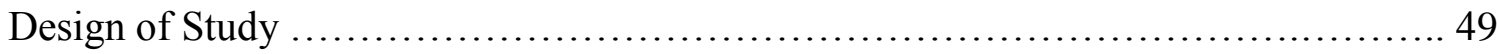

INSTRUMENTS:

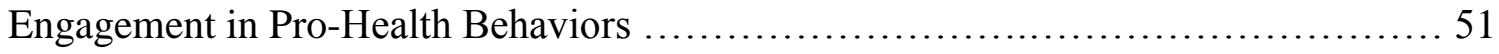

Alcohol Consumption Scoring Rules ............................................ 54

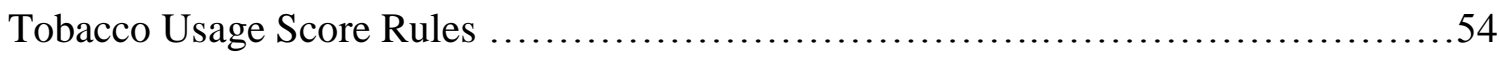

Fruit \& Vegetable Consumption Scoring Rules .................................. 55

Cardiovascular Exercise Scoring Rules ........................................... 55

Strengthening Exercise Scoring Rules ........................................ 56

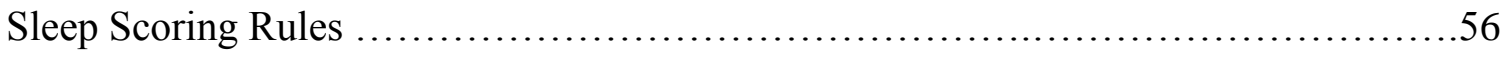

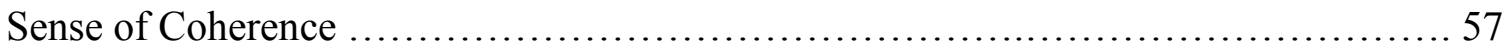

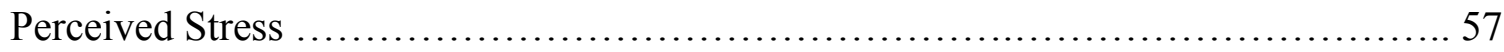

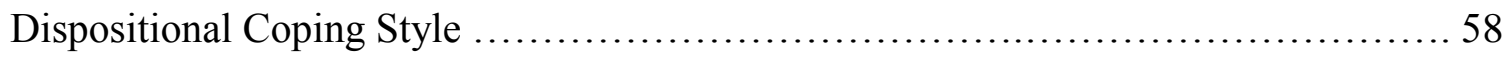


Data Analysis .......................................................... 60

Mediation Analysis ....................................................... 61

\section{CHAPTER 4: RESULTS}

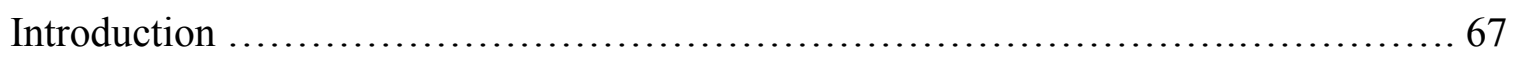

Sense of Coherence ................................................... 70

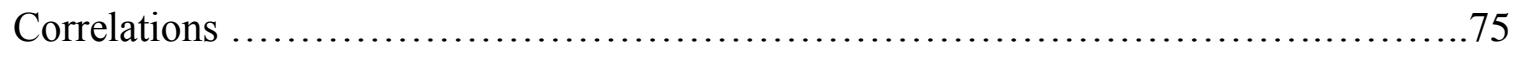

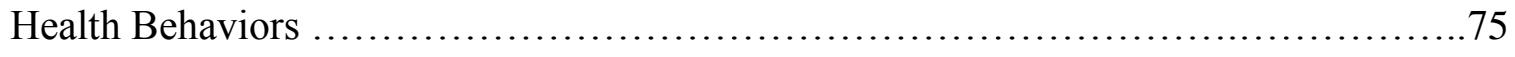

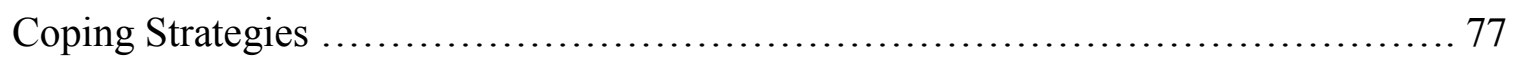

Pro-Health Behaviors and Coping Strategies ................................. 80

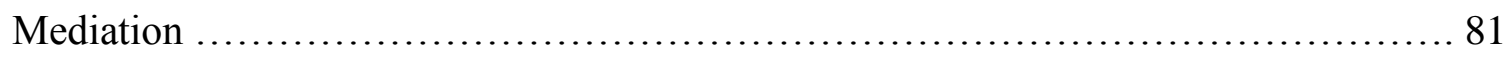

Academic Performance ................................................... 87

\section{CHAPTER 5: DISCUSSION}

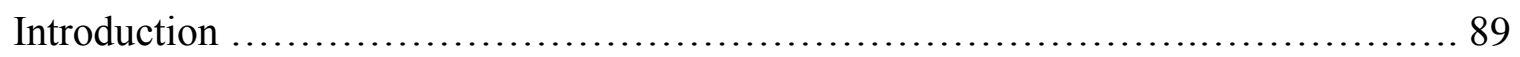

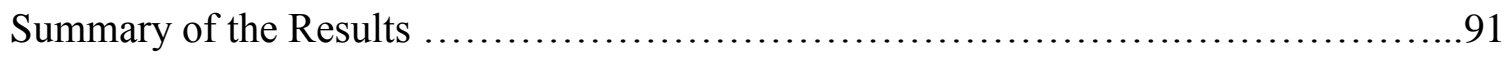

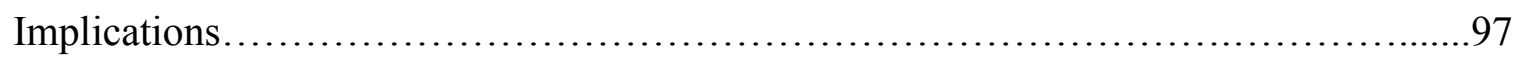

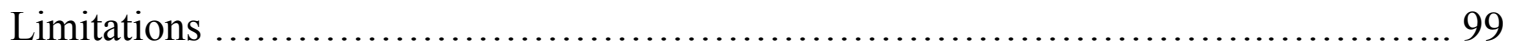

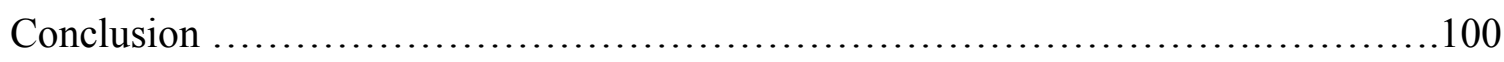

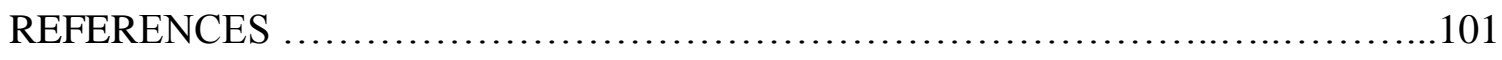

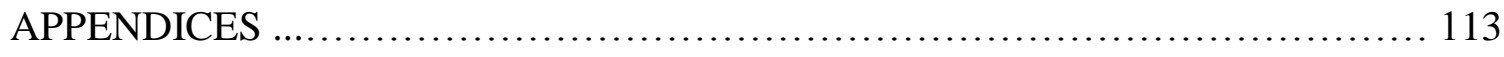

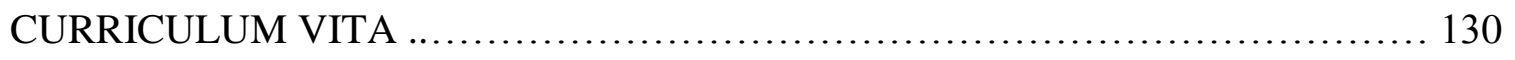




\section{LIST OF TABLES}

$\begin{array}{lll}\text { TABLE } & \text { PAGE }\end{array}$

1. Survey Administration Breakdown by College, Number of Students

Enrolled and Total Number of Surveys Completed ..........................68

2. Breakdown of Undergraduate Student Classification for Sample

Population

3. Sample Race and Gender Breakdown \& Comparison with Total

Institutional Undergraduate Population

4. Results of Independent Samples t-Test Comparing Mean Perceived

Stress, Problem-Focused Coping, Emotion-Focused Coping, and Health

Behavior Scores, of Male and Female Students

5. Results of Independent Samples t-Test Comparing Mean Perceived

Stress, Problem-Focused Coping, Emotion-Focused Coping, and Health

Behavior Scores, of Caucasian and Minority Students

6. Zero-Order Correlations Between Sense of Coherence, Perceived

Stress, Emotion-Focused Coping, Problem-Focused Coping, Health Behavior

Score, and Term Grade Point Average (GPA) ............................... 74

7. Independent Samples t-Test Results Comparing Mean SOC scores Based on Each

Health Behavior Stratification (Zero or One)

8. Model Summary of Total Effect of SOC on Number of Pro-Health Behaviors

Reported, Controlling for Age, Gender, Ethnicity, and International Status 
9. Model Summary of Total Effect of SOC on Problem-Focused Coping Score, Controlling for Age, Gender, Ethnicity, and International Status

10. Model Summary of Total Effect of SOC on Emotion-Focused Coping Score, Controlling for Age, Gender, Ethnicity, and International Status .86

11. Model Summary of Total Effect of SOC, Problem-Focused Coping, and EmotionFocused Coping on Number of Pro-Health Behaviors Reported, Controlling for Age, Gender, Ethnicity, and International Status .86

12. Summary of $95 \%$ Bias Corrected and Accelerated Boot-Strapped Confidence Intervals For the Indirect Effect of Problem-Focused and Emotion-Focused Coping on the Relationship Between SOC and Number of Reported Pro-Health Behaviors, Controlling for Age, Gender, Ethnicity, and International Status .87

13. Correlation between Sense of Coherence and Perceived Stress, and Cumulative and Term Grade Point Average from a Sample of Traditional U.S. College Students....88 


\section{LIST OF FIGURES}

$\begin{array}{ll}\text { FIGURE } & \text { PAGE }\end{array}$

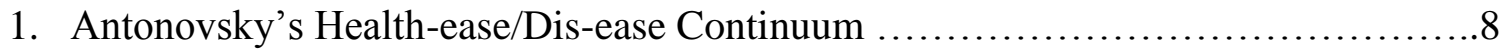

2. Mediation model testing the degree to which emotion-focused and problem focused coping mediate the relationship between sense of coherence and the engagement in

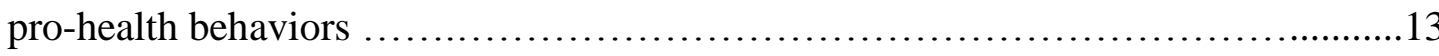

3. The level of sense of coherence and the intensity if health behaviors according to the Inventory of Health Behaviors ................................42

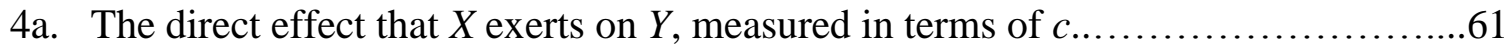

4b. A multi-mediator model depicting the indirect effect of $X$ on $Y$ through two

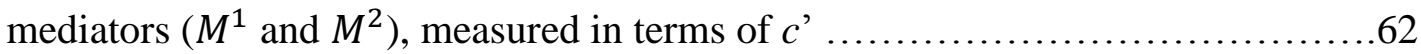

4c. The direct effect that Sense of Coherence exerts on the engagement in pro-health behaviors measured in terms of $c$

4d. Mediation model representing the indirect effect of sense of coherence on the engagement in pro-health behaviors mediated through problem and emotion-focused coping. 
5a. Scatterplot depicting the relationship between Sense of Coherence and EmotionFocused Coping within a Sample of Traditional U.S. College Students $(n=380)$

5b. Scatterplot depicting the relationship between Sense of Coherence and ProblemFocused Coping within a Sample of Traditional U.S. College Students ..............80

6. Mediation model depicting the indirect relationship between sense of coherence and the engagement in pro-health behaviors through problem-focused and emotionfocused coping 


\section{CHAPTER 1 \\ INTRODUCTION TO THE STUDY}

This opening chapter provides an introduction to the study, the conceptual and theoretical foundations of the study, research questions, and significance of the study. The chapter will conclude with a list of terms used in the study and their definitions.

Due in part to the growing competition between world economies employers are demanding a higher number of skilled workers and employees with college degrees. At present there are approximately 17.7 million undergraduate students enrolled in 2 and 4year degree granting institutions in the United States and according to the National Center for Education Statistics by 2020 over 24 million students will enroll in higher education. Traditional college students' aged18-24 years of age represent the vast majority of undergraduate students enrolled at degree granting institutions. In 2012, approximately $88 \%$ of undergraduate students were under the age of 25 . In many ways students enrolling in higher education represent our nations' future. Many by virtue of their education will drive innovation, be leaders of industry, small business owners, and leaders within local, state, and national government. This increasing demand and rising enrollment levels is proving to be more that the present system of higher education can handle. Despite higher education's mission to produce college graduates, the national four year graduate rate for students attending 4 -year institutions is only $38.6 \%$ and the 6 year graduation rate is $59 \%$. Given the overall poor performance of higher education in 
producing college graduates and the growing demand for college graduates it is therefore essential that institutions address factors that impact a students' ability to succeed in higher education (National Center for Education Statistics, 2011, 2012b).

Students attending higher education are confronted by many challenges inside and outside the lecture hall. For many traditional college students, attending college marks the first time in their lives they will live away from home. It is a time where for the first time they will be required to adjust to new social settings, and manage their time and finances. Therefore, it is no surprise that elevated stress is a common, arguably inevitable obstacle that all students will face (Bland, Melton, Welle, \& Bigham, 2012; Pryor et al., 2010). According to the American College Health Associations National College Health Assessment II (ACHA-NCHA II) data more than half (53.2\%) of all students reported experiencing "more than average stress" or "tremendous stress" over the previous 12 months (American College Health Association, 2012). For college students, stressors come from many sources that have variable impacts on their experience of stress. Life events are characterized as stressful when they cause changes in, and demand readjustment of an average person's normal routine (American Psychological Association, 2012). The most commonly reported stressors by students attending higher education include a change in living conditions, conflict with a roommate, pressure from parents to do well in school, concern for a family member and/or friend, academic demands from faculty, conflict with a faculty or staff member, work demands, lack of sleep, financial difficulties, and time management difficulties (Bland et al., 2012; Dusselier, Dunn, Wang, II, \& Whalen, 2005; Economos, Hildebrandt, \& Hyatt, 2008; Hicks \& Heastie, 2008; Pryor et al., 2010; Welle \& Graf, 2011). For 
many students, the common stressors they face have the potential to undermine both their health and academic performance (Grade Point Average (GPA)) (Barry, Hudley, Kelly, \& Cho, 2009; M. Cohen, Ben-Zur, \& Rosenfeld, 2008; Friedlander, Reid, Shupak, \& Cribbie, 2007; Vaez \& Laflamme, 2008).

ACHA defines an academic impact as receiving a lower grade on an exam or an important project, receiving a lower grade in a course, receiving an incomplete or dropping a course, or experiencing a significant disruption in thesis, dissertation, research, or practicum work. According to published results from the ACHA-NCHA, stress has ranked among the top two academic impacts every year since 2000 (American College Health Association, 2006, 2012). There is strong empirical evidence suggesting that stress is positively associated with academic difficulties and lower graduation rates. Fatigue and perceived stress have significant impacts on overall cognitive function and learning abilities in college students (Palmer, 2013). Additionally, students who report elevated levels of stress from academic demands are less likely to graduate (Vaez \& Laflamme, 2008).

Academic difficulties represent only one of the serious byproducts of poorly managed stress. Individual health is also compromised by poorly managed stress. There is ample scientific evidence showing that stress is associated with behaviors that place college student health in jeopardy. College students who report higher levels of perceived stress are less likely to engage in regular physical activity, eat fewer fruits and vegetables, report higher frequency of suicide ideation, engage in binge-eating more frequently, are more likely to consume alcohol, are more likely to be a smoker, and display a greater frequency of procrastination behaviors when compared with students 
reporting lower levels of perceived stress (Bray \& Born, 2004; Dallman et al., 2003; Hudd et al., 2000; Pritchard, Wilson, \& Yamnitz, 2007a; Rice \& Van Arsdale, 2010; Wilburn \& Smith, 2005). These behaviors often are a by-product of a students' response to the stress saturated college environment.

It is important to note that the experience of stress is not limited to the college environment, it is ubiquitous throughout life. In the 1930's Hans Selye first defined stress as "the nonspecific response of the body to any demand, whether it is caused by or results in, pleasant or unpleasant conditions" (Selye, 1976b). Selye first coined the term "stressor" to differentiate between stress as a "nocuous agent" and stress as the effect of the "nocuous agent" (Selye, 1976a). In general, stressors can come from internal or external stimuli that induce the stress response. Selye was the first scientist to discover that all stressors elicit the same physiological response by the body which he termed the "General Adaptation Syndrome" (GAS). According to Selye's GAS, in response to stressors, heart rate and breathing frequency increase, adrenaline is released, and blood moves away from the central organs to the larger muscle groups in preparation for action (Selye, 1950, 1976a). This reaction is more commonly referred to as "the fight or flight" response and represents the first of the three stages of the General Adaptation Syndrome (Selye, 1976a). The final two stages of the GAS are the resistance, and exhaustion stages. The resistance stage is when energy is expended while the body works to resolve the stressor and the exhaustion stage is when the body no longer has the capacity to resolve the stressor and becomes physically and/or mentally exhausted. It is typically in the exhaustion phase that physical and/or mental health is compromised (Selye, 1950, 1976a). 
A stressor by itself is typically benign unless the stressor is a direct overt threat to your health like an automobile accelerating toward you. The degree to which a stressor leads to the experience of stress is largely perceptual and therefore is individually dependent. Richard Lazarus and Susan Folkman, two leading stress researchers define psychological stress as "a particular relationship between a person and the environment where it is appraised by the person as taxing or exceeding his or her resources and endangering his or her well-being"(Lazarus \& Folkman, 1984b). Using the term "psychological" in their characterization of stress further clarifies the nature of stress as being largely perceptual. Stress is based on the perceptual appraisal of a stressor as being a threat or not. If appraised as a threat, the magnitude of the threat is dependent on the subjective capacity of the individual to manage the stressor. It is important to note that stressors are not universally negative or pathogenic. Selye differentiated between two types of stress within his concept of stress. Stress resulting from unpleasant or harmful sources he called "distress" and stress resulting from pleasant sources he called "eustress" (Selye, 1976b). Quick et al. (2013) expanded on Selye's definition of eustress, defining it "as the healthy, positive, or constructive outcome of stressful events and the stress response", conversely they defined distress "as the degree of physiological, psychological, and/or behavioral deviation from an individual's healthy functioning" (Quick, Wright, Adkins, Nelson, \& Quick, 2013). Overall, Selye characterized stress as the "common denominator of all adaptive reactions in the body", therefore depending on the individuals reaction to a stressor, adaptation has the potential to be either pathogenic or salutary (Selye, 1976c). 
There is a tremendous body of research studying the relationship between stress and coping. Coping is defined as the constantly changing cognitive and behavioral efforts to manage internal or external demands that are appraised as taxing or exceeding the resources of the person (Lazarus \& Folkman, 1984a). In 1966, Richard Lazarus first proposed the transactional model of coping. His model consisted of three stages in the coping process: primary appraisal being the first stage where the level of perceived threat is assessed, secondary appraisal being the second stage where ones available capacities and resources to respond to the stressor are assessed, and the coping response where the coping strategy is employed. Within their conceptualization of coping, Lazarus \& Folkman (1984) describe two distinct coping styles: one that is more adaptive and directed at managing or altering the stressor and one that is more maladaptive and directed at regulating the emotional response to the stressor. These coping styles are referred to as problem-focused coping and emotion-focused coping respectively. According to Lazarus \& Folkman (1984) emotion-focused coping occurs more frequently when there is a perception that nothing can be done to alter the threatening, challenging or harmful stressor. Furthermore, they state that problem-focused coping is more likely to occur when there is a perception that the threatening qualities of the stressor are changeable (Lazarus \& Folkman, 1984a). According to research, problem-focused coping is an efficient way to cope with stressful situations and has a positive association with positive affect. Positive affect reflects the presence of positive emotional states including interest, excitement, confidence, and alertness. Emotion-focused coping on the other hand is a more inefficient way to cope with stress and has a positive correlation with negative affect. Negative affect describes subjective distress and dissatisfaction and 
is composed of negative emotional states including anger, fear, disengagement, and disinterest (Ben-Zur, 2002; Carver et al., 1993; M. Cohen et al., 2008; Snell, Siegert, Jean, Hay-Smith, \& Surgenor, 2011).

As described earlier, the experience of stress is pervasive among students attending college, and is associated with poor academic performance and health inhibiting behaviors. What is not clear is why some students, despite the pervasiveness of stressors are able to do well in school and maintain/improve their health, while other students struggle to maintain their health and do poorly in school.

In 1965 Aaron Antonovsky, an American-Israeli medical sociologist was conducting several studies investigating the relationship between stressors and disease. One such study involved the review of research studying the relationship between social class and disease. Through this research he found that poor people had poorer health due in part to their inability to effectively manage stress, resulting in greater exposure to tension. In Antonovsky's view tension was the result of an unresolved interaction with a stressor. What struck him was that theoretically two people who are confronted by the same stressor could produce different outcomes. One outcome being resolved tension, and the other being unresolved tension. These observations along with further research lead Antonovsky to formulate what he termed the "breakdown" concept. His "breakdown" concept was inspired by Selye's general adaptation syndrome and represents the point where Selye's resistance stage transitions to the exhaustion phase, resulting in compromised health. Antonovsky's "breakdown" concept proposed a fundamental distinction between factors that cause a particular disease and factors that diminish an individuals' present state of health. What Antonovsky became interested in 
were the factors that enabled individuals to maintain or improve their current state of health regardless of the presence or absence of disease. In his view, humans enter the world as terminal cases and throughout their lives are all somewhat healthy and somewhat diseased. He believed that no matter the extent of a disease, we all possess the capacity to improve our current level of health. Therefore Antonovsky characterized health status along a continuum between ideal health and death (Figure 1.).

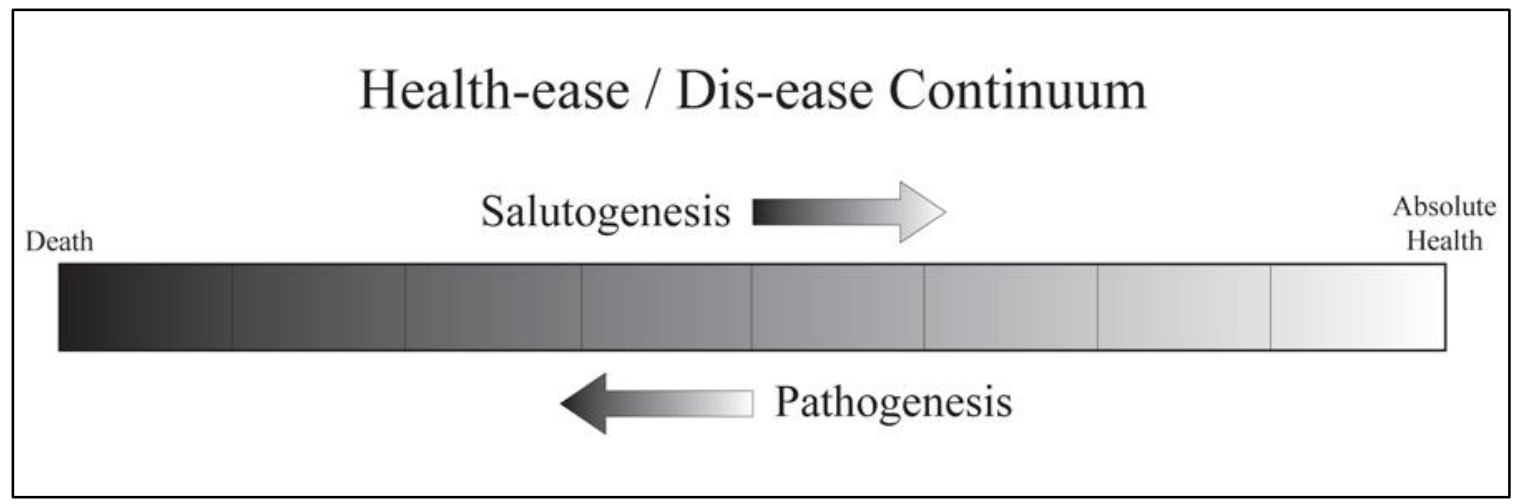

Figure 1. A visual representation of Antonovsky's breakdown theory, where salutogenic factors lead to improved health and pathogenic factors lead to disease and death.

Within his conceptualization, one's position on this continuum is dependent on how well one is able to manage their subjective response to stressors. This initial concept lead Antonovsky to focus on what he termed as "generalized resistance resources" (GRR's) which people use to manage the stressors of life. In general, GRR's are life experiences and assets that contribute to one's ability to cope with stress. Given that the demands on people are so variable and prevalent, Antonovsky chose to explore factors related to successful psychological, social, and cultural adaptation to stressors. Antonovsky contended that stressors are "omnipresent", and that an individuals' position on the "breakdown" continuum is determined to a large extent by how well they manage 
tensions that result from stress. According to Antonovsky, depending on one's ability to manage tension, the state of tension has the potential to have a pathological, neutral or salutary impact on an individual (A. Antonovsky, 1979a, 1979b, 1979c). He emphasized his departure from the pathogenic focus on factors that cause disease to his focus on salutogenic factors that encourage health, which he termed "salutogenesis". The word salutogensis comes from the Latin word "salus", which means health, and the Greek word "genesis" which means origin. It is therefore the study of factors that lead to the improvement of health. Throughout literature the word "stress" is used interchangeably with "distress", "perceived stress", or "psychological stress". Despite the varying expressions of stress they all have the common tie of being affiliated with a condition or outcome that is inherently damaging. Antonovsky's' salutogenic approach to health promotion seeks to rehabilitate our view of stress and stressors as exclusively damaging or disease causing to a perspective of adaptation that see's the presence of a stressor as potentially health promoting. Therefore, in his view health depends on the availability of generalize resistance resources (i.e. life experiences) to successfully cope with stress.

Over the next 10 years Antonovsky developed the Orientation to Life Questionnaire (OLQ) to assess an individual's capacity to manage stressful life situations. He termed this capacity as an individual's sense of coherence (SOC). Antonovsky defined sense of coherence (SOC) as a generalized orientation toward the world that is measured on continua of comprehensible, manageable, and meaningful (A. Antonovsky, 1993). In Antonovsky's view GRR's contribute in varying amounts to each of the three continua however he does note that SOC is a distinct measure that should not be separated into its three subcomponents. Research has validated his assertion. According 
to factor analyses of the 29 item version and 13 item version of the OLQ SOC is indeed a distinct measure that should not be used to differentiate between measures of comprehensibility, manageability, and meaningfulness (Bernabé et al., 2009a; Eriksson \& Lindstrom, 2005; Frenz, Carey, \& Jorgensen, 1993; Keeling \& Hersh, 2011). Antonovsky theorized that when confronted with a stressor a person with a high SOC will be motivated to cope, believe the challenge is understood and that the necessary resources to cope with the stressor are available. Overall, Antonovsky theorized that SOC is a significant factor contributing to overall health (A. Antonovsky, 1996).

Empirical evidence indicates that an individual's SOC develops throughout childhood into early adulthood and tends to increase with age (M. Cohen et al., 2008; Hakanen, Feldt, \& Leskinen, 2007). It is a by-product of the interaction between an individual and the social and cultural environment in which he or she is raised and lives (M. Cohen et al., 2008; J. P. Grayson, 2007). Research supports Antonovsky's theory that individuals with high SOC will tend to choose effective coping strategies that lead to lower perceived stress (Grayson, 2007; Hicks \& Heastie, 2008; Smedley, Myers, \& Harrell, 1993). Antonovsky's theory proposes that the resulting lower stress response leads to improved health however he does not articulate a causal pathway to health (A. Antonovsky, 1996; Welle \& Graf, 2011).

Statement of the Problem

Within the traditional college student population (students aged 18-24), there is strong evidence that the experience of stress is related to poor academic performance, and the increased incidence of health inhibiting behaviors including smoking, lack of physical activity, and excessive alcohol consumption (Bray \& Born, 2004; Dallman et al., 2003; 
Pritchard et al., 2007a; Rice \& Van Arsdale, 2010; Rod, Grønbaek, Schnohr, Prescott, \& Kristensen, 2009). Therefore depending on a students' ability to manage stress, the experience of stress has the potential to undermine a college students' health and success.

Research has consistently shown that stress is negatively associated with SOC (M. Cohen et al., 2008; McSherry \& Holm, 1994; Sarenmalm, Browall, Persson, FallDickson, \& Gaston-Johansson, 2013). There is also evidence that SOC has a positive relationship with various health promoting behaviors including, self-care, physical activity, and the consumption of fruits and vegetables, and SOC has a negative relationship with health inhibiting behaviors including smoking, alcohol consumption, sedentary behaviors, and sugar intake (Bernabé et al., 2009b; Suominen, Blomberg, Helenius, \& Koskenvuo, 1999; Wainwright et al., 2007). Overall the research indicates that SOC has the potential to predict the engagement in health behaviors and academic success within a traditional college student population. Since Antonovsky first introduced the SOC in construct in 1979 the majority of the research has been conducted in Scandinavian countries and Israel where Antonovsky developed his theories. The most recent published systematic review of research involving the SOC construct reported that it had been studied in 32 countries with the majority being conducted in Scandinavian and European countries (Eriksson \& Lindstrom, 2005). Through the present literature review only 20 of the 92 studies reviewed were conducted in the United States and of those only 14 used undergraduate students as the study population. To date no study has investigated the relationship between SOC, and health behaviors within the traditional aged U.S. college student population. Therefore this study will cast further light on the predictive value of the SOC construct within the traditional aged U.S. college 
student. Additionally, the literature also shows that the use of adaptive coping strategies are associated with lower stress, improved health, and improved academic achievement within the college student population (Devonport \& Lane, 2006; Hsieh, Sullivan, Sass, \& Guerra, 2012; Mahmoud, Staten, Hall, \& Lennie, 2012; Snell et al., 2011). While Antonovsky contends that SOC does not predict a specific coping style, there is evidence in the literature to suggest that a high SOC is associated with a greater tendency to employ more problem-focused coping strategies and a low SOC is associated with more emotion-focused health behaviors. The reported interactions between SOC, coping style, and health behaviors provide evidence that a mediating relationship may exist between SOC and the engagement in health influencing behaviors. In 2000, Amirkhan and Greaves studied the mechanisms of how SOC influences health within a traditional aged U.S. college student population. They found that coping acted as a partial mediator in the relationship between SOC and health as measured by the General Health Questionnaire (Keeling \& Hersh, 2011). The present study will also seek to expand on the findings of Amirkhan and Greaves and investigate the relationship between SOC, the engagement in health promoting behaviors, and coping style. Overall, this study will be the first to investigate the interaction between SOC, health behaviors, and coping style within any population and will provide valuable insight into how these variables relate. The results of this study will add to the understanding of how SOC is related to pro-health behaviors of traditional aged (18-24 years) U.S. college students and further shed light on the potential use of SOC as a predictor of student health and success in higher education. 


\section{Research Question:}

Does coping style mediate the relationship between frequency of health behaviors and sense of coherence among Traditional U.S. college students aged 18-24 attending a 4 year public university?

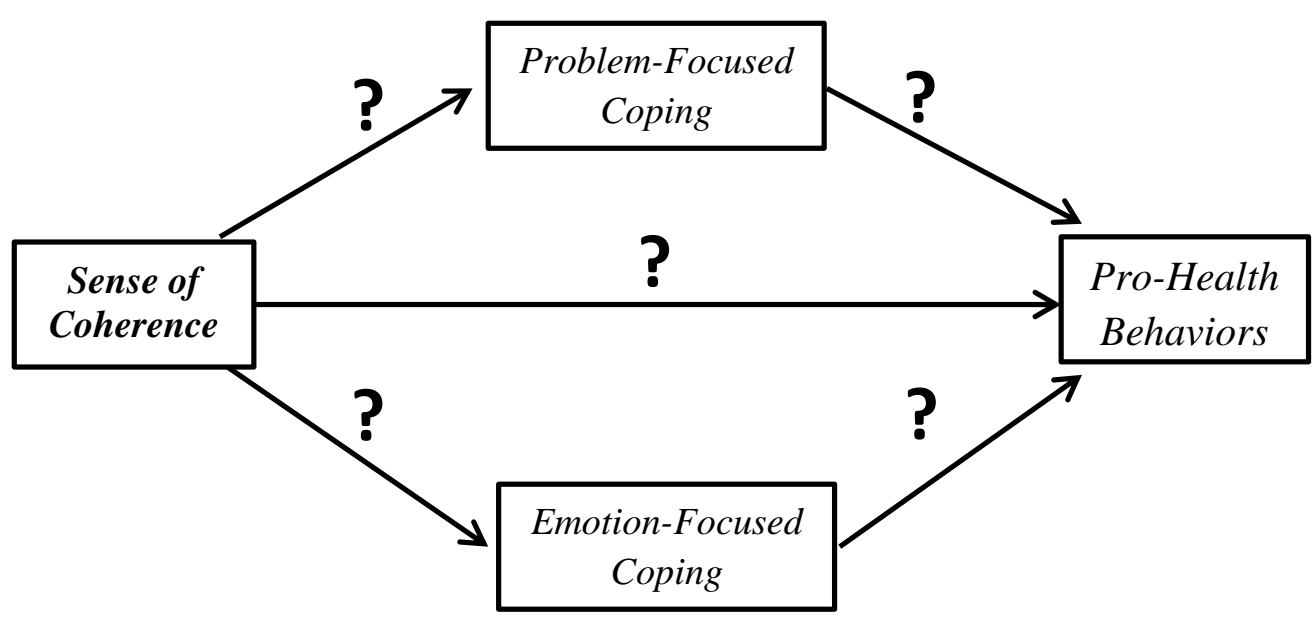

Figure 2. A Mediation model testing the degree to which emotion-focused coping and problem-focused coping mediate the relationship between sense of coherence and the engagement in pro-health behaviors. Sense of coherence is measured using the 13 item questionnaire Orientation to Life Questionnaire scored from 13-91(A. Antonovsky, 1987c). Problem-focused coping and emotion focused coping are measured using the Brief Cope, scores for problem-focused coping range from 8 - 32 and scores for emotionfocused coping range from $6-24$ (Carver, 1997). Pro-health behaviors are measured using questions taken from the American College Health Associations, National College Health Assessment measuring self-reported smoking habits, alcohol consumption patterns, fruit and vegetable consumption, cardiovascular exercise and strengthen exercise habits, and average sleep hours per night. Respondents receive a score of zero or one based on their responses (American College Health Association, 2013). Zero 
indicates they are not engaging in the pro-health behavior and one indicates they are engaging in the pro-health behavior. Score for pro-health behavior range from $0-6$. Hypotheses:

Null Hypothesis I:

There will be no statistically significant relationship between SOC and the engagement in pro-health behaviors by traditional aged U.S. college students. Null Hypothesis II:

There will be no statistically significant relationship between SOC and the Problem-Focused Coping score of traditional aged U.S. college students. Null Hypothesis III:

There will be no statistically significant relationship between SOC and the Emotion-Focused Coping score of traditional aged U.S. college students. Null Hypothesis IV:

There will be no statistically significant relationship between Problem-Focused Coping and the engagement in pro-health behaviors by traditional aged U.S. college students.

Null Hypothesis V:

There will be no statistically significant relationship between Emotion-Focused Coping and the engagement in pro-health behaviors by traditional aged U.S. college students. 


\section{Null Hypothesis: VI}

There will be no statistically significant mediating effect of Problem-Focused Coping on the relationship between SOC and the engagement in pro-health behaviors by traditional aged U.S. college students.

Null Hypothesis VII:

There will be no statistically significant mediating effect of Emotion-Focused Coping on the relationship between SOC and the engagement in pro-health behaviors by traditional aged U.S. college students.

Null Hypothesis VIII:

There will be no statistically significant relationship between SOC and Term Grade Point Average of traditional aged U.S. college students. 
Definitions:

Coping: "Constantly changing cognitive and behavioral efforts to manage specific external and/or internal demands that are appraised as taxing or exceeding the resources of the person" (Lazarus \& Folkman, 1984a).

Dis-ease: Factors that contribute to ones' movement toward the disease/death end of the Health-ease/Dis-ease Continuum (A. Antonovsky, 1979a).

Distress: The degree of physiological, psychological, and/or behavioral deviation from an individual's healthy functioning (Quick et al., 2013).

Emotion-Focused Coping (Maladaptive): Cognitive and behavioral efforts directed at managing the emotional response to a stressor. Emotion-focused coping occurs more frequently when there is a perception that nothing can be done to alter the threatening, challenging or harmful stressor. (Lazarus \& Folkman, 1984a).

Eustress: The healthy, positive, or constructive outcome of stressful events and the stress response (Quick et al., 2013).

Generalized Resistance Resources: A set of life experiences that contribute to ones' capacity to successfully cope with the stressors of life; they help individuals make sense of internal and external stimuli, and removes the noise and confusion.(A. Antonovsky, 1996)

Hardiness: A personality characteristic that is an important factor in mediating the effects of stress on individual health. Hardiness consists of three subcomponents: control, commitment, and challenge (Kobasa, 1979).

Health-ease: Factors that contribute to ones' movement toward the optimal health end of the Health-ease/Dis-ease Continuum (A. Antonovsky, 1979a). 
Hope: A measure of ones beliefs in their ability to plan for and motivate oneself to pursue one's goals (Davidson, Feldman, \& Margalit, 2012).

Negative Affect: Reflects the presence of subjective distress and dissatisfaction and is composed of negative emotional states including anger, fear, sadness, guilt, contempt, and disgust (Ben-Zur, 2002).

Optimism: An individual difference measure that reflects the extent to which individuals hold generally favorable expectancies for the future (Carver, Scheier, \& Segerstrom, 2010).

Pathogenesis: The study of factors associated with the origins and prevention of disease (A. Antonovsky, 1987c).

Positive Affect: Reflects the presence of subjective positive emotional states including interest, excitement, confidence, and alertness (Ben-Zur, 2002).

Positive Psychology: Positive psychology seeks to answer the question about what makes life worth living. At the individual level, positive psychology is about positive individual traits including the capacity to love, wisdom, perseverance, and sense of coherence. How individuals flourish under conditions ranging from benign to toxic. It seeks to identify and build the qualities that lead to and enhance health and well-being (M. Seligman \& M. Csikszentmihalyi, 2000).

Problem-Focused Coping (Adaptive): Cognitive and behavioral efforts directed at altering or managing a stressor. Problem-focused coping is more likely to occur when there is a perception that the threatening qualities of the stressor are changeable (Lazarus \& Folkman, 1984a). 
Resilience: The ability to recover from or adjust to physical and/or psychological stressors (Merriam-Webster, 2013; Rutter, 1985).

Salutogenesis: The study of factors associated with effective management of stressors leading to health promoting outcomes. (A. Antonovsky, 1987c).

Self- Efficacy: An individuals' perception about their ability to control events affecting their lives and speaks to the level of confidence one possesses about their ability to successfully execute necessary actions to manage life events (Johnson, Oliff, \& Williams, 2011).

Sense of Coherence: A construct that evaluates that capacity of an individual to select effective copy strategies to manage life stressors. "A global orientation that expresses the extent to which one has a pervasive, enduring though dynamic feeling of confidence that the stimuli deriving from one's internal and external environments in the course of living are structured, predictable, and explicable; the resources are available to one to meet the demands posed by these stimuli; and these demands are challenges worth of investment and engagement" (A. Antonovsky, 1987a).

Stress: "The nonspecific response of the body to any demand, whether it is caused by or results in, pleasant or unpleasant conditions" (Selye, 1976b).

Stressor: Internal or external stimuli that induce the stress response(Selye, 1976b) . Tension: The physiological and psychological precursor to stress. Unresolved tension results in stress (Aaron Antonovsky, 1979). 


\section{CHAPTER 2}

\section{REVIEW OF LITERATURE}

This chapter will explore a broad review of relevant literature regarding the SOC construct. The literature review will begin with a detailed review of generalized resistance resources, constructs similar to SOC within the literature, validity and reliability information relative to the SOC construct, and how SOC changes over time. Following the detailed review of the SOC construct, research relevant to the research question will be reviewed including the relationship between SOC and coping styles, the relationship between SOC and perceived stress, SOC among college student populations, and the relationship between SOC and health behaviors.

Origin of Sense of the Coherence Construct:

Prior to discovering the SOC construct, Antonovsky had grown dissatisfied with what he characterized as a focus on the causes of disease that dominated health research and practice. Though he acknowledged the value of understanding the cause of disease, Antonovsky was concerned with the lack of focus on the salutary aspects of health. Antonovsky described his salutogenic orientation as a departure from the typical aphorism shared by those who embrace disease care, and disease prevention orientations (pathogenic approach) to one that emphasizes health. His viewpoint was that the disease prevention orientation imposes a classification of people into those who are "temporarily diseased, permanently diseased, or fatally diseased", essentially ignoring individual 
health qualities. Antonovsky believed that regardless of our present health or disease state we always have the capacity to improve our health. He contended that stressors are ubiquitous and that an individuals' health is determined not by the number of stressors encountered but by how well individuals manage the tension (stress) that results from the stressors of life (A. Antonovsky, 1979d). According to Antonovsky one's ability to manage stress has the potential to have a pathological, neutral or salutary impact on an individual's health (A. Antonovsky, 1987b). According to his salutogenic philosophy, Antonovsky believed that the availability of what he termed as generalized resistance resources determined ones capacity to improve health. Relative to Antonovsky's view of health the objective or subjective classification of stressors are no longer the focus, rather the focus is on the generalized resistance resources people rely on to meet the stressful demands of life (Antonovsky, 1979b).

Generalized Resistance Resources:

Generalized resistance resources (GRRs) refer to a set of life experiences that contribute to one's capacity to successfully cope with the stressors of human existence. The common thread that extends between GRRs is that they all foster repeated life experiences that help one to see the world as making sense cognitively, instrumentally and emotionally. Put another way, GRRs help individuals make sense of the world around them (A. Antonovsky, 1996). In Health, Stress and Coping (1979), Antonovsky outlines six GRR categories: physical/biochemical, artifactual-material, cognitive and emotional, valuative-attitudinal, interpersonal-relational, and macrosociocultural (Aaron Antonovsky, 1979). 
Physical/biochemical GRRs refer to factors of a physical or biochemical nature that a person acquires through life that predisposes their immune system and physical capacities to effectively adapt to and combat a variety of antigens and threats to their physical health. Artifactual-material GRRs refer to material and interpersonal resources that are available to cope with stressors. These include money or wealth that afford the opportunity to access healthcare, purchase sufficient food, and afford to live in a safe house. Additionally, this GRR also refers to acquired or inherited power, prestige, status, and availability of services.

Cognitive and emotional GRR's consist of two sub-categories: knowledgeintelligence, and ego identity. Knowledge-intelligence refers to the degree to which an individual possesses a knowledge base about the real world and the skills to build on their knowledge base. Wisdom is the central component of knowledge-intelligence. It is often tied to educational attainment, familiarity with a system or community, and the capacity to accurately evaluate the quality of information you are receiving. Ego identity is the possession of an inner sense of who you are (a picture of yourself) that is integrated into society, predictable, and yet dynamic and flexible to the ever-changing world.

Valuative-attitudinal GRRs are characterized as individual coping styles that have developed through life experiences. This GRR places an emphasis on ones assessment of the coping resources that are at their disposal or necessary resources they lack to effectively cope with a stressor. Antonovsky defines a copy strategy as "an overall plan of action for overcoming stressors." He lists three variables that make up a coping style: rationality, flexibility, and farsightedness. Rationality refers to how accurate the objective threat assessment of the stressor. It refers to the primary appraisal of the 
stressor (transactional model). Flexibility refers to the degree to which the strategy is open to revision based on new information, and farsightedness refers to the ability to predict the inner and outer responses to the coping strategy.

Interpersonal-relational GRRs refer to the presence of stable relationships and the extent to which one has integrated into a social network to which one is committed. Finally, macrosociocultural GRRs are culturally and socially structured measures to aid individuals in dealing with various stressors (i.e. food stamps, social security, and organized religion). Overall, Antonovsky defines GRRs as a set of life experiences characterized by a sense of familiarity, where individuals have contributed to their outcomes, and having a balance between too many demands and too few demands from life (Aaron Antonovsky, 1979).

In 1977, while conducting a study using his health-ease/dis-ease (“breakdown”) continuum as the dependent variable and combinations of generalized resistance resources, Antonovsky found that one combination was not only highly correlated to overall health status it also appeared to produce an intervening variable between the other GRR's and health. He concluded that this new variable was a way of looking at the world and eventually called it the "sense of coherence" (A. Antonovsky, 1979c). According to Antonovsky, GRRs shape ones sense of coherence. In his later book titled "Unraveling the Mystery of Health" (1987), Antonovsky refined his characterization of GRR's to include three components of varying magnitude: meaningfulness, comprehensibility, and manageability; where each GRR contributes in some way to each of the three components. Comprehensibility refers to the extent to which the GRR contributes to the perception that demands confronting one internally or externally make 
cognitive sense. Manageability refers to the extent to which the GRR contributes to the perception that one has the necessary resources (i.e. skills, knowledge, money, etc.) to meet the demands that confront one internally or externally. The third component meaningfulness, refers to the extent to which each GRR contributes to an individual's sense of purpose, the overall perception that life makes sense emotionally, and that the problems of life are worth investing energy to achieve ones sense of purpose (A. Antonovsky, 1987a). According to Antonovsky it is these three components that collectively make up an individuals' sense of coherence. He defines SOC as "a global orientation that expresses the extent to which one has a pervasive, enduring though dynamic feeling of confidence that the stimuli deriving from one's internal and external environments in the course of living are structured, predictable, and explicable; the resources are available to one to meet the demands posed by these stimuli; and these demands are challenges, worthy of investment and engagement" (A. Antonovsky, 1987a). Given the variability of the stressors of life, Antonovsky contends that while SOC does not predict a specific coping strategy, he argues that SOC predicts the use of the most effective coping style for every situation leading to improved stress management and overall health.

Throughout literature stress is inseparably tied to diminishing health outcomes and negative affect. The word "stress" is used interchangeably with "distress", or "perceived stress", or "psychological stress". Despite the varying expressions of stress they all have the common tie of being affiliated with a condition or outcome that is inherently damaging. Antonovsky's salutogenic approach to health promotion seeks to rehabilitate our view of stress and stressors as exclusively damaging or disease causing to 
a perspective of adaptation that see's the presence of a stressor as potentially health promoting (A. Antonovsky, 1987c; A. Antonovsky, 1996). In Antonovsky’s view the stronger a persons' SOC, the more likely he or she will experience salutary outcomes when confronted with a stressor.

Salutogenesis and Positive Psychology:

Aaron Antonovsky was not the only researcher to acknowledge the hegemony of pathogenic philosophies and research. Since his 1998 American Psychological Association inaugural address Martin Seligman along with Mihaly Csikszentmihalyi have pushed forward positive psychology theories, constructs, and research. In their view positive psychology seeks to understand how individuals flourish under conditions ranging from benign to toxic. Much like Antonovsky's theory of salutogensis, positive psychology seeks to identify and build on the qualities that lead to and enhance health and well-being. According to Seligman and Csikszentmihalyi the qualities emphasized through positive psychology are well-being, contentment, satisfaction, hope, optimism, flow and happiness. Given Antonovsky's definition of salutogenesis as the study of the origins of health, and positive psychology's emphasis on qualities that lead to enhanced health both salutogenesis and positive psychology are synonymous placing SOC theoretically within the parameters of both theories. Therefore, research relative to SOC contributes to the literature supporting both the salutogenic and positive psychology theories (A. Antonovsky, 1987c; M. E. P. Seligman \& M. Csikszentmihalyi, 2000). Constructs Similar to Sense of Coherence:

In the literature the SOC construct shares conceptual similarities with other concepts around their interaction between health and stress. While similarities exists 
between SOC and resilience, self-efficacy, hope, optimism and hardiness there are theoretical differences that will assist the reader in differentiating between SOC and these constructs.

Sense of Coherence and Resilience:

Rutter (1985) characterized individual resistance to stress or "resilience" relative to environmental and constitutional factors that vary over time and that are mediated by the circumstances around which they occur. According to Rutter the quality of resilience is determined by evaluating how people manage life changes and adversities. It is similar to SOC's generalized resistance resources because the quality of resilience originates from early life experiences that influence the outcome of the stressful interaction (Rutter, 1985). Both Antonovsky and Rutter point to the specific qualities and outcomes of life experiences that contribute to the effective management of stress. In the case of resilience, Rutter describes protective factors that influence a person's response to a stressor. He points out that protective factors do not originate from intentionally pleasurable experiences rather they originate from stressful life experiences, have no detectable effect in the absence of a stressor, and relate to a quality or characteristic of a person (i.e. gender, physical size, age). While both Antonovsky and Rutter agree that one's capacity to effectively manage life stressors originates from life experiences, Antonovsky does not limit experiences to ones that are not pleasurable; he emphasizes the importance of how those experiences contribute to the meaningfulness of the world around us and the tools those experiences provide us that shape our capacity to manage stressors. Through SOC, Antonovsky was able to operationalize the resilience concept, 
broadly describe the generalized resistance resources hinted at by Rutter, and integrate it into a well-tested and validated assessment tool (Aaron Antonovsky, 1979; Rutter, 1985). Sense of Coherence and Self-Efficacy:

Self-efficacy refers to an individuals' perception about their ability to control events affecting their lives and speaks to the level of confidence one possesses about their ability to successfully execute necessary actions to manage life events (Johnson et al., 2011). Self-efficacy relates closely to SOC's sense that one has the necessary resources at their disposal to meet a demand, and that in areas of life that one values, the demands are worth the investment of time and energy. The core elements of the self-efficacy concept are essentially included as part of the larger SOC construct. However selfefficacy diverges from SOC when it comes to the perception of control. The manageability component of SOC emphasizes the perception that one has the necessary resources at one's disposal, and that those resources need not be directly under ones control. SOC requires that those resources so are controlled by a legitimate other (if not yourself) that one feels they can count on or trust. Where self-efficacy emphasizes a personal confidence in ones abilities, SOC emphasizes a personal confidence in the abilities of trusted others and in oneself (A. Antonovsky, 1987a; McAlister, Perry, \& Parcel, 2008).

Sense of Coherence, Hope and Optimism:

Hope is a function of ones belief in one's ability to plan for and motivate oneself to pursue goals. Similar to SOC, measures of hope are positively associated with problem-focused coping, and academic achievement. However unlike SOC, hope is not specific to managing stressors. It is more closely associated with the expected outcomes 
of ones efforts to achieve goals in life (Davidson et al., 2012). SOC is concerned more with the degree to which people perceive the events in the world as being manageable, comprehensible, and worth the effort to overcome. While hope may contribute to ones confidence in their ability to successfully manage a stressor, hope is generally considered to be future oriented whereas SOC is concerned more with ones' present ability to successfully manage a stressor.

Optimism is a measure that reflects the extent to which individuals hold generally favorable expectancies for the outcomes of present and future events (Carver et al., 2010). Both optimism and SOC are to some degree the result of past experiences however unlike SOC's manageability component that emphasizes the availability of necessary resources, optimism is the expectancy that positive outcomes will occur regardless of one's personal resources. In expectancy-value theory literature, optimism is often tied to hope. Expectancy-value theories assume that behaviors are the product of goal pursuits where the more important the goal, the greater its value. Hope and optimism contribute to ones confidence in eventually achieving a goal. Those with greater hope and optimism show higher levels of perseverance and are better able to overcome the influence of stressors (Carver et al., 2010). While optimism and hope have theoretical differences they theoretically come together under the SOC's valuativeattitudinal GRRs. Valuative-attitudinal GRRs are coping styles that have developed through life experiences. Where life experiences contribute to ones capacity to rationally assess the threat of a stressor, develop and modify strategies to manage the stressor, and predict the outcome of the strategy (Aaron Antonovsky, 1979). Both hope and optimism contribute to the outcome prediction, the higher the hope and optimism the more 
favorable the outcome prediction of the coping strategy (Davidson et al., 2012). There is evidence in the literature that optimism partially mediates the influence of SOC on the experience of stress. Therefore people with a strong SOC may have a more optimistic outlook on the current and future experience of stress when compared to individuals with weaker SOC (Gustavsson-Lilius, Julkunen, Keskivaara, Lipsanen, \& Hietanen, 2012). Sense of Coherence and Hardiness:

SOC is most commonly compared to Kobasa's hardiness construct and in some instances authors have asserted that they measure the same thing (A. Antonovsky, 1987b; Grota, 2006; Skirka, 2000; Smith \& Meyers, 1997; Sullivan, 1993). SOC and hardiness emerged from similar questions around how some people manage to stay healthy despite their exposure to high stress loads (American Psychological Association, 2012; A. Antonovsky, 1979c). Suzanne Kobasa first articulated her hardiness construct in 1979 when she characterized personality as an important factor in mediating the effects of stress on individual health. Kobasa characterized hardiness as consisting of three subcomponents: control, commitment, and challenge. Control refers to the belief that one can control or alter the events that occur in ones' life. Commitment refers to the level of commitment one possesses to the various areas of one's life, where through their commitment they are less likely to give up in the face of adversity. Finally, challenge is where change in one's life is viewed as a challenge and an opportunity for growth (Kobasa, 1979). The hardiness and SOC constructs share the assumption that how one sees the world is a determining factor in coping strategies and individual health outcomes (A. Antonovsky, 1987b). Kobasa's commitment component is similar to Antonovsky's meaningfulness component where both emphasize a sense of purpose and drive to persist 
and overcome adversities in areas of one's life that are important. However, SOC conceptually diverges from the control and challenge components of hardiness. Unlike hardiness, a sense of personal control is not required as part of SOC's manageability component, rather what is required is that events in one's life are perceived to be ordered and under some kind of control, not necessarily one's own control. Furthermore Kobasa emphasizes a sense of instability or continual change in the challenge component. She describes it as possessing a positive attitude toward change where change is thought to be stimulating and promotes flexible coping styles. From Antonovsky's view point stability is a desired characteristic of life and that challenge is a function of meaningfulness where the demands in ones' life that are perceived as more meaningful will be viewed as challenges worthy of engagement (A. Antonovsky, 1987b).

Overall, SOC shares theoretical similarities with several constructs within the social sciences. An argument can be made that SOC does not exclude hope, optimism, resilience, self-efficacy, and hardiness. Rather, SOC includes each of them as part of the larger SOC theory.

Validity and Reliability of the Sense of Coherence Construct:

The SOC construct possesses a high degree of validity and reliability across cultures and throughout the literature. The Orientation to Life Questionnaire (OLQ) is published in Antonovsky's 1987 book titled "Unraveling the Mysteries of Health". The SOC scale has been used in many research projects across many countries and in multiple languages. The OLQ has been administered in at least 33 languages, in 32 countries and is a valid, reliable, and cross culturally applicable instrument. Internal consistency of the scales in the OLQ measured by Cronbach's $\alpha$ range from $0.70-0.95$ using the 29 item 
OLQ, and $0.70-0.92$ using the 13 item SOC scale in the literature, indicating good internal consistency. Internal consistency refers to the extent to which items in an instrument are measuring the same general construct. The OLQ also possesses good testretest reliability in the literature with measures ranging from 0.92 at one week, to 0.78 at one year for the 29 -item scale and $0.69-0.72$ for the 13 -item scale. Regarding validity, there is a high degree of face validity due to the SOC scales use in multiple cultures and languages and a high predictive validity for health outcomes. Predictive validity in this case refers to the extent the instrument predicts future health. The SOC scale is positively correlated with measures of health from the General Health Questionnaire, Health Index, Hopkin's Symptom Checklist and Mental Health Inventory. Furthermore the literature reports good criterion validity. Criterion validity in this case measures the extent to which the OLQ predicts future health measures. The results of the OLQ (SOC) has a high negative correlation with anxiety and depression, and a high positive correlation with optimism, self-esteem, and to a lesser extent with high quality of life (Eriksson \& Lindstrom, 2005).

According to validation studies of the 29 -item and 13 -item OLQ, SOC is a distinct measure that should not be used to differentiate between measures of comprehensibility, manageability, and meaningfulness. Bernabe et al., (2009) examined the structure of the SOC construct which consists of three sub-components: manageability, comprehensibility, and meaningfulness. They were interested in evaluating the construct validity of the short version of the Orientation to Life Questionnaire that is used to assess sense of coherence. They evaluated the construct as a simple one factor structure that does not differentiate between the three sub-components 
(manageability, comprehensibility, meaningfulness) and as a second order factor evaluating each sub-component as dependent variables influencing overall sense of coherence. The investigators analyzed the responses of 6,217 subjects aged 30 years and over who participated in the Finnish Health 2000 survey. Their results revealed that evaluating all three subcomponents as a whole was a better characterization of the SOC construct. For the one factor structure the comparative fit index was $0.97-0.98$, the Tucker-Lewis index was $0.96-0.97$, and the root mean square error of approximation was $0.05-0.09$ across genders and age categories. The second order factor evaluating each sub-component had correlations between factors of greater than 1.0, raising suspicion of the existence of a more complex structure. Therefore based on their findings the SOC construct is best interpreted as a whole rather than breaking it into separate parts (Bernabé et al., 2009b).

How Sense of Coherence Changes over Time:

SOC develops throughout childhood into early adulthood and is a by-product of the interaction between an individual and the social and cultural environment in which he or she is raised and lives (M. Cohen et al., 2008; J. P. Grayson, 2007; Hakanen et al., 2007). For children, the parent-child relationship is a critical component affecting the child's SOC. During adolescence there is empirical evidence that SOC has a positive correlation with the parent-adolescent relationship. In general the closer a child is to his or her parent(s) the higher their resulting SOC and the lower their trait anxiety levels in anticipation of a potentially stressful encounter (H. Antonovsky \& Sagy, 1986).

Recent research has demonstrated that SOC tends to increase with age. Nilsson et al. (2010) investigated the relationship between SOC, and age, gender, and psychological 
well-being within a sample of 43,598 Swedish adults aged 18-85. SOC was measured using the 13-item OLQ and psychological well-being was measured using the 12-item General Health Questionnaire (GHQ). The results of their data analysis revealed that SOC and psychological health were positively correlated with age, and there was a significant positive correlation $\left(R^{2}=0.308, p<.001\right)$ between SOC and GHQ indicating that as psychological well-being increased, SOC increased. Overall the researchers concluded that both SOC and psychological well-being increased with age, even after adjusting for education and ethnicity (Nilsson, Leppert, Simonsson, \& Starrin, 2010). Aging is not the only mechanism for change in individual SOC levels. There is increasing evidence that individual SOC is responsive to intervention. Vastamaki et al. (2009) investigated the temporal stability of SOC in a sample of 74 unemployed Finnish adults ranging in age from 18 to 57 years of age. They found that SOC improved significantly following a six-month intervention designed to boost re-employment (Vastamäki, Moser, \& Paul, 2009). Within the college setting Berger et al. (2009), evaluated the impact of an academic course designed to provide students with theoretical knowledge of and practical application of cognitive behavioral techniques on individual SOC and situational moods as measured by the Profile of Moods States. There were 37 students in the experimental group and 43 students in the control group. Experimental group students participated in a course designed to provide students with additional theoretical knowledge of and practical guidance about how to apply cognitive behavioral techniques, and the control group did not receive the additional instruction. The experimental group experienced a statistically significant $(p<.001)$ increase in SOC and a statistically significant $(p<.01)$ decrease in scores for tension-anxiety and confusion, 
while the control group experienced no significant change (Berger, Sarid, Hurvitz, \& Anson, 2009).

Sense of Coherence and Coping:

In general a high SOC is assumed to impact an individuals' health by predisposing them to the use of effective coping strategies in response to stressors, which ultimately leads to lower stress (A. Antonovsky, 1993; A. Antonovsky, 1996). The use of effective coping strategies refers to a dispositional orientation to coping behaviors that is temporally stable and consistent across situations. While some researchers have argued that coping styles vary from situation to situation, Ptacek et al (2008) provide supporting evidence that individuals tend to exhibit cross-situational similarities in coping styles. Overall they reported that coping styles tend to be consistent regardless of the situation (Ptacek, Smith, Raffety, \& Lindgren, 2008). Examples of behavioral coping responses to stressors include excessive eating, aggression, venting of emotions, exercise, smoking, and consumption of alcohol, each having an impact on health. In order for a coping strategy to impact health it must be used consistently over a long period of time (Ptacek et al., 2008).

Within the college student population there is evidence that the use of emotionfocused coping styles is associated with disordered eating, smoking, alcohol consumption, and fewer help seeking behaviors among college students (Britton, 2004; Filaire, Treuve, \& Toumi, 2012; Julal, 2013; Freda Patterson, Caryn Lerman, Vyga G. Kaufmann, Geoffrey A. Neuner, \& Janet Audrain-McGovern, 2004; Wichianson, Bughi, Unger, Spruijt-Metz, \& Nguyen-Rodriguez, 2009). Furthermore, research has demonstrated a positive association between SOC and problem-focused coping styles and 
a negative association between SOC and emotion-focused coping styles. Cohen et al. (2008) assessed the associations between test anxiety, coping style, and SOC within a sample of 216 first-year undergraduate students attending a university in Israel.

Outcomes of the short COPE scale were stratified into three categories: problem-focused, emotion-focused, and avoidance. Their results revealed that SOC was negatively associated with emotion-focused coping $(r=-0.33, p<0.001)$, and avoidance $(r=-0.30$, $p<0.001)$ and positively associated with problem-focused coping $(r=0.17, p<0.01)$ (M. Cohen et al., 2008). Heiman (2004) examined the relationship between SOC, social support, coping style, and perceived stress of college students in Israel. A total of 261 students, ages 20 - 55 years, attending one of three Israeli institutions of higher education participated in this study. Their results revealed that older students had higher SOC and used problem-focused coping more frequently when compared to younger respondents who more frequently used emotion-focused coping strategies and tended to have lower SOC. Overall they found that SOC was positively associated with problem-focused coping strategies and negatively associated with emotional and avoidance coping strategies. Their results showed that students with strong social support resources had higher SOC when compared to students with fewer social support resources (Heiman, 2004).

Within the U.S. student population the associations between SOC and coping styles are not dissimilar to those found within the non-U.S. population. McSherry and Holm (1994) examined the relationship between SOC and individual psychological and physiological responses to a controlled stressful situation. The respondents were then stratified into three groups based on their SOC score: those scoring in the higher third of 
SOC scores $(M=168.30)$; those scoring in the middle third $(M=141.15)$; and those scoring in the lower third $(M=101.37)$. They found that low SOC subjects were significantly less likely to believe they had the personal resources necessary to cope with the situation than the high SOC subjects. Furthermore, high and middle SOC subjects coping behaviors were significantly more approach-oriented when compared to the low SOC group and the low SOC individuals reported fewer generalized resistance resources (material resources, social resources and psychological resources) when compared to the middle and high SOC subjects (McSherry \& Holm, 1994). In 2005 Barbara L. Grota investigated the mediating role of coping strategies with SOC and perceived stress. The study sample was comprised of 385 undergraduate students attending a small liberal arts university in the northeastern United States. The results of the study demonstrated that those students scoring high in SOC used significantly more problem-focused coping strategies as compared to those who scored lower in SOC and higher in perceived stress. Overall their results indicated that those with greater levels of SOC used more adaptive coping, and used significantly fewer maladaptive coping strategies (Grota, 2006).

Amirkhan and Greaves (2003) provided additional insight into the relationship between SOC and coping. While investigating the mechanisms of how SOC and health interact, they sought to determine whether the strength of ones SOC influences the characterization of a stressor as "coherent" or "noncoherent" within a population of U.S. undergraduate students. For the purpose of their study, coherent was described to the participants as an event that "happened for a reason", and/or was "part of the grand plan", and "noncoherent" described events that were "random", "chaotic", or "meaningless". They found that participants with high SOC were more likely to view stressful events as 
coherent when compared to participants with lower SOC. Therefore, high SOC individuals were better able to make sense of the stressor and select an effective coping response. They reported that SOC was significantly related to coping strategies, where those with higher SOC were less likely to use avoidance $(r=-0.28, p, 0.01)$ and more likely to use problem-solving coping strategies $(r=0.24, p, 0.01)$ (Amirkhan \& Greaves, 2003).

Sense of Coherence and Perceived Stress:

Throughout the literature there is evidence of a negative association between SOC and perceived stress. Pallant et al. (2002) studied the construct and incremental validity of the 13-item OLQ using a sample of 439 Australian adults ranging in age from 18-82, living in the same community. Within their study they investigated the relationship between SOC and perceived stress and found a significant negative correlation between SOC and perceived stress (Pallant \& Lae, 2002). More recently, Sarenmalm et al. (2013) investigated the relationship between SOC and stressful life events, coping strategies, health status and quality of life of women with breast cancer. Newly diagnosed women with breast cancer or who had experienced recurrent breast cancer were included in their study. Their results revealed that SOC was negatively correlated with the reported presence of distress $(r=-0.31 ; p \leq 0.01)$ and higher SOC was associated with a higher number of days without stressful events reported $(r=0.22 ; p \leq 0.05)$ (Sarenmalm et al., 2013). Hover (2014) investigated the relationship between SOC, perceived stress and mindfulness of first generation and non-first generation clinical psychology trainees and found no difference between the groups. However, collectively there was a significant 
negative relationship found between SOC and perceived stress $(r=-0.40, p<0.001)$ (Hover, 2014).

Within the undergraduate student population, SOC has routinely demonstrated a negative association with perceived stress. Smith and Meyers (1997) examined the correlations between SOC and perceived stress, self-efficacy, hardiness, locus of control, learned helplessness, and physical health. They surveyed 336 introduction to psychology students and found that individuals who scored higher on the SOC scale were more likely to score lower for learned helplessness, and perceived stress, report higher self-efficacy, possess more internal locus of control, and measure higher in hardiness (Smith \& Meyers, 1997). McSherry and Holm (1994) in their investigation of the relationship between SOC and controlled stressful situations found that mean stress, anxiety, and anger scores were significantly higher for those scoring low in SOC when compared to those scoring middle to high in SOC. Their mean scores for stress, anxiety, and anger were 7.85, 20.73, and 12.05 respectively for the low SOC individuals, and 2.95, 16.03, and 10.28 respectively for the middle SOC individuals (Middle and high scores did not differ significantly) (McSherry \& Holm, 1994). Shirka (2000) investigated why under stressful conditions some people stay healthy and others do not. They collected data from both athletes and non-athletes and found that collectively there was a significant negative correlation between SOC and overall perceived stress as measured by the Daily Hassles scale $(r=-0.42, p<0.001)$ and Profile of Moods States scale $(r=-0.70, p<$ 0.001) (Skirka, 2000).

As mentioned earlier, stressors for college students come from multiple sources. Darling et al. (2007) investigated the stress experiences of college students and evaluated 
the relationship between SOC and various sources of relational stress. They used four Likert-scale questions to assess the level of stress experienced from friendships, love relationships, parents, and other family members. Darling et al. (2007) found that SOC had a significant negative association with all four stressors for women (friendships: $r=$ 0.42 , love relationships: $r=-0.37$, parents: $r=-0.29$, and family: $r=-0.21, p=\leq 0.05$ ), and a significant negative association for three out of the four stressors (friendships: $r=$ 0.37, love relationships: $r=-0.26$, and parents: $r=-0.26, p \leq 0.05$ ) (Darling, McWey, Howard, \& Olmstead, 2007).

Overall, based on the results from several studies, a strong SOC appears to protect people from the physical and psychological damages from stress, directly through the perceptual mechanism of determining the meaning of a stressor and indirectly through the more frequent use of problem-solving coping strategies and the less frequent use of emotion-focused coping strategies (Amirkhan \& Greaves, 2003; Darling et al., 2007; "Innocents Abroad? Student Health Behaviors Overseas," 2004; McSherry \& Holm, 1994; Skirka, 2000; Smith \& Meyers, 1997).

Sense of Coherence and Health Behaviors:

Throughout the literature there is substantial evidence that a higher SOC is associated with a higher incidence of health promoting behaviors. G.A. Johnsen evaluated the relationship between SOC, health-promoting lifestyle as measured by Pender, Walker, and Sechrist's Health Promoting Lifestyle Profile of 228 adult men and women employed at six rural industrial sites. The Health Promoting Lifestyle Profile is a 48-item questionnaire designed to quantify health promoting behaviors using a 4 point Likert scale measuring self-actualization, health responsibility, exercise, nutrition, 
interpersonal support, and stress management. The results of their assessment revealed that SOC possessed a significant positive association $(r=0.489, p<0.001)$ with a health promoting lifestyle (Johnsen, 1992a).

Mattila et al. (2011) explored the relationship between SOC and physical, psychological, and social health behaviors among 15 year old adolescents. Use of alcohol, smoking, overweight, oral health behaviors, and social competence as measured by the Youth Self Report were assessed to quantify health behaviors and the 13-item Orientation to Life questionnaire was used to measure SOC. Their results showed that SOC was significantly inversely associated with alcohol use, injury frequency, smoking, overweight, and positively associated with oral health behaviors. Additionally, SOC was positively associated with social competence at school, and relations with parents and negatively associated with reported social problems. Overall, the authors found that SOC was a good screening tool to identify adolescents at greater risk for poor health behaviors, and a lack of social support and competence (Mattila et al., 2011).

Wainwright et al. (2007) investigated the relationship between SOC and various health promoting behaviors within a cohort of 18,287 residents of Norfolk, UK who were stratified according to social class. Their results revealed that while SOC was positively associated with social class and age, and men scored higher in SOC than women. Additionally, after controlling for the influence of social class and age, SOC was significantly associated with several health promoting behaviors. When compared with those scoring the lowest in SOC, those scoring the highest SOC were $28 \%$ less likely to smoke, $36 \%$ less likely to be physically inactive, and consumed on average more fruits, vegetables and fiber (Wainwright et al., 2007). Midanik and Zabkiewicz (2009) studied 
the role of SOC on alcohol-related problems in a sample of participants in the 2000 U.S. National Alcohol Survey. Alcohol consumption is not by itself a negative health behavior, taken in moderation alcohol consumption is considered by many to be a health promoting behavior. It is only a health problem when taken to excess which often leads to problems. Within their study they investigated the pattern of alcohol-related social problems of current drinkers and how they related to SOC. The author found that SOC was a significant predictor of alcohol related social problems among current drinkers. Overall they found a negative association between SOC and alcohol-related social problems. Low SOC scoring individuals reported no social consequences of their drinking $80.7 \%$ of the time compared with high SOC scoring individuals who reported no social consequences $91.2 \%$ of the time (Tobamidanik \& Zabkiewicz, 2009).

Research has also provided evidence that a positive association between SOC and self-care behaviors exists. Cohen and Kanter (2004) examined the relationship between glycemic control and SOC and to evaluate the role of distress and adherence to self-care behaviors. Their results revealed that a strong SOC was significantly related to better adherence to self-care behaviors $(r=0.33, p<0.05)$ including regular clinic attendance, blood testing, medication use, adhering to nutritional guidelines, and regular physical activity (M. Cohen \& Kanter, 2004). Alohoa et al. (2012) found a similar pattern of association between SOC and self-care behaviors of Type I diabetics. They reported that SOC was positively associated with adherence to dietary recommendations $(r=0.20, p<$ $0.001)$, and weekly physical activity $(r=0.10, p<0.01)$. This pattern of relationship between adherence to behavioral recommendations and SOC has also been demonstrated recovering drug addicts. Abramsohn et al. (2009), studied the stability of SOC over time 
among a group of former heroin addicts enrolled in methadone maintenance treatment and found that individuals scoring 130 or above on the 29 -item Orientation to Life questionnaire had longer program retention than those scoring lower than 130 (Abramsohn, Peles, Potik, Schreiber, \& Adelson, 2009).

There are relatively few studies in the literature assessing the relationship between SOC and health behaviors of traditional aged college students. Binkowska-Bury and Januszewicz (2010) studied the relationship between SOC and the health-related behaviors of 521 university students attending one of two Polish universities as measured by the Inventory of Health-Related Behavior (IHRB). The IHRB was developed in 1997 by Zygfryd Juczynski as a means to quantify the intensity of the following "pro-health" behaviors: proper nutrition habits, efforts to prevent disease, possessing good psychological health, sleep habits, recreation, and physical activity. The results of their research revealed that the higher the SOC, the higher the intensity of behaviors in all categories of health behaviors included in the IHRB (proper eating habits, disease prevention behaviors, positive attitude, active forms of leisure, and good sleep habits (Figure 3) (Binkowska-Bury \& Januszewicz, 2010). 


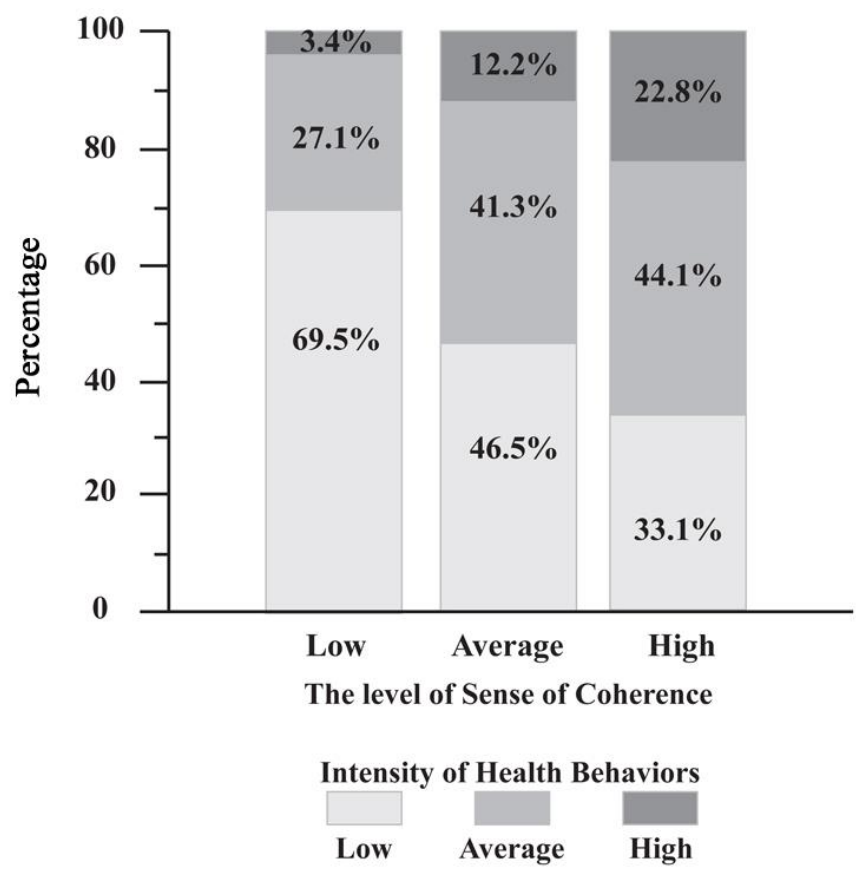

Figure 3: The level of sense of coherence and the intensity of health behaviors according to the Inventory of Health Behaviors. The Inventory of Health Behaviors measures the general intensity of proper nutrition habits, following health recommendations, possessing a positive attitude relative to stress, anxiety and depression and pro-health practices including recreation, and physical activity habits. Sense of coherence was measured using the 29-item Sense of Coherence questionnaire. Intensity of health behaviors was divided into three levels (low, average and high), and Sense of coherence was stratified into three levels (low, average and high) (Binkowska-Bury \& Januszewicz, 2010).

Posadzki et al. (2010) conducted a cross-sectional survey of a random sample of 455 healthy college students in Poland to measure the relationships among sense of coherence, optimism, self-efficacy, and health behavior. Their results showed a statistically significant $(r=0.45, p<.001)$ difference between the SOC of students scoring low on the Health Behavior Inventory and students scoring high on the Health 
Behavior Inventory. They found that the higher the SOC score, the higher the health behavior index score and, the higher the health behavior inventory score, the higher the SOC score. However the limitation of their survey was the relative lack of descriptive information about the Health Behavior Inventory making it difficult to interpret which health behaviors it was referencing. (Posadzki, Stockl, Musonda, \& Tsouroufli, 2010). Suraj and Singh (2010) studied the relationship between SOC and health promoting behaviors of a sample of Indian college students. Health promoting behaviors were assessed using the Health Promoting Lifestyle Profile (HPLP). In general the higher the HPLP score the higher the overall number and frequency of health promoting behaviors. The authors found that SOC was had a significant positive association with overall HPLP score $(r=0.26, p<0.001)$ (Suraj \& Singh, 2011). While these results suggest a positive relationship between SOC and health promoting behaviors there is a relative lack of data concerning the relationship between SOC and health promoting behaviors among U.S. college students. This research project will be among the first if not the first to evaluate the relationship between health promoting behaviors and SOC within a U.S. student population.

Sense of Coherence and College

According to Antonovsky, a person with a strong SOC will better select an appropriate coping strategy to deal with the stressors they are confronting. Within the traditional college student population, there is evidence that students exhibiting high levels of stress tend to demonstrate greater use of emotion-focused coping strategies including procrastination, smoking, and alcohol consumption. Whereas, college students who exhibit lower perceived stress levels tend to use more problem-focused coping 
strategies including learning new skills, and getting more information when compared to those who use emotion-focused coping strategies (Brougham, Zail, Mendoza, \& Miller, 2009; M. Cohen et al., 2008; Richardson \& Ratner, 2005). J.P Grayson (2008, p. 475) writes that "all else being equal, it might be expected that university students with a high SOC would have less difficulty than others in coping with the problems of university life, and that if they did encounter academic problems, they would be more likely than others to take the appropriate steps to deal with them" (J. Grayson, 2008). Indeed there is evidence that students with high SOC are more likely to have a higher GPA than students with low SOC. However, how SOC interacts with GPA is relatively unclear. Potential interactions include engagement with faculty members and living on campus. In general, students living on campus tend to have higher SOC and GPA, and high SOC students are more likely to have a favorable opinion of their professors' performance than students with a low SOC (J. Grayson, 2008). There is also evident that SOC influences the experience of stressors. In general, students who report higher levels of stress tend to report more health inhibiting behaviors and a lower GPA. According to research, college students scoring high in SOC report fewer problems with finances, making friends, living conditions, parents and academic classes when compared with students scoring lower in SOC (Darling et al., 2007; J. P. Grayson, 2007). Furthermore there is evidence that SOC is positively related to emotional health and quality of life and inversely related to stress from friendships and parents. Darling et al. (2007) found that emotional health was a strong predictor of SOC regardless of gender and that SOC was positively related to emotional health, physical health and perceived quality of life (Darling et al., 2007). 
Overall, there is sufficient evidence to warrant further investigation of SOC's potential to predict student health behaviors, academic success and engagement in higher education. Summary:

Based on the results of this literature review, there is compelling evidence that SOC is positively related to the engagement in health promoting behaviors and subsequent health. However, there is a relative lack of research concerning the relationship between SOC and health promoting behaviors within the traditional aged U.S. college student population. Additionally, questions remain relative to the causal pathway that appears to exist between SOC and health. Evidence has been presented demonstrating that coping style influences both perceived stress, and health behaviors, and that SOC is positively related to health promoting behaviors, and adaptive coping strategies. Together this evidence points to a potential mediating relationship between coping style, SOC, and health promoting behaviors. Therefore further research is necessary to assess the relationship between these variables and add to the understanding of how SOC relates to health behaviors, coping style, and perceived stress within the U.S. college student population. 


\section{CHAPTER 3}

\section{METHODOLOGY}

Introduction:

The purpose of this study was to measure sense of coherence (SOC) in a sample of traditional aged U.S. college students, measure its relationship to perceived stress, coping style, health behaviors, and grade point average, and determine if coping style serves as a mediator between SOC and the engagement in pro-health behaviors. As was outlined in Chapter 2, there is evidence that coping style may play an intervening or mediating role in the relationship between SOC and the engagement in health promoting behaviors. Mediating variables are described as behavioral, biological, psychological, or social constructs that transmit the effect of one variable to another variable. In this instance, dispositional coping style was be evaluated to determine if it serves a mediating role between individual sense of coherence and the engagement in pro-health behaviors. The main survey consisted of 59 questions including the Perceived Stress Scale, Brief COPE, Orientation to Life Questionnaire and health behavior questions. The health behavior questions were copied with permission from the American College Health Associations, National College Health Assessment.

Test-Retest Reliability Survey:

A class of 37 students attending Western Kentucky University (WKU) was recruited to assess the inter-rater reliability of the survey questions that were used in this proposed study. With instructor permission the survey was administered twice to a more 
students attending a general education course on WKU's main campus. The second administration of the survey was conducted 7 days following the first administration. Students attending the class were instructed to read and agree to an informed consent document (Appendix A). Respondents were informed that their completion of the survey (Appendix B) signified their acceptance of the risks and benefits associated with completing the survey. Students were asked to generate a unique identifying number using the year they were born, the last 2 digits of their phone number, and the date in the month they were born (i.e. 91-93-04). Using the unique identifying number, student questionnaires were matched up to compare their responses on both questionnaires. Both surveys were scored and two measures of association were applied to estimate the survey's reliability coefficient (Kappa) and item percentage agreement. A Kappa greater than or equal to 0.41 was used to indicate an acceptable level of reliability (J. Cohen, 1960; Viera \& Garrett, 2005).

\section{Study Participants:}

Participants in the main survey consisted of a convenience sample of traditional aged college students (18-24 years) attending Western Kentucky University (WKU). The study sample was limited to traditional students aged 18-24 because the majority (88\%) of U.S. college undergraduate students are under the age of 25 (81\% at WKU). WKU is a 4 year public institution located in south central Kentucky that offers undergraduate and graduate degree programs. In the fall 2013, 13,507 students were enrolled as students on WKU's main campus in Bowling Green, KY. Over $80 \%$ of those students were traditional aged students, $96.3 \%$ U.S. citizens, with $91 \%$ of the U.S. students originating from the South as designated by the U.S. Census Bureau. The student body was $59.1 \%$ 
female and $40.9 \%$ male, with an average age of 23 , representing several races and nationalities. In the fall $2013,79 \%$ of the student body was Caucasian, followed by $11 \%$ African American, and 4\% non-resident alien (National Center for Education Statistics, 2012a; Pritchard, Wilson, \& Yamnitz, 2007b; WKU Office of Institutional Research, 2013).

Hypotheses:

Null Hypothesis I:

There will be no statistically significant relationship between SOC and the engagement in pro-health behaviors by traditional aged U.S. college students.

Null Hypothesis II:

There will be no statistically significant relationship between SOC and the Problem-Focused Coping score of traditional aged U.S. college students.

Null Hypothesis III:

There will be no statistically significant relationship between SOC and the Emotion-Focused Coping score of traditional aged U.S. college students. Null Hypothesis IV:

There will be no statistically significant relationship between Problem-Focused Coping and the engagement in pro-health behaviors by traditional aged U.S. college students.

Null Hypothesis V:

There will be no statistically significant relationship between Emotion-Focused Coping and the engagement in pro-health behaviors by traditional aged U.S. college students. 


\section{Null Hypothesis: VI}

There will be no statistically significant mediating effect of Problem-Focused Coping on the relationship between SOC and the engagement in pro-health behaviors by traditional aged U.S. college students.

Null Hypothesis VII:

There will be no statistically significant mediating effect of Emotion-Focused Coping on the relationship between SOC and the engagement in pro-health behaviors by traditional aged U.S. college students.

Null Hypothesis VIII:

There will be no statistically significant relationship between SOC and Term Grade Point Average of traditional aged U.S. college students. Design of the Study

A non-experimental, cross-sectional survey design was used to evaluate the relationship between sense of coherence, coping style, and the engagement in health promoting behaviors of traditional aged students attending a 4 year institution in located in the south eastern United States. According to the Office of Institutional Research in the fall 2012 semester there were 13,507 students enrolled at the institutions main campus. Statistical power reflects the probability that the null hypothesis will be correctly rejected. A commonly used minimum statistical power in the literature is 0.8 therefore, it was necessary to obtain a sample size from the target population that provided a minimum statistical power of 0.8 . At present there is no standardized approach to calculating statistical power for multi-variable mediation analysis therefore given that mediation analysis requires the use of multivariate regression models, sample 
size was estimated using multivariate regression as the type of statistical test to be measured. To determine a sample size that will yield sufficient statistical power it was necessary to determine a predicted effect size based on the available literature. According to results reported by Britton (2004) and Tomaka et al. (2013) an effect size ranging from 0.28 and 0.43 should be expected between emotion-focused coping and health behaviors. Therefore, using the Gpower program a minimum sample size of 209 students was determined to be the required samples size to elicit a statistical power of 0.95 (Britton, 2004; Tomaka, Morales-Monks, \& Shamaley, 2013). Instructors of general education classes were solicited via email to allow the survey to be administered in their class (Appendix C). A paper survey (Appendix D) was administered in the classrooms that granted permission to administer the survey. Prior to beginning the survey, students were instructed to read and agree to an informed consent document (Appendix E). Respondents were informed that their completion of the survey signified their acceptance of the risks and benefits associated with completing the survey. All students who complete the survey were asked to grant access to their academic records to collect their demographics, number of hours enrolled, and cumulative grade point average (GPA). To grant access to their student records, students had the option to provide their student ID and signature on a form (Appendix F) beside the number that corresponded with the unique number on their survey. Students who complete the survey and provided their student ID were entered in a drawing for one of five $\$ 100$ scholarships. Following the collection period, all student ID's were randomly listed within an SPSS data file and a random number generator was used to select the winners of each of the $\$ 100$ scholarships. 
Instruments:

The following demographics were collected using the student ID:

- Age: Only respondents ages $18-24$ will be included in the study.

- Gender: Male; female; other

- Race: White; Black or African American; Hispanic, Asian or Pacific Islander; More than one race; Nonresident Alien.

- International student status: Yes or No

- Hours Enrolled: 0 - 17+

- Cumulative and term grade point average (GPA) (Calculated at the end of the spring 2014 semester for all courses taken while enrolled).

The following information was collected using the paper survey (Appendix D):

Engagement in Pro-Health Behaviors:

Individual volitional behaviors have the potential to improve or undermine health. Chronic disease for example is to a large extent the result of volitional behaviors. According to the National Center for Chronic Disease Prevention and Health Promotion the four common causes of chronic disease are a lack of physical activity, eating insufficient fruits and vegetables, the use of tobacco products, and excessive alcohol consumption. Additionally, the American College Health Associations, Healthy Campus initiative includes improved physical activity, increased fruit and vegetable consumption, lower tobacco usage, and more responsible alcohol consumption behaviors among their Healthy Campus 2020 student health objectives (National Center for Chronic Disease Prevention and Health Promotion, 2012). The Healthy Campus 2020 document was developed over several years using the thoughts and perspectives of over 600 
professionals from higher education. The resulting document provides the frame work for improving the health status of students attending higher education institutions across the United States. Sleep habits are another behavior that is that is a point of emphasis in the Healthy Campus objectives to improve student performance in school. According to the National Sleep Foundation, insufficient sleep duration is associated with, depressed immune function, impaired glucose tolerance, increased blood pressure, depressed mood, and compromised alertness to name a few (National Sleep Foundation, 2013). Therefore, tobacco use, aerobic exercise, strengthening exercise, fruit and vegetable consumption, alcohol consumption, and sleep habits were evaluated to assess the number of pro-health behaviors (Pro-Health Behavior score) students engage in. For the purpose of this research project, each behavior was scored according to its impact on health. A score of one was assigned to behaviors that are considered health promoting, and a score of zero was assigned to behaviors that are considered health inhibiting. The cumulative score of health behaviors for each participant was calculated and used to calculate their ProHealth Behavior score. Scores had the potential to range from 6 indicating the engagement in health promoting behaviors for each category, to 0 indicating no engagement in health promoting behaviors for each category.

Health behaviors were assessed using selected questions from the well validated American College Health Associations, National College Health Assessment (ACHANCHA) used across the U.S. to assess relevant health issues and behaviors. The ACHANCHA was developed by an interdisciplinary team of health professionals and originally piloted in 1998-1999. Reliability and validity analyses have revealed the ACHA-NCHA to be a valid and reliable assessment tool (American College Health Association, 2013b). 
The following questions were copied with permission from the ACHA (Appendix G):

1. NCHA 8.0: Within the last 30 days, on how many days did you use: cigarettes, cigars, little cigars, clove cigarettes, and/or tobacco from a water pipe (hookah)

2. NCHA 10.0: The last time you "partied"/socialized how many drinks of alcohol did you have? (One drink of alcohol is defined as one 12oz. can or bottle of beer or wine cooler, a 4 oz. glass of wine, or a shot of liquor straight or in a mixed drink.)

3. NCHA 13.0: Over the last two weeks, how many times have you had five or more drinks of alcohol at a sitting?

4. NCHA 28.0: How many servings of fruits and vegetables do you usually have per day? $(1$ serving = 1 medium piece of fruit; $1 / 2$ fresh, frozen or canned fruits/vegetables; 3/4 cup fruit/vegetable juice; 1 cup salad greens; or 1/4 cup dried fruit).

5. NCHA 29.0: On how many of the past 7 days did you?

- Do moderate-intensity cardio or aerobic exercise (caused a noticeable increase in heart-rate, such as a brisk walk) for at least 30 minutes?

- Do vigorous-intensity cardio or aerobic exercise (caused large increases in breathing or heart rate, such as jogging) for at least 20 minutes?

- Do 8-10 strength training exercises (such as resistance weight machines) for $8-12$ repetitions each?

(American College Health Association, 2013a) 
Alcohol Consumption Scoring Rules:

According to the Dietary Guidelines for Americans, 2010, moderate alcohol consumption is defined as one drink per day for women and 2 drinks per day for men. When consumed in moderation, alcohol is associated with a lower risk for cardiovascular disease, and a reduced risk for all-cause mortality among middle-aged and older adults. According to the Dietary Guidelines for Americans, 2010, heavy or high-risk drinking is the consumption of more than 3 drinks on any day for women and more than 4 drinks on any day for men (U.S. Department of Agriculture and U.S. Department of Health \& Human Services, 2010). Therefore any individual who reported that drink alcohol and reported having drank more than 3 drinks if they are women and more than 4 drinks if they are men the last time they drank and/or indicated over the past two weeks that they consumed five or more drinks in a sitting were scored as 0 indicating they engaged in an unhealthy behavior. A drink equals one $12 \mathrm{oz}$ beer or wine cooler, 4ozglass of wine, or shot of liquor. Individuals who reported that they do not drink alcohol or that they drink 3 or fewer drinks on any day and they are a woman, or that they drank 4 or fewer on any day if they are a man were scored as a 1 indicating they engaged in a health promoting behavior.

\section{Tobacco Usage Scoring Rules:}

According to the Surgeon General, the detrimental health impacts of tobacco use are well documented. Tobacco is the leading cause of preventable and premature death therefore any use of tobacco products indicates an unhealthy behavior. Respondents who indicated that they have used tobacco within the previous 30 days were assigned a score of zero indicating they engage a health inhibiting behavior, and respondent reporting that 
they did not use tobacco within the previous 30 days were assigned a score of one indicating they engaged in a health promoting behavior (U.S. Department of Health \& Human Services, 2012).

Fruit \& Vegetable Consumption Scoring Rules:

According to the U.S. Department of Agriculture's Choose My Plate Guidelines, men and women aged 19-30 years of age should be consuming a total of 2 servings of fruits and 2.5 servings of vegetables for women and 3 servings of vegetables for men every day. Please note that a serving is equivalent to 1 cup of fruits or vegetables. Therefore, respondents who reported that they consumed an average of 5 or more servings per day were scored as 1 given that this is a recommended health promoting behavior, and those reporting less than 5 were scored as a zero because they did not consume the recommended amount of daily fruits and vegetables (U.S. Department of Agriculture Center for Nutrition Policy and Promotion; U.S. Department of Agriculture Center for Nutrition Policy and Promotion).

Cardiovascular Exercise Scoring Rules:

According to the 2008 Physical Activity Guidelines for Americans, adults aged 18-64 years of age should engage in an average of 30 minutes moderate-intensity physical activity on 5 or more days every week, or an average of 20 minutes of vigorousintensity aerobic exercise on 4 or more days per week (U.S. Department of Health \& Human Services, 2008). Therefore students who reported that they engaged in an average of 30 minutes of moderate-intensity aerobic exercise on 5 or more days per week or an average of 20 minutes or more of vigorous-intensity aerobic exercise on 4 or more days per week were scored as 1 given that this is a health promoting behavior and those 
reporting less activity were scored as 0 because they did not engage in the recommended amount of weekly aerobic exercise.

Strengthening Exercise Scoring Rules:

According to the 2008 Physical Activity Guidelines for Americans, adults ages 18-64 should engage in muscle-strengthening activities that are moderate to high intensity involving all major muscle groups (chest, back, and legs) on 2 or more days each week (U.S. Department of Health \& Human Services, 2008). Therefore respondents who reported engaging in muscle-strengthening activities on 2 or more days per week were scored as 1 because this is a health promoting behavior and those who reported less than 2 days per week were scored as 0 because they did not engage in the recommended amount of weekly muscle strengthening activities.

Sleep Scoring Rules:

According to the National Sleep Foundation, 7 -9 hours per night of sleep is recommended. Among adults, insufficient sleep duration is associated with, depressed immune function, impaired glucose tolerance, increased blood pressure, depressed mood, and compromised alertness to name a few(National Sleep Foundation, 2013). Within this study, respondents who reported sleeping less than 7 hours or more than 9 hours were scored as a 0 indicating that they engaged in a health inhibiting behavior. Conversely, those respondents who reported sleeping an average of 7 - 9 hours per night were scored as a 1 indicating they engaged in a health promoting behavior (National Sleep Foundation, 2013). 
Sense of Coherence:

Sense of Coherence was assessed using the 13-item Orientation to Life Questionnaire. The 13-item OLQ is an abbreviated version of the 29-item OLQ. Both questionnaires can be found in the back of Antonovsky's book titled "Unraveling the Mystery of Health" (A. Antonovsky, 1987c). As detailed in Chapter Two, according to a systematic review of research published from 1992-2003 the 13-item OLQ has good internal consistency (Cronbach's Alpha ranges: $0.70-0.92$ ), and a high degree of validity and reliability (one year test-retest correlation range: $0.69-0.78$ ) across many cultures including students attending higher education (Eriksson \& Lindstrom, 2005). Each question in the OLQ was scored from 1-7, (questions 1, 2, 3, 7, and 10 were reverse scored), the potential score range for the survey was from $13-91$. The higher scores reflected a higher sense of coherence (A. Antonovsky, 1987c).

Perceived Stress:

The Perceived Stress Scale (PSS) was initially developed in 1983 by Cohen et al. as a 14-item questionnaire and was refined by Cohen and Williamson in 1988 to a 10item questionnaire. The PSS is a valid, reliable and widely used instrument to measure the degree to which events over the previous month of one's life are perceived as stressful (S. Cohen, Kamarck, \& Mermelstein, 1983; S. Cohen \& Williamson, 1988). Cohen and Williamson (1988) administered the 10-item PSS telephonically to 2,387 individuals and reported good internal consistency (Cronbach's Alpha $=0.78$ ); a mean score of 13.02 and a standard deviation of 6.35 (S. Cohen \& Williamson, 1988). A recent study by Roberti et al. (2006) assessed the psychometric properties of the 10-item PSS in a college student population. They surveyed 285 students ranging in age from $17-60$, 
and a mean age of 23.8 years. The average score for their sample was 17.4 with a standard deviation of 6.1. Overall they found that the PSS had good internal consistency $($ Cronbach's Alpha $=0.89)$ and was positively associated with Spielberger's State-Trait Anxiety Inventory indicating good convergent validity (Roberti, Harrington, \& Storch, 2006). The 10-item Perceived Stress Scale instructed respondents to reflect on their feelings and thoughts over the previous month relative to each of the questions asked. Respondents were provided five possible responses (never; almost never; sometimes, fairly often; and very often) scored from 0 to 4 respectively with the exception of the four positive questions (4,5,7, and 8) which were reverse scored prior to summing all questions to determine the score. Scores can range from $0-40$ with the higher scores indicating a higher level of perceived stress (S. Cohen et al., 1983). Dispositional Coping Style:

In 1989 Charles Carver et al. (1989) expanded on Lazarus and Folkmans' coping styles arguing that while the distinction between these two coping styles is helpful, it is also too simple. Carver argued that many coping responses overlap between problem and emotion-focused coping prompting them to develop the COPE scale and later the Brief COPE scale to better differentiate between coping styles (Carver, 1997). Both the COPE and the Brief COPE scales show good internal validity (Cronbach's Alpha of 0.5 or greater for all sub-scales), and test-retest reliability (Carver, 1997; Carver, Scheier, \& Weintraub, 1989). For the purposes of this study; given its validity and brevity the Brief COPE scale was used to assess coping style. The Brief COPE assesses dispositional coping style through the measurement of 14 conceptually different coping reactions. It measures active coping, planning, reframing acceptance, humor, use of religion, using 
emotional support, using instrumental support, self-distraction, denial, venting, substance use, behavioral disengagement, and self-blame. Originally Carver et al. reported that the 14 subscales of the Brief COPE loaded onto 9 factors and accounted for $72.3 \%$ of the total variance, however more recent factor analyses of the Brief COPE have operationalized coping into 2 subscales: Problem Focused or Adaptive, and Emotion Focused or Maladaptive. In their article reviewing the varying structures of coping, Skinner et al (2003) reported that when stratifying coping styles it is important to classify them according to their adaptive functions (Skinner, Edge, Altman, \& Sherwood, 2003). Within the College population, Mammoud et al (2012) stratified the 14 subscales of the Brief COPE into 2 categories maladaptive and adaptive. They reported internal consistency measures within the college population between $0.81-0.88$. These results were also verified by Snell et al. (2011) who assessed the factor structure of the Brief COPE in people with mild traumatic brain injury. They reported good internal consistency for problem-focused (adaptive) (Cronbach's Alpha $=0.80)$ and emotionfocused (maladaptive) (Cronbach's Alpha $=0.77)$ coping categories (Snell, Siegert, Jean, Hay-Smith, \& Surgenor, 2011). Subcategories for the 14 Brief COPE scales are as follows: (1) Active coping: "I've been concentrating my efforts on doing something about the situation I'm in"; (2) Planning: "I've been thinking hard about what steps to take"; (3) Use of emotional support: "I've been getting emotional support from others";

(4) Use of instrumental support: "I've been getting help and advice from other people";

(5) Positive reframing: "I've been trying to see it in a different light, to make it seem more positive"; (6) Acceptance: "I've been accepting the reality of the fact that it has happened"; (7) Religion: "I've been trying to find comfort in my religion or spiritual 
beliefs"; (8) Humor: “I’ve been making jokes about it”; (9) Venting: “I've been expressing my negative feelings”; (10) Denial: “I've been saying to myself 'this isn't real' "; (11) Substance use: "I've been using alcohol or other drugs to help me get through it"; (12) Behavioral disengagement: "I've been giving up trying to deal with it"; (13) Self-distraction: "I've been turning to work or other activities to take my mind off things"; and (14) Self-blame: "I've been blaming myself for things that happened." Scales 1 through 8 were classified as adaptive, and scales 9 through 14 were classified as maladaptive (Carver et al., 1993). Each question was scored from 1-4 according to their response to each question. The higher the score, the more the person employed that style of coping. To achieve an adaptive/problem-focused score and a maladaptive/emotionfocused score the questions from each list were summed. Scores for problem-focused coping fell within the range of $8-32$ and for emotion-focused coping they fell within the range of $6-24$ with the high scores indicating a stronger disposition to that particular coping style. Evidence indicates that adaptive coping scales tend to be linked with desirable outcomes, whereas maladaptive coping scales tend to be associated with undesirable outcome (Carver et al., 1993; Mahmoud, Staten, Hall, \& Lennie, 2012; Snell et al., 2011).

Data Analysis:

The survey was administered over a 2 week period. Following the administration period the data from each survey was manually entered into an SPSS data file and stored in a secure, password protected online database. A list of all student ID's and their corresponding survey numbers was compiled and sent to the Office of Institutional Research who added gender, age, ethnicity, housing status, enrollment hours, term GPA 
and cumulative GPA beside each corresponding student ID and survey number. The cumulative and term GPA's were calculated at the end of the spring semester and represented the most up to date measure of GPA. Prior to returning this information, the Office of Institutional Research was required to clear the student ID's from the list so as to maintain student anonymity within the dataset. Using the SPSS software Sense of Coherence, Perceived Stress, and Coping Style were scored using their respective scoring protocols. The Brief COPE provided a problem-focused coping score, and an emotionfocused coping score; while SOC and Perceived Stress provided single scores.

Prior to conducting a mediation analysis it was important to evaluate the relationships between SOC, Perceived Stress Emotion-Focused Coping, ProblemFocused Coping, Pro-Health Behavior Engagement, and Cumulative GPA and compare the results to those found in the literature. Independent-samples t-tests were conducted to assess differences in means and zero order correlations were conducted using all of the study variables to assess co-linearity between variables.

Mediation Analysis:

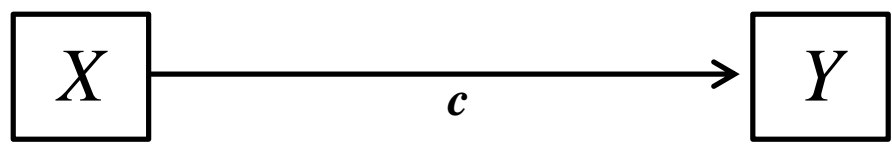

Figure 4a. The direct effect that $X$ exerts on $Y$, measured in terms of $c$. 


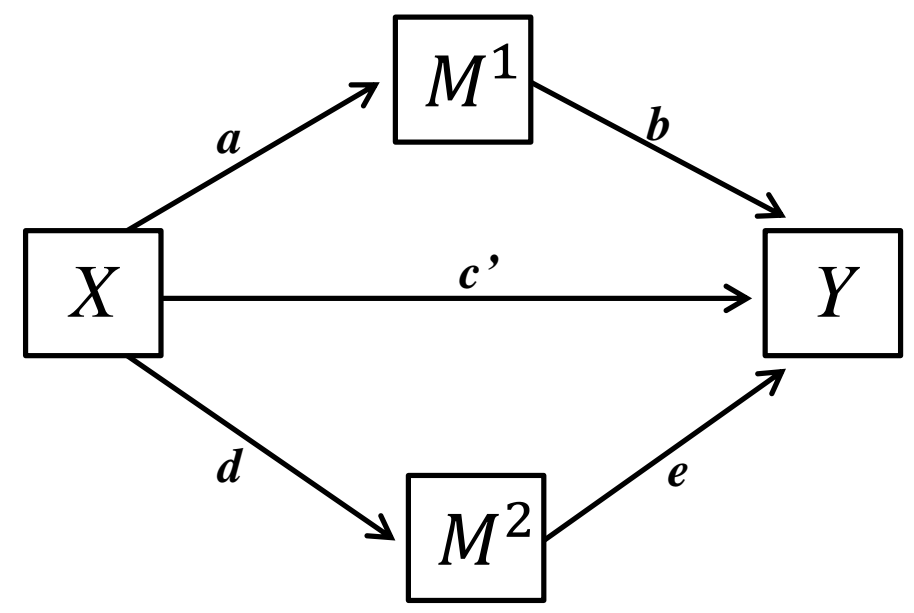

Figure 4b. A multi-mediator model depicting the indirect effect of $X$ on $Y$ through two mediators $\left(M^{1}\right.$ and $\left.M^{2}\right)$, measured in terms of $c^{\prime}$.

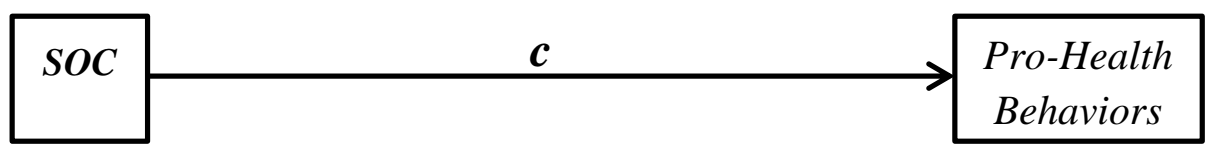

Figure 4c. The direct effect sense of coherence exerts on the engagement in pro-health behaviors, measured in terms of $c$. Sense of coherence was measured using the 13 item questionnaire Orientation to Life Questionnaire scored from 13-91(A. Antonovsky, 1987c). Pro-health behaviors are measured using questions taken from the American College Health Associations, National College Health Assessment measuring selfreported smoking habits, alcohol consumption patterns, fruit and vegetable consumption, cardiovascular exercise and strengthen exercise habits, and average sleep hours per night. Respondents receive a score of zero or one based on their responses (American College Health Association, 2013). Zero indicates they are not engaging in the pro-health 
behavior and one indicates they are engaging in the pro-health behavior. Score for prohealth behavior range from $0-6$.

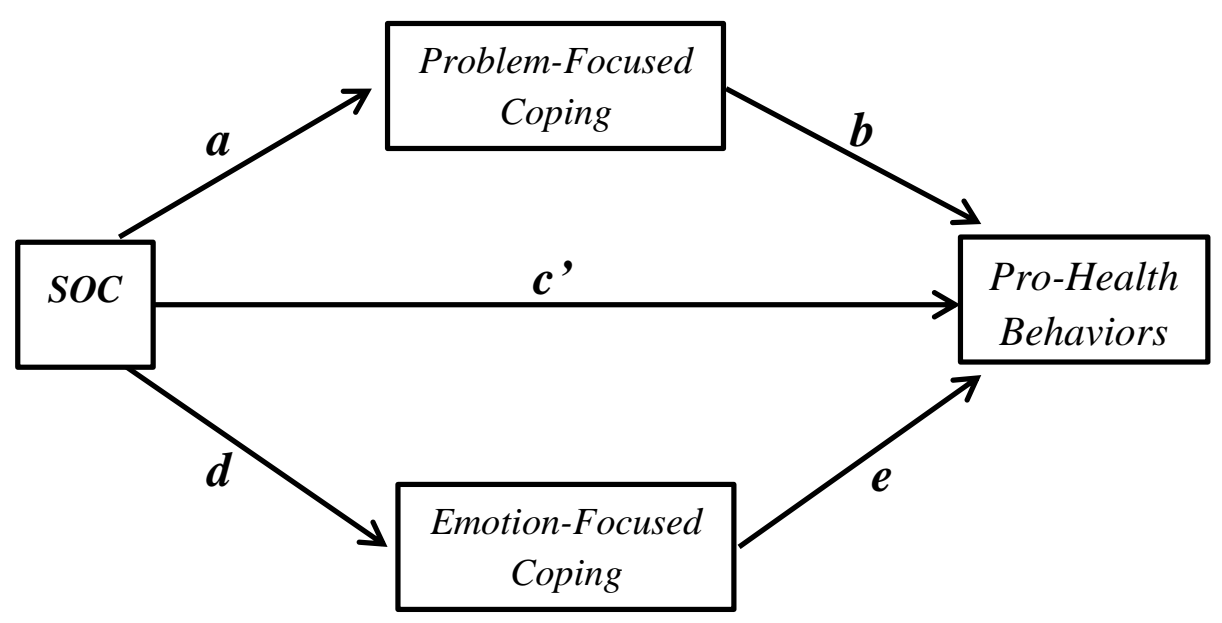

Figure 4d. A Mediation model testing the degree to which emotion-focused coping and problem-focused coping mediate the relationship between sense of coherence and the engagement in pro-health behaviors. Sense of coherence is measured using the 13 item questionnaire Orientation to Life Questionnaire scored from 13-91(A. Antonovsky, 1987c). Problem-focused coping and emotion focused coping are measured using the Brief Cope, scores for problem-focused coping range from $8-32$ and scores for emotionfocused coping range from 6 - 24 (Carver, 1997). Pro-health behaviors are measured using questions taken from the American College Health Associations, National College Health Assessment measuring self-reported smoking habits, alcohol consumption patterns, fruit and vegetable consumption, cardiovascular exercise and strengthen exercise habits, and average sleep hours per night. Respondents receive a score of zero or one based on their responses (American College Health Association, 2013). Zero 
indicates they are not engaging in the pro-health behavior and one indicates they are engaging in the pro-health behavior. Score for pro-health behavior range from $0-6$.

Mediation analysis seeks to measure the extent to which the effect of an independent variable $(X)$ on a dependent variable $(Y)$ is transmitted through one of more intervening variables $(M)$. Figure 4a depicts the direct effect of $X$ on $Y$, where c represents the direct effect of $X$ on $Y$. In this study, $c$ represents the effect SOC has on the number of health promoting behaviors reported by college students in this sample (Figure 4c.). Antonovsky originally theorized that individuals with higher SOC will use more effective coping strategies when faced with a stressor, resulting in improved health. Empirical evidence has been presented demonstrating a positive relationship between SOC and the engagement in pro-health behaviors thus supporting Antonovsky's theory of improved health. Mediation analysis was used to evaluate the mediating (indirect) effect $\left(c^{\prime}\right)$ of problem-focused coping and emotion-focused coping on the relationship between SOC and the number of pro-health behaviors reported by traditional aged U.S. college students (Figure 4d.), and if the mediating influence of problem-focused coping and/or emotion-focused coping was significant $\left(c-c^{\prime}\right)$ (MacKinnon, Fairchild, \& Fritz, 2007b; Preacher \& Hayes, 2004).

Within the social sciences Baron \& Kenny's (1986) causal steps approach is the most commonly used method to assess mediation however, MacKinnon et al. (2007) point out that their method has several limitations relative to the statistical power to detect mediated effects and the frequency of Type I errors (rejecting null hypothesis when it should be accepted). They report that the causal steps approach has low statistical power to detect mediation in part because it requires a significant relationship 
between the dependent and independent variables. They note that there are many cases in research where a significant mediation exists when there is no significant relationship between the dependent and independent variables. MacKinnon et al. (2007) state that a significant relationship between the dependent and mediator variables, and a statistically significant relationship between the independent and mediator variables provides sufficient evidence to conclude that mediation exists. Preacher and Hayes (2004) go even further by proposing that a more powerful strategy for testing mediation only requires that an effect (however large or small) exists between an independent and dependent variable and that the indirect effect be statistically significant in the direction predicted by the mediation hypothesis. They recommend using the bootstrapping method to test the significance of a mediating relationship. Bootstrapping is a resampling procedure that does not assume a normal sampling distribution. It involves repeatedly sampling from the data set and estimating the indirect effect in each resampled dataset. According to Preacher \& Hayes (2004), repeating the sampling process thousands of times produces a more accurate approximation of the sampling distribution of the product of $a$ and $b$ that is used to calculate the size and significance of the indirect effect of $X$ on $Y$ through $M^{1,2}$ (Figure 3b.). Therefore given the limitations of the causal steps approach and the recommendation of bootstrapping, mediation was evaluated using SPSS macros developed by Preacher \& Hayes that is available to download at: http://www.afhayes.com/spss-sas-and-mplus-macros-and-code.html. Using this added feature and controlling for age, gender, ethnicity and international status, bootstrapping analyses were conducted using SOC as the independent variable $(X)$, pro-health behavior score as the dependent variable $(Y)$, coping style ( problem-focused coping and emotion- 
focused coping) as the mediating variables $\left(M^{1,2}\right)$ to determine if a mediating effect existed and if it was statistically significant (Ievers-Landis, Burant, \& Hazen, 2011;

James, Mulaik, \& Brett, 2006; MacKinnon et al., 2007b; Preacher \& Hayes, 2004, 2008). 


\section{CHAPTER 4}

\section{RESULTS}

Introduction:

The purpose of this study was to assess SOC in a sample of traditional aged U.S. college students, assess its relationship with the engagement in health promoting behaviors (e.g. non-smoking, responsible drinking, sufficient nightly sleeping, sufficient weekly cardiovascular and resistance exercise, and consumption of sufficient daily fruits and vegetables), the use of coping strategies and the potential mediating role that coping style serves within the relationship between SOC and health behaviors in a sample of traditional U.S. college students.

Prior to administrating the surveys, a class of 37 students completed the survey on two separate occasions seven days apart to estimate the survey's reliability coefficient (Kappa) and item percentage agreement. A total of 22 students agreed to participate in both survey administrations. A Kappa greater than or equal to 0.41 was used to indicate an acceptable level of reliability (J. Cohen, 1960; Viera \& Garrett, 2005). All questions derived from the NCHA survey received a weighted Kappa score greater than 0.41 , all questions but one from the Orientation to Life Questionnaire received a weighted Kappa greater than 0.41, all questions from the Perceived Stress Scale received a weighted Kappa score greater than 0.41 , and 22 out of the 28 questions on the Brief COPE received 
a weighted Kappa score greater than 0.41 (see Appendix 12). Based on the weighted Kappa scores, the instrument has an acceptable level of reliability.

Four hundred and twenty nine students completed the survey. Surveys were only administered to instructor classes who agreed to allow the survey to be administered during class time. Those classes included: Personal Health, Introductory Sociology, Foundations of Human Services, Basic Computer Literacy, Life Fitness and Wellness, and Campus Recreation (senior level course).

Table 1.

Survey Administration Breakdown By College, Number of Students Enrolled and Total Number of Surveys Completed.

\begin{tabular}{lccc}
\hline & $\begin{array}{c}\text { Number of } \\
\text { Classes } \\
\text { Sampled }\end{array}$ & $\begin{array}{c}\text { Number of } \\
\text { Students } \\
\text { Enrolled in } \\
\text { Sampled Classes }\end{array}$ & $\begin{array}{c}\text { Number of } \\
\text { Completed } \\
\text { Surveys }\end{array}$ \\
\hline $\begin{array}{l}\text { College of Health \& Human } \\
\text { Services }\end{array}$ & 11 & 475 & $350(74 \%)$ \\
$\begin{array}{l}\text { College of Science \& } \\
\text { Engineering } \\
\text { College of Arts \& Letters }\end{array}$ & 2 & 57 & $45(79 \%)$ \\
& 2 & 47 & $34(72 \%)$ \\
\hline
\end{tabular}

A total of 401 respondents granted access to their academic records by providing a valid institutional student identification number (ID). Institutional ID's are a nine figure unique number assigned to each student when they first enroll at the university. Using each student institutional ID, age, gender, race, student classification, hours enrolled in the spring semester, cumulative grade point average (GPA), term GPA and international status were obtained through the Office of Institutional Research at the end of the spring semester. 
Table 2.

Breakdown of Undergraduate Student

Classification for Sample Population.

\begin{tabular}{ccc}
\hline Student Classification & $n$ & $\%$ \\
\hline Freshman & 192 & $51 \%$ \\
Sophomore & 101 & $27 \%$ \\
Junior & 47 & $13 \%$ \\
Senior & 35 & $9 \%$ \\
\hline
\end{tabular}

Note: $\mathrm{n}=375$

According to the institutional data a total of 380 students were between the ages of 18 and 24, with a mean age of 19.6 years (WKU mean age $=23$ ). The sample population consisted of 55\% (211) female and 45\% (169) male students, 64\% (245) being Caucasian and 35\% (135) representing a minority race (see Table 3). The race and gender breakdown for the sample population were comparable to the total institution breakdown of race and gender with the exception of a significantly higher proportion of Nonresident Alien students, and African American or Black students and a resulting lower percentage of Caucasian students (see Table 3). 
Table 3.

Sample Ethnicity and Gender Breakdown \& Comparison with Total Institutional Undergraduate Population.

\begin{tabular}{|c|c|c|c|c|}
\hline Ethnicity & Male & Female & $\begin{array}{c}\% \text { of Total } \\
(n=380)\end{array}$ & $\begin{array}{c}\text { Institution } \\
\% *\end{array}$ \\
\hline Caucasian & 100 & 145 & $64 \%$ & $79 \%$ \\
\hline Black or African American & 30 & 33 & $17 \%$ & $11 \%$ \\
\hline Hispanic & 4 & 7 & $3 \%$ & $2 \%$ \\
\hline Asian & 2 & 1 & $1 \%$ & $1 \%$ \\
\hline Two or more Races & 2 & 6 & $2 \%$ & $2 \%$ \\
\hline $\begin{array}{l}\text { Nonresident Alien } \\
\text { Race and Ethnicity }\end{array}$ & 30 & 16 & $12 \%$ & $4 \%$ \\
\hline Unknown & 1 & 3 & $1 \%$ & $2 \%$ \\
\hline$\%$ of Total $(n=380)$ & $44.5 \%$ & $55.5 \%$ & & \\
\hline Institution $\% *$ & $42 \%$ & $58 \%$ & & \\
\hline
\end{tabular}

Note: No ethnicity assigned by WKU to Nonresident Alien students.

Sense of Coherence:

Sense of Coherence was measured using the 13-item Orientation to Life Questionnaire which has a theoretical range of $13-91$. The current sample scores ranged from $24-90$, with a mean score of 61 . The sample mean of 61 fell within the mean range of 35.39 and 77.60 for the 13 item Orientation to Life Questionnaire reported in the literature (Eriksson \& Lindstrom, 2005). Independent-samples t-tests were conducted to compare SOC scores of males and females and SOC scores of Caucasian and minority students (see Tables 4 \& 5). African American, Hispanic, Nonresident aliens, multi-racial and individuals who reported "unknown" were combined to determine if any differences existed between the majority race (Caucasian) and students representing the minority races on campus. The results of the independent samples t-test revealed that the mean $(M)$ SOC score for males $(M=61.08, \mathrm{SD}=11.13)$ and females $(M$ $=61.06, S D=11.60$ ) were not statistically different (see Table 4.) however, there was a 
statistically significant difference between the mean $(M)$ SOC score for Caucasian students $(M=62.28, S D=11.65)$ and minority students $(M=58.87, S D=10.56) ; t(378)$ $=2.820, p<0.01$ ) with Caucasian students scoring significantly higher than minority students (see Table 5).

Table 4.

Results of Independent Samples t-Test Comparing Mean Perceived Stress, ProblemFocused Coping, Emotion-Focused Coping, and Health Behavior Scores, of Male and Female Students.

\begin{tabular}{|c|c|c|c|c|c|c|c|}
\hline \multirow[b]{2}{*}{ Variable } & \multicolumn{2}{|c|}{ Males } & \multicolumn{2}{|c|}{ Females } & \multirow[b]{2}{*}{$t$} & \multirow[b]{2}{*}{$d f$} & \multirow[b]{2}{*}{$\begin{array}{l}\text { Sig. }(2- \\
\text { tailed) }\end{array}$} \\
\hline & Mean & $S D$ & Mean & $S D$ & & & \\
\hline $\begin{array}{l}\text { Sense of } \\
\text { Coherence }\end{array}$ & 61.083 & 11.128 & 61.062 & 11.596 & 0.018 & 378 & 0.986 \\
\hline $\begin{array}{l}\text { Perceived } \\
\text { Stress Score }\end{array}$ & 15.73 & 5.692 & 18.09 & 6.42 & -3.735 & 377 & $0.0002 * * *$ \\
\hline $\begin{array}{l}\text { Problem- } \\
\text { Focused } \\
\text { Coping Score }\end{array}$ & 22.94 & 9.469 & 26.99 & 8.613 & -4.312 & 370 & $0.00002 * * *$ \\
\hline $\begin{array}{l}\text { Emotion- } \\
\text { Focused } \\
\text { Coping Score }\end{array}$ & 10.05 & 5.968 & 11.70 & 5.539 & -2.731 & 368 & $0.007 * *$ \\
\hline $\begin{array}{l}\text { Health } \\
\text { Behavior } \\
\text { Score }\end{array}$ & 2.85 & 1.247 & 2.81 & 1.263 & 0.328 & 374 & 0.743 \\
\hline Term GPA & 2.713 & 0.888 & 3.037 & 0.815 & -3.705 & 378 & $0.0002 * * *$ \\
\hline
\end{tabular}

Note: Sense of coherence is measured using the 13 item questionnaire Orientation to Life Questionnaire scored from 13-91(A. Antonovsky, 1987c). Problem-focused coping and emotion focused coping are measured using the Brief Cope, scores for problem-focused coping range from 8 - 32 and scores for emotion-focused coping range from $6-24$ 
(Carver, 1997). Pro-health behaviors are measured using questions taken from the American College Health Associations, National College Health Assessment measuring self-reported smoking habits, alcohol consumption patterns, fruit and vegetable consumption, cardiovascular exercise and strengthen exercise habits, and average sleep hours per night. Respondents receive a score of zero or one based on their responses (American College Health Association, 2013). Zero indicates they are not engaging in the pro-health behavior and one indicates they are engaging in the pro-health behavior. Score for pro-health behavior range from $0-6$. Perceived stress was measured using the 10 item Perceived Stress Scale scored from 10 - 40 (S. Cohen et al., 1983). Term grade point average (GPA) was provided by WKU's institutional research office. It was calculated after all spring 2014 grades had been submitted. $S D=$ Standard Deviation; $d f$ $=$ Degrees of Freedom. ${ }^{*} p<0.05 * * p<0.01,{ }^{* * *} p<0.001$ 
Table 5.

Results of Independent Samples t-Test Comparing Mean SOC, Perceived Stress, Problem-Focused Coping, Emotion-Focused Coping, Health Behavior Scores, and Term GPA of Caucasian and Minority Students.

\begin{tabular}{|c|c|c|c|c|c|c|c|}
\hline \multirow{2}{*}{ Variable } & \multicolumn{2}{|c|}{ Caucasian } & \multicolumn{2}{|c|}{ Minority } & \multirow[b]{2}{*}{$t$} & \multirow[b]{2}{*}{$d f$} & \multirow[b]{2}{*}{ Sig. (2-tailed) } \\
\hline & Mean & $S D$ & Mean & $S D$ & & & \\
\hline $\begin{array}{l}\text { Sense of } \\
\text { Coherence }\end{array}$ & 62.282 & 11.647 & 58.874 & 10.555 & 2.82 & 378 & $0.005^{* *}$ \\
\hline $\begin{array}{l}\text { Perceived } \\
\text { Stress Score }\end{array}$ & 16.55 & 6.345 & 17.93 & 5.881 & -2.079 & 377 & $0.038 *$ \\
\hline $\begin{array}{l}\text { Problem- } \\
\text { Focused } \\
\text { Coping Score }\end{array}$ & 24.14 & 9.546 & 27.19 & 8.225 & -3.069 & 378 & $0.002 * *$ \\
\hline $\begin{array}{l}\text { Emotion- } \\
\text { Focused } \\
\text { Coping Score }\end{array}$ & 9.91 & 5.49 & 12.98 & 5.914 & -4.963 & 378 & $0.000001 * * *$ \\
\hline $\begin{array}{l}\text { Health } \\
\text { Behavior } \\
\text { Score }\end{array}$ & 2.758 & 1.303 & 2.947 & 1.155 & -0.943 & 378 & 0.164 \\
\hline Term GPA & 3.086 & 0.788 & 2.544 & 0.883 & 6.143 & 378 & $0.000001^{* * *}$ \\
\hline
\end{tabular}

Note: Minority students represent all students that did not classify themselves as Caucasian. $\mathrm{SD}=$ Standard Deviation; $d f=$ Degrees of Freedom. $* p<0.05 * * p<$ $0.01, * * * p<0.001$ 
Table 6.

Zero-Order Correlations Between Sense of Coherence, Perceived Stress, Emotion-Focused Coping, Problem-Focused Coping, Health Behavior Score, and Term Grade Point Average (GPA).

\begin{tabular}{|c|c|c|c|c|c|c|c|}
\hline & & $\begin{array}{c}\text { Sense of } \\
\text { Coherence }\end{array}$ & $\begin{array}{l}\text { Perceived } \\
\text { Stress }\end{array}$ & $\begin{array}{c}\text { Problem- } \\
\text { Focused } \\
\text { Coping }\end{array}$ & $\begin{array}{c}\text { Emotion- } \\
\text { Focused } \\
\text { Coping }\end{array}$ & $\begin{array}{c}\text { Pro-Health } \\
\text { Behavior } \\
\text { Score } \\
\end{array}$ & Term GPA \\
\hline \multirow{3}{*}{ Sense of Coherence } & Correlation $(r)$ & 1 & $-.677^{* * * *}$ & $.105^{*}$ & $-.544^{* * *}$ & $.137^{* *}$ & $.151^{* *}$ \\
\hline & Sig. (2-tailed) & & .0000001 & .043 & .0000001 & .008 & .003 \\
\hline & $n$ & 380 & 379 & 372 & 370 & 376 & 380 \\
\hline \multirow{3}{*}{ Perceived Stress } & Correlation $(r)$ & $-.677^{* *}$ & 1 & -.056 & $.568^{* * *}$ & $-.206^{* *}$ & $-.161^{* *}$ \\
\hline & Sig. (2-tailed) & .0000001 & & .281 & .000 & .0001 & .086 \\
\hline & $n$ & 379 & 379 & 371 & 369 & 375 & 379 \\
\hline \multirow{3}{*}{$\begin{array}{l}\text { Problem-Focused } \\
\text { Coping }\end{array}$} & Correlation $(r)$ & $.105^{*}$ & -.054 & 1 & $.222^{* * *}$ & .094 & .034 \\
\hline & Sig. (2-tailed) & .043 & .296 & & .00002 & .072 & .508 \\
\hline & $n$ & 372 & 371 & 372 & 365 & 368 & 372 \\
\hline \multirow{3}{*}{$\begin{array}{l}\text { Emotion-Focused } \\
\text { Coping }\end{array}$} & Correlation $(r)$ & $-.544^{* * *}$ & $.568^{* * *}$ & $.222^{* * *}$ & 1 & $-.136^{*}$ & $-.187^{* * *}$ \\
\hline & Sig. (2-tailed) & .0000001 & .000 & .00002 & & .011 & .0003 \\
\hline & $n$ & 370 & 379 & 380 & 370 & 376 & 370 \\
\hline \multirow{3}{*}{$\begin{array}{l}\text { Pro-Health } \\
\text { Behavior Score }\end{array}$} & Correlation $(r)$ & $.137^{* *}$ & $-.206^{* * * *}$ & .094 & $-.136^{* *}$ & 1 & .076 \\
\hline & Sig. (2-tailed) & .008 & .0001 & .072 & .009 & & .144 \\
\hline & $n$ & 376 & 375 & 368 & 366 & 376 & 376 \\
\hline \multirow{3}{*}{ Term GPA } & Correlation $(r)$ & $.151^{* *}$ & $-.161^{* *}$ & .034 & $-.187^{* * *}$ & .076 & 1 \\
\hline & Sig. (2-tailed) & .003 & .002 & .508 & .0003 & .144 & \\
\hline & $n$ & 380 & 379 & 372 & 370 & 376 & 367 \\
\hline
\end{tabular}

***. Correlation is significant at the 0.001 level (2-tailed); **. Correlation is significant at the 0.01 level (2-tailed);

*. Correlation is significant at the 0.05 level (2-tailed). 


\section{Correlations:}

Zero-order correlations between sense of coherence, perceived stress score, emotion-focused coping score, problem-focused coping score, pro-health behavior score, and term grade point average were assessed to determine the direction and magnitude of relationships between the study variables. According to the results reported in Table 6, perceived stress, problem-focused coping, emotion-focused coping, pro-health behavior score, and term grade point average all possessed a statistically significant relationship with sense of coherence (SOC) in the same direction reported in the literature. Health Behaviors:

On average students reported engaging in $2.82(S D=1.25)$ out of the 6 health behaviors evaluated through the survey. According to the results of the zero-order correlations reported in Table 6 , SOC had a small but statistically significant positive relationship with the number of pro-health behaviors reported by students $(r=0.137, p=$ 0.008). Independent samples t-tests were conducted to determine if there was a significant difference in mean numbers of pro-health behaviors reported by study participants based on their race and gender. The results revealed there was no significant difference between the mean number of pro-health behaviors reported by males and females nor was there any significant difference between Caucasian and minority students (see Table 4 \& 5).

Independent $\mathrm{t}$-tests were conducted comparing the average SOC for the score assigned for each pro-health behavior (zero or one) assessed in this study. According to the results presented in Table 7, there was a significant difference in mean SOC score between smokers $(M=58.11, S D=10.43)$ and non-smokers $(M=62.23, S D=11.52)$ 
$t(375)=-3.114, p=0.002$ and individuals reporting 7-9 hours of sleep per night $(M=$ $62.36, S D=10.96)$ and those who did not report sleeping 7-9 hours per night $(M=59.36$, $S D=11.73) t(378)=-2.566, p=0.011)$.

Table 7.

Independent Samples t-Test Results Comparing Mean SOC scores Based on Each Health Behavior Stratification (Zero or One).

\begin{tabular}{rcccccc}
\hline & Mean & $S D$ & $F$ & $t$ & $d f$ & Sig. \\
\hline Smoker & 58.112 & 10.429 & 0.784 & -3.114 & 375 & $0.002^{* *}$ \\
Non-Smoker & 62.226 & 11.523 & & & & \\
\hline Unhealthy Sleeper & 59.356 & 11.725 & 0.515 & -2.566 & 378 & $0.011^{*}$ \\
Healthy Sleeper & 62.359 & 10.956 & & & & \\
\hline Unhealthy Drinker & 60.896 & 10.298 & 2.39 & -0.32 & 375 & 0.749 \\
Healthy Drinker & 61.283 & 12.039 & & & & \\
\hline Not Enough Cardio & 60.987 & 11.397 & 0.044 & -0.185 & 378 & 0.853 \\
Enough Cardio & 61.211 & 11.377 & & & & \\
\hline Not Enough Strength & 60.619 & 11.086 & 0.721 & -0.825 & 378 & 0.41 \\
Enough Strength & 61.584 & 11.705 & & & & \\
\hline Not Enough Fruits \& & 60.997 & 11.501 & \multirow{2}{*}{1.74} & -0.567 & \multirow{2}{*}{378} & \multirow{2}{*}{0.571} \\
Veggies & 60.578 & 8.577 & & & & \\
\hline Enough Fruits \& Veggies & 62.556 & & &
\end{tabular}

Note: $* \mathrm{p}<0.05, * * \mathrm{p}<0.01$. Smokers were defined as individuals who reported smoking within the past 30 days. Unhealthy sleepers were defined as individuals who reported sleeping on average less than 7 hours or more than 9 hours per night over the previous 30 days. Unhealthy drinkers were defined as individuals who reporting drinking 5 or more drinks in a sitting, or more than 3 drinks in a day if they are a woman and more than 4 drinks a day if they are a man. Not enough cardio was defined as individuals who reported engaging in moderate cardiovascular exercise for at least 30 minutes on fewer than 5 days/week, or reported engaging in vigorous cardiovascular exercise for at least 20 
minutes on fewer than 4 days per week. Not enough strength was defined as individuals who reported engaging in strengthening exercises on fewer than 2 days per week. Not enough fruits and veggies were defined as individuals who reported on average consuming fewer than 5 servings of fruits and vegetables per day.

Based on the data collected in this study showing that SOC had a statistically significant positive relationship with the pro-health behavior score of traditional aged U.S. college students sampled $(r=0.137, p=0.008)$, Null Hypothesis I, which stated that there will be no statistically significant relationship between SOC and the engagement in pro-health behaviors by traditional aged U.S. college students can be rejected.

Coping Strategies:

Emotion-focused coping and problem-focused coping were measured using the Brief Cope which has a theoretical scoring range of $0-36$ and $0-48$ respectively. The current samples scores ranged from $0-29$ for emotion-focused coping, with an average score of 10.97, and problem-focused coping scores ranged from 0 - 44 with an average score of 25.19. According to the results reported in Table 6, problem-focused coping had a small but statistically significant relationship with SOC $(r=0.105, p=0.043)$ and Emotion-Focused Coping had a larger, more statistically significant relationship with SOC $(r=-0.544, p<0.001)$. Independent-samples t-tests were conducted to compare emotion-focused coping and problem-focused coping scores of males and females and of Caucasian and minority students. According to the results presented in Tables 4 and 5, there was a statistically significant difference in both mean problem-focused and mean emotion-focused coping between Caucasian $(M=24.14, S D=9.546$ and $M=9.91, S D=$ 5.49 respectively) and minority students $(M=27.19, S D=8.225$ and $M=12.98, \mathrm{SD}=$ 
5.914 respectively) $\mathrm{t}(378)=-3.069, \mathrm{p}<0.01$ and $\mathrm{t}(378)=-4.963, p<0.001$ respectively. Additionally there was a statistically significant difference in both mean problem-focused and emotion-focused coping scores for males $(M=22.94, S D=9.469$ and $M=10.05, S D$ $=5.68$ respectively $)$ and females $(M=26.99, S D=8.613$ and $M=11.7, S D=5.539$ respectively) $\mathrm{t}(370)=-4.312, \mathrm{p}<0.001$ and $\mathrm{t}(368)=-2.731, p<0.01$ with females scoring higher in both coping styles.

To better understand the amount of variation in SOC that can be assigned to coping styles, emotion-focused coping and problem-focused coping were regressed onto SOC. The results of regressing problem-focused coping on to SOC revealed that problem-focused coping only accounted for $1.1 \%$ of the variation in SOC $\left(R^{2}=0.011, \mathrm{~F}\right.$ $(4.112)=33.54, p<0.05)$ and the results of regressing emotion-focused coping on to SOC revealed that emotion-focused coping accounted for $29.6 \%$ of the variation in SOC $\left(R^{2}=0.296, \mathrm{~F}(154.62)=68.20, p<0.001\right)$. Collectively, problem-focused and emotionfocused coping accounted for $35.3 \%$ of the variation in SOC $\left(R^{2}=0.353, \mathrm{~F}(100.399)=\right.$ $42.622, p<0.001)$.

Based on the results of the analysis of the relationship between SOC and Problem-Focused Coping, SOC had a small but statistically significant relationship with Problem-Focused Coping score $(r=0.105, p<0.05)$ (see Figure 5b). Therefore, Null Hypothesis II which stated that there will be no statistically significant relationship between SOC and the Problem-Focused Coping score of traditional aged U.S. college students is rejected. SOC has a statistically significant positive relationship with problem-focused coping. 
Based on the results of the analysis of coping style relationships with SOC, SOC had a statistically significant negative relationship with emotion-focused coping $(r=-$ 0.542, $p<0.001$, see Figure 5a), Null Hypothesis III which stated that there will be no statistically significant relationship between SOC and the emotion-focused coping score of traditional aged U.S. college students, can be rejected. SOC had a statistically significant negative relationship with emotion-focused coping (see Table 6.).

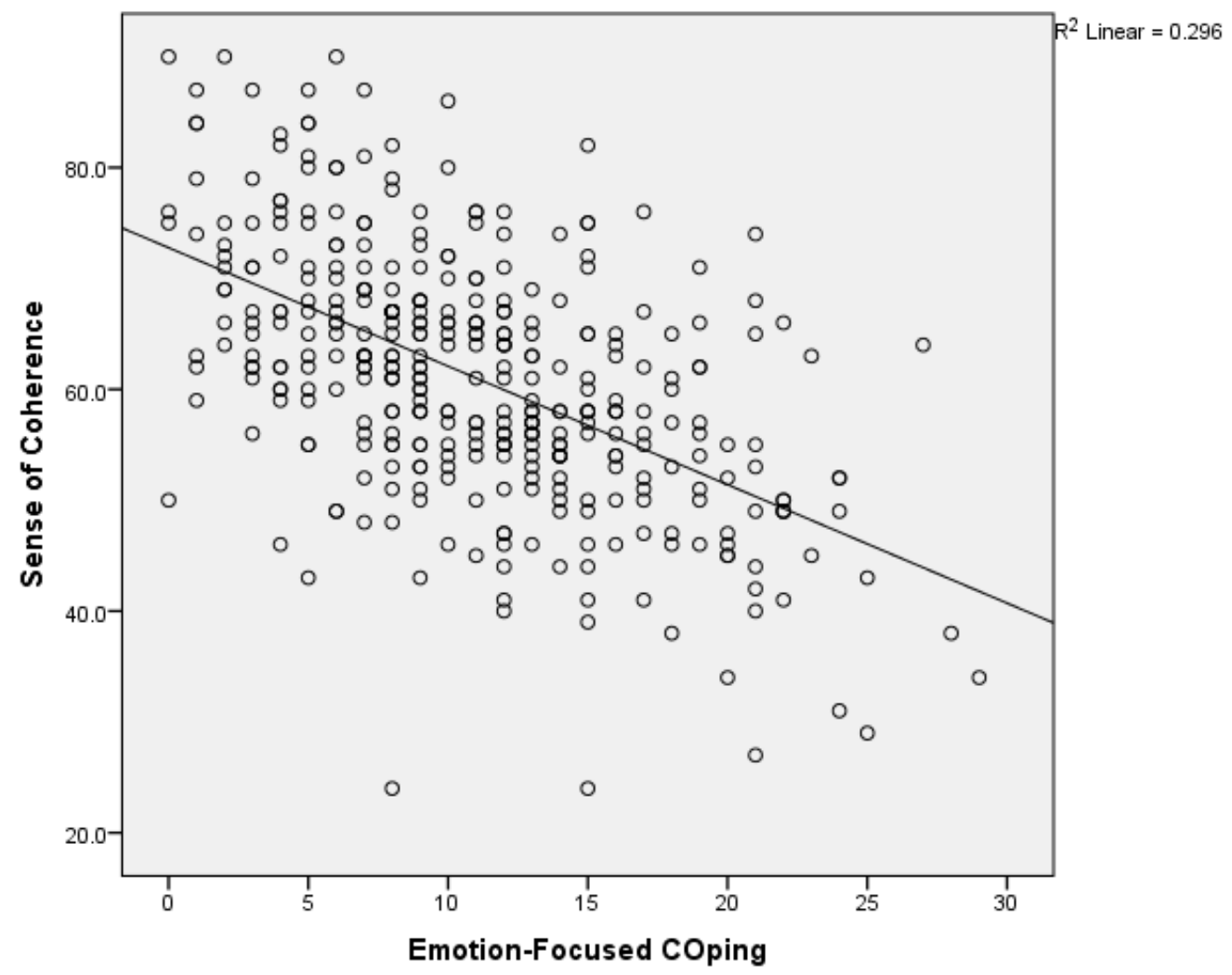

Figure 5a. Relationship between sense of coherence and emotion-focused coping score $(r$ $=-0.542, p<0.001$. Sense of coherence was measured using a 13 item questionnaire scored from 13-91, and emotion focused coping was measured using the Brief Cope, scores for emotion-focused coping ranged from $6-24$. 


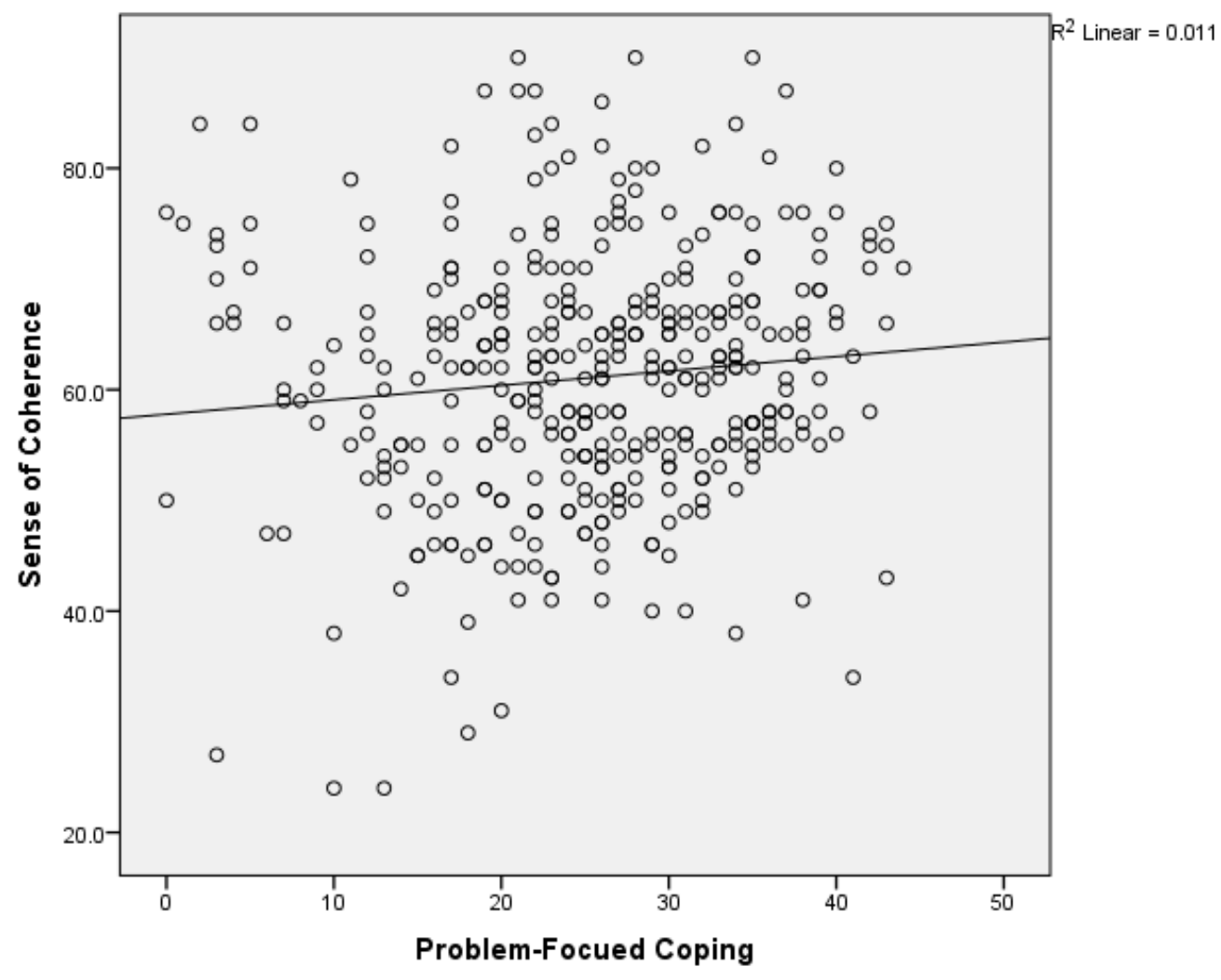

Figure 5b. Relationship between sense of coherence and problem focused coping $(r=$ $0.105, p=0.043)$. Sense of coherence is measured using a 13 item questionnaire scored from 13-91, problem-focused coping was measured using the Brief Cope, scores for problem-focused coping ranged from $0-48$.

Pro-Health Behaviors and Coping Strategies:

According to the results of the zero-order correlations reported in Table 6, the number of pro-health behaviors reported by students (Pro-Health Behavior Score) in this study had a statistically significant negative relationship with emotion-focused coping $(r$ $=-0.136, p<0.01)$ and no significant relationship with problem-focused coping $(r=$ 0.094, $p=0.072$ ). Therefore the results of this study fail to reject Null Hypothesis IV which states that there will be no statistically significant relationship between problem- 
focused coping and the engagement in pro-health behaviors by traditional aged U.S. college students, and rejects the Null Hypothesis V which states that there will be no statistically significant relationship between emotion-focused coping and the engagement in pro-health behaviors by traditional aged U.S. college students.

Mediation:

Based on the results of this study showing statistically significant relationship between SOC pro-health behavior score and emotion-focused coping and a statistically significant relationship between emotion-focused coping and pro-health behavior score (see Table 6) there is sufficient evidence to suggest that coping style mediates the relationship between SOC and the number of pro-health behaviors reported. (MacKinnon et al., 2007b). Throughout the mediation analyses the influences of gender, age, ethnicity, and international student status (covariates) were controlled for to account for their impact on the variation in SOC, coping style, and pro-health behavior score. According to Preacher and Hayes (2004), testing for mediation requires the following steps:

1. Regress the independent variable onto the dependent variable (controlling for covariates) to determine the direct effect of the independent variable on the dependent variable (c) (see Figure 4a). If the direct effect is not equal to zero, there is sufficient evidence to proceed with the mediation analysis. The results from regressing SOC onto pro-health behavior score $\left(R^{2}=0.036, \mathrm{~F}(5,370)=\right.$ $2.762, p<0.01$ ) (see Table 8.) revealed that SOC had a statistically significant direct effect $(c=0.017, p<0.01)$ on the number of pro-health behaviors reported 
(c) (see Figure 6). Therefore $c$ was not equal to zero indicating that there was sufficient evidence to proceed with the mediation analysis.

2. Regress each mediating variable onto the independent variable (SOC) to assess the effect each mediator has on the independent variable (SOC) (see Tables $9 \&$ 10). The results from regressing problem-focused coping on to SOC $\left(R^{2}=0.097\right.$, $\mathrm{F}(5,374)=8.011, p<0.01)$ revealed that problem-focused coping did have a statistically significant effect (0.099) on SOC (a) (see Figure 6). The results from regressing emotion-focused coping on to $\operatorname{SOC}\left(R^{2}=0.35, \mathrm{~F}(5,374)=40.303, p<\right.$ 0.001 ) revealed that emotion-focused coping had a statistically significant negative effect $(d=-0.263, p<0.001)$ on $\operatorname{SOC}(d)$.

3. Regress the independent variable and proposed mediating variables onto the dependent variable (controlling for covariates) to determine the indirect effect ( $\left.c^{\prime}\right)$ of the independent variable and mediator(s) on the dependent variable (see Figure 4b). The results from regressing SOC, problem-focused coping and emotionfocused coping on to the number of pro-health behaviors reported $\left(R^{2}=0.053\right.$, $\mathrm{F}(7,368)=2.929, p<0.01)$ revealed that the indirect effect $\left(c^{\prime}\right)$ of SOC on the number of pro-health behaviors reported was not statistically significant $\left(c^{\prime}=\right.$ $0.008, \mathrm{p}=0.278)($ see Table 11)

4. Subtract the indirect effect ( $\left(c^{\prime}\right)$ from the direct effect $(c)$ to determine the total mediating (indirect) effect. According to the results of the regression analyses the total indirect effect (mediating effect) is equal to $c-c^{\prime}$, in this case $0.017-0.008$ $=0.009$. Note: All beta coefficients within the mediation analysis are plotted in Figure 6. 
5. Use the bootstrapping statistical resampling process to assess the significance of the total mediating effect. In bootstrapping, mediation is significant if the $95 \%$ bias corrected and accelerated confidence intervals (Boot LLCI and Boot ULCI) for the indirect effect do not include zero (Preacher, Rucker, \& Hayes, 2007). After resampling 5,000 times, according to the results of the 95\% bias corrected confidence intervals from emotion-focused coping (Boot LLCI $=0.0014$, Boot $\mathrm{ULCI}=0.0167)$ and problem-focused coping (Boot LLCI $=0.0002$, Boot ULCI $=0.0051)$, they both do not contain zero, therefore they are significant mediators of the relationship between SOC and the number of pro-health behaviors reported by students in this sample (see Table 12). As a result of the bootstrapping analysis null hypothesis VII and VIII which state that there will be no statistically significant mediating effect of problem-focused coping and emotion-focused coping on the relationship between SOC and the engagement in pro-health behaviors by traditional aged U.S. college students are rejected because the upper and lower level bootstrapped confidence intervals do not contain zero. 


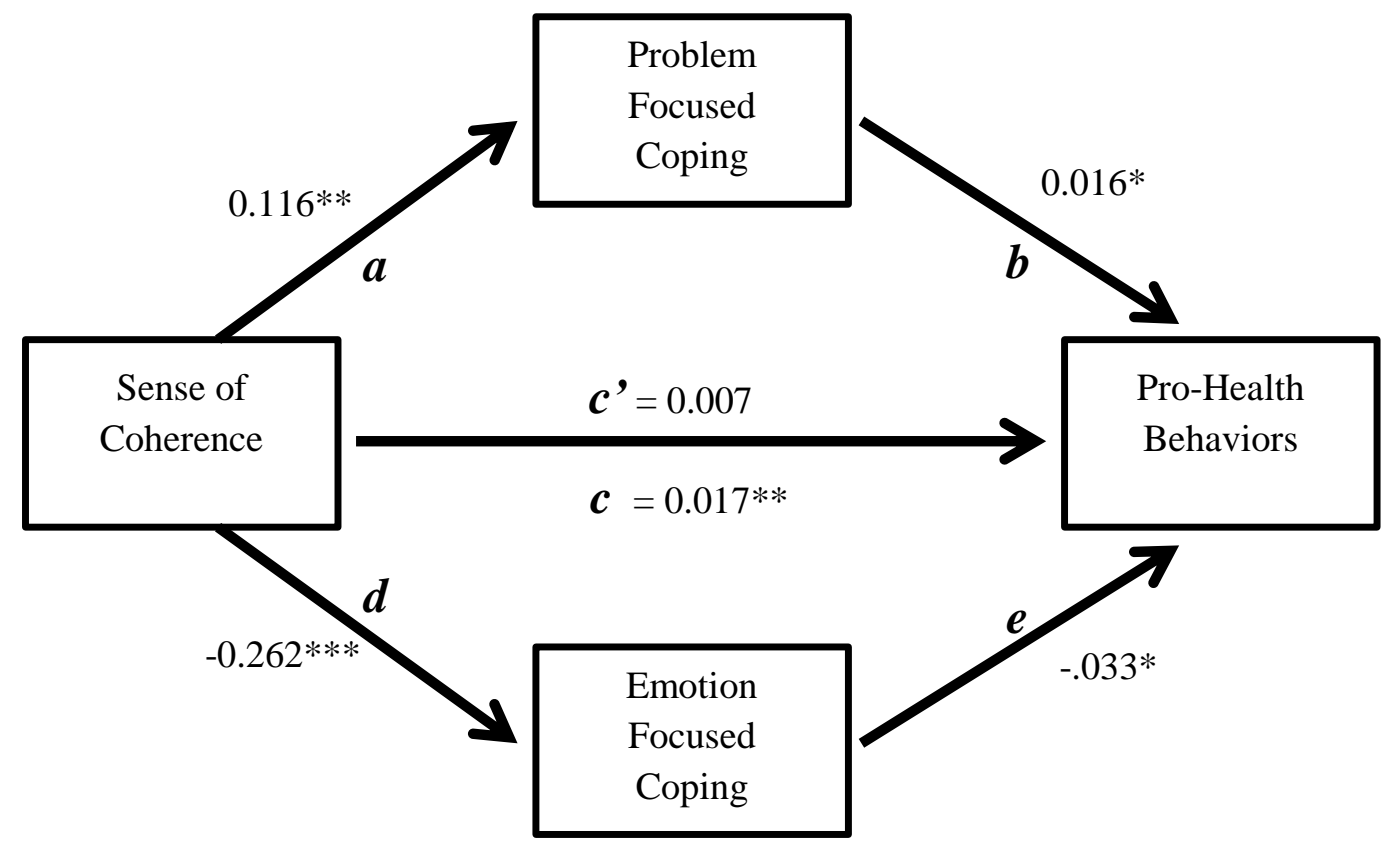

Figure 6. A mediation model depicting the indirect relationship between sense of coherence and the engagement in pro-health behaviors through problem-focused and emotion-focused coping variables. Throughout the mediation analysis the influences of gender, age, ethnic, and international status were controlled for in the regression analyses. Regression coefficients represent the number of standard deviations a dependent variable will change for every single standard deviation change of the predictor variable. $a=$ the direct effect of sense of coherence on problem-focused coping, $b=$ the direct effect of problem-focused coping on pro-health behavior engagement, controlling for the influence of SOC and emotion-focused coping, $d=$ the direct effect of SOC on emotion-focused coping, $e=$ the direct effect of emotion-focused coping on pro-health behavior engagement, controlling for the influence of SOC and problem-focused coping. $\mathrm{c}=$ the direct effect of SOC on pro-health behavior engagement, $c^{\prime}=$ the indirect effect of SOC 
on pro-health behavior engagement, through problem-focused and emotion-focused coping. Note: ${ }^{*} p<0.05, * * p<0.01, * * * p<0.001, n=361$.

Table 8 .

Model Summary of Total Effect of SOC on Number of Pro-Health Behaviors Reported, Controlling for Age, Gender, Ethnicity, and International Status.

\begin{tabular}{lcccccc}
\hline & $\mathrm{R}$ & $\mathrm{R}^{2}$ & $\mathrm{~F}$ & $\mathrm{df1}$ & $\mathrm{df2}$ & Sig. \\
\hline & .190 & .036 & 2.645 & 5 & 355 & .023 \\
& Coif. & $\mathrm{se}$ & $\mathrm{t}$ & Sig. & LLCI & ULCI \\
\hline Constant & 3.162 & 1.054 & 3.002 & .003 & 1.090 & 5.235 \\
SOC $^{\vee}$ & .017 & .006 & 3.009 & .003 & .006 & .029 \\
\hline
\end{tabular}

$=$ Total Effect $(c)$

Table 9.

Model Summary of Total Effect of SOC on Problem-Focused Coping Score, Controlling for Age, Gender, Ethnicity, and International Status.

\begin{tabular}{|c|c|c|c|c|c|c|}
\hline & $\mathrm{R}$ & $\mathrm{R}^{2}$ & $\mathrm{~F}$ & df1 & df2 & Sig. \\
\hline & .342 & .117 & 9.447 & 5 & 355 & .000 \\
\hline & Coeff. & se & $\mathrm{t}$ & Sig. & LLCI & ULCI \\
\hline Constant & 1.073 & 7.37 & 0.532 & .884 & 13.44 & 15.585 \\
\hline $\mathrm{SOC}^{\sim}$ & .116 & .040 & 2.885 & .004 & $\begin{array}{c}- \\
.3055\end{array}$ & -.2195 \\
\hline Gender & 4.984 & .945 & 5.275 & .000 & 3.126 & 6.842 \\
\hline Ethnicity & 3.966 & 1.135 & 3.495 & .001 & 1.734 & 6.198 \\
\hline Age & .596 & .341 & 1.749 & .081 & -.074 & 1.267 \\
\hline $\begin{array}{l}\text { International } \\
\text { Status }\end{array}$ & .1 .246 & 1.694 & .735 & .463 & 2.086 & 4.578 \\
\hline
\end{tabular}

$\because=a$ 
Table 10.

Model Summary of Total Effect of SOC on Emotion-Focused Coping Score, Controlling for Age, Gender, Ethnicity, and International Status.

\begin{tabular}{lcccccc}
\hline & $\mathrm{R}$ & $\mathrm{R}^{2}$ & $\mathrm{~F}$ & $\mathrm{df1}$ & $\mathrm{df2}$ & Sig. \\
\hline & .597 & .357 & 39.352 & 5 & 355.0 & .0000 \\
& & & & & & \\
\hline Constant & Coeff. & $\mathrm{se}$ & $\mathrm{t}$ & $\mathrm{Sig}$. & LLCI & ULCI \\
SOC & 22.253 & 4.008 & 5.551 & .000 & 14.37 & 30.14 \\
Gender & -.263 & .022 & -12.0 & .000 & -.306 & -.220 \\
Ethnicity & 2.075 & .513 & 4.044 & .000 & 1.066 & 3.085 \\
Age & 2.070 & .616 & 3.36 & .0001 & .858 & 3.283 \\
International & .177 & .185 & .953 & .341 & -.188 & .541 \\
Status & -.666 & .920 & -.723 & .470 & -2.476 & 1.144 \\
\hline
\end{tabular}

$\sim \sim d$

Table 11.

Model Summary of Total Effect of SOC, Problem-Focused Coping, and EmotionFocused Coping on Number of Pro-Health Behaviors Reported, Controlling for Age, Gender, Ethnicity, and International Status.

\begin{tabular}{|c|c|c|c|c|c|c|}
\hline & $\mathrm{R}$ & $\mathrm{R}^{2}$ & $\mathrm{~F}$ & df1 & df2 & Sig. \\
\hline & .235 & .055 & 2.944 & 7 & 353 & .005 \\
\hline & Coeff. & se & $\mathrm{t}$ & Sig. & LLCI & ULCI \\
\hline $\begin{array}{l}\text { Constant } \\
\text { Problem- }\end{array}$ & 3.869 & 1.094 & 3.538 & .0005 & 1.718 & 6.02 \\
\hline $\begin{array}{l}\text { Focused } \\
\text { Coping^ } \\
\text { Emotion- }\end{array}$ & .0159 & .008 & 2.03 & .043 & .0005 & .031 \\
\hline $\begin{array}{l}\text { Focused } \\
\text { Coping }^{\wedge}\end{array}$ & -.033 & .014 & -2.256 & .025 & -.061 & -.004 \\
\hline SOC* & .007 & .007 & 0.982 & .327 & -.007 & .021 \\
\hline
\end{tabular}

$*=$ Direct Effect $\left(c^{\prime}\right),{ }^{\wedge}=b,{ }^{\wedge}=e$ 
Table 12.

Summary of $95 \%$ Bias Corrected and Accelerated Boot-Strapped

Confidence Intervals For the Indirect Effect of Problem-Focused and Emotion-Focused Coping on the Relationship Between SOC and Number of Reported Pro-Health Behaviors, Controlling for Age, Gender, Ethnicity, and International Status.

\begin{tabular}{lcccc}
\hline & Effect & $\begin{array}{c}\text { Boot } \\
\text { SE }\end{array}$ & Boot LLCI & Boot ULCI \\
\hline Total & .0104 & .0042 & .0026 & .0192 \\
Problem-Focused & .0019 & .0012 & .0002 & .0051 \\
Emotion-Focused & .0085 & .0038 & .0014 & .0167 \\
Direct Effect & -.0067 & .0038 & -.0148 & .0005 \\
\hline
\end{tabular}

Note: Bootstrapped confidence intervals that do not contain zero are indicative of a statistically significant result.

Academic Performance:

The final stage of the analysis was to test null hypothesis VIII which states that there will be no statistically significant relationship between SOC and Term Grade Point Average (GPA) of traditional aged U.S. college students. Based on the results shown in Table 16, which are similar to results reported by Grayson (2008), SOC has a statistically significant positive relationship with the Cumulative and Term grade point average of the traditional aged U.S. college students in this sample population $(r=0.135, p=0.008 ; r=$ $0.151, p=0.003$ respectively) null hypothesis IX is rejected (J. Grayson, 2008).

Additionally, it is worth noting that both Term and Cumulative GPA were significantly related to emotion-focused coping score. Students who scored high in the use of emotion-focused coping styles scored significantly lower in both Cumulative and Term GPA (see (Table 13.). Overall, SOC accounted for only $2.3 \%$ of the variance in Term GPA $\left(R^{2}=0.023, \mathrm{~F}(8.811)=9.916, p<0.01\right)$, emotion-focused coping accounted for $3.5 \%$ of the variance in Term GPA $\left(R^{2}=0.035, \mathrm{~F}(13.30)=34.02, p<0.001\right)$ and 
problem-focused coping accounted for less than $1 \%$ of the variance $\left(R^{2}=0.001, \mathrm{~F}(0.439)\right.$ $=22.22, p<0.001$ ).

Table 13.

Correlation between Sense of Coherence and Perceived Stress, and Cumulative and Term Grade Point Average from a Sample of Traditional U.S. College Students.

\begin{tabular}{ll|l}
\hline & \multicolumn{1}{c}{ Cum. GPA } & \multicolumn{1}{c}{ Term GPA } \\
\cline { 2 - 3 } & \multicolumn{1}{c}{$\begin{array}{c}\text { Correlations } \\
(r)\end{array}$} & $\begin{array}{c}\text { Correlations } \\
(r)\end{array}$ \\
\hline Sense of Coherence & $.135^{* *}$ & $.151^{* *}$ \\
Emotion-Focused Coping & $-.171^{* *}$ & $-.187 * * *$ \\
Problem-Focused Coping & .033 & .034 \\
Perceived Stress & $-.137 * *$ & $-.161 * *$ \\
\hline
\end{tabular}

Note: $\mathrm{n}=380,{ }^{*} \mathrm{p}<0.05, * * \mathrm{p}<0.01, * * * \mathrm{p}<0.001$ 


\section{CHAPTER 5}

\section{DISCUSSION}

Introduction:

Stress is an inevitable consequence of life that requires attention to manage and overcome. Hans Selye described stress as a dichotomous variable with the capacity to lead to constructive or destructive outcomes. Research has shown that the outcomes of any stressful encounter are dependent to a large extent on one's perceptual reaction to each stressor they encounter (Lazarus \& Folkman, 1984c; Selye, 1976b). Therefore, Aaron Antonovsky developed the Sense of Coherence construct as a means to assess one's capacity to successfully manage stressors which in his view determined their health outcomes. In the time since Antonovsky first proposed the SOC construct the majority of the research has been conducted in European and Scandinavian countries prompting the necessity to evaluate the SOC construct within the U.S population. Also due to the increasing globalization of higher education in the U.S. it is important to investigate cross-culturally valid metrics like SOC to better standardize efforts to develop crossculturally valid interventions (Eriksson \& Lindstrom, 2005).

There is extensive evidence showing that increased stress levels within the college student population are associated with poor health behaviors including smoking, binge eating, suicide ideation, and binge drinking (Bray \& Born, 2004; Dallman et al., 2003; Hudd et al., 2000; Pritchard et al., 2007a; Wilburn \& Smith, 2005). Furthermore, in addition to poor health behaviors, increased stress is also associated with poor academic 
performance within the college student population (Barry et al., 2009; M. Cohen et al., 2008; Friedlander et al., 2007). Therefore SOC has the potential to effectively predict college student health and academic success.

Antonovsky theorized that the pathway to improved health outcomes flowed through an individuals' capacity to manage stress. Coping mechanisms represent the strategies people use to manage stress. Antonovsky described SOC as a measure of one's ability to select the most appropriate coping mechanism for each stressor they encounter. In his view, SOC did not predict a specific coping style. It measured the extent to which one had amassed life experiences they could draw on to choose the best coping approach to a given stressor. Contrary to Anonovsky's theory, there is empirical evidence showing a significant relationship between SOC and specific coping styles (emotion and problemfocused coping styles) (Amirkhan \& Greaves, 2003; M. Cohen et al., 2008; Grota, 2006; Heiman, 2004; McSherry \& Holm, 1994). Lazarus and Folkman (1983) defined emotion-focused coping as cognitive and behavioral efforts directed at managing the emotional response to a stressor. Emotion-focused coping is commonly referred to as maladaptive coping given it is more commonly associated with higher perceived stress and health inhibiting behaviors. It occurs more frequently when there is a perception that nothing can be done to alter the threatening, challenging or harmful stressor. Problemfocused coping on the other hand is defined as cognitive and behavioral efforts directed at altering or managing a stressor. Problem-focused coping is commonly referred to as adaptive coping given that it is associated with lower perceived stress levels and the engagement in health-promoting behaviors. It is more likely to occur when there is a perception that a stressor is changeable. Research has shown that SOC has a positive 
relationship with problem-focused coping and a negative relationship with emotionfocused coping. (Britton, 2004; M. Cohen et al., 2008; Filaire et al., 2012; Julal, 2013; Lazarus \& Folkman, 1984c; F. Patterson, C. Lerman, V. G. Kaufmann, G. A. Neuner, \& J. Audrain-McGovern, 2004; Ptacek et al., 2008). Therefore the influence of SOC on the engagement in health promoting behaviors may be mediated by the coping style individuals choose.

Summary of the Results:

The aim of this study was to better understand the process through which SOC affected a student's choice to engage in health promoting behaviors. The results of the data analysis adds to the results from previous research reporting a positive relationship between SOC and the engagement in health promoting behaviors, and academic performance by college students. Within the present study, SOC had a weak though statistically significant positive relationship with the engagement in pro-health behaviors by traditional U.S. college students in the study sample $(r=0.137, p=0.008)$. This weak relationship indicates that there are other variables that potentially have a larger influence on the engagement in health promoting behaviors than SOC. The pro-health behaviors assessed were: nonsmoking (no smoking within last 30 days), sleeping an average of 7-9 hours per night, responsible drinking behaviors (non-drinkers, non-binge drinkers, and women who drank 3 or fewer drinks, and men who drank 4 or fewer drinks on average during social engagements), eating 5 or more servings of fruits and vegetables per day, engaging in moderate cardiovascular exercise 4 or more days per week or vigorous cardiovascular exercise 3 or more days per week, and engaging in strength training activities 2 or more days per week. These results support results reported by Johnsen 
(1992), Waintwright et al. (2007) and Binkowska-Bury and Januszewicz (2010) who reported a statistically significant positive relationship between SOC and the engagement in pro-health behaviors (Binkowska-Bury \& Januszewicz, 2010; Johnsen, 1992b; Wainwright et al., 2007). On average students in this study reported engaging in 2.82 out of the six pro-health behaviors assessed in this study with nonsmoking and healthy sleep habits (sleeping 7-9 hours/night) showing significant positive relationships with SOC $(r=0.159, p=0.022 ; r=0.131, p=0.011$ respectively $)($ see Table 7$)$. However, only $2.0 \%$ of the variance in pro-health behavior score could be accounted for by SOC, therefore it is important to understand the process of how SOC relates to the engagement in pro-health behaviors.

Research suggests that behaviors are often the function of coping responses to stress. The results of the present study show that emotion-focused coping had a statistically significant negative relationship with the number of pro-health behaviors reported by students in this sample $(r=-0.136, p<0.01)$ and a significant positive relationship with perceived stress $(r=0.571, p<0.001)$. The use of alcohol and other drugs, self-criticism and self-blame were coping mechanisms that had a statistically significantly negative relationship with the number pro-health behaviors students reported $(r=-0.198, p<0.001 ; r=-0.137, p=0.008$ respectively). The results of this study show that the use of emotion-focused coping styles had a statistically significantly negative relationship with health promoting behaviors in this population. These results support previous research reporting that the use of emotion-focused coping styles is negatively associated with several pro-health behaviors including non-smoking, healthy eating habits and responsible drinking habits (Britton, 2004; Filaire et al., 2012; 
Mahmoud et al., 2012; Freda Patterson et al., 2004; Wichianson et al., 2009).

Additionally, the results from this study contribute to the evidence reported by Bland et al (2012) who reported that coping mechanisms employed by college students place them at greater risk for low stress tolerance. Stress tolerance refers to the capacity of individuals to effectively adapt to stressors. In general, individuals with low stress tolerance are less able to adapt to and resolve stressful situations than those with a higher stress tolerance. According to Bland et al (2012) traditional college students with low stress tolerance show a higher frequency of procrastination behaviors, and substance use when compared with their high stress tolerance peers (Bland et al., 2012). Within the present study population, emotion-focused coping style consistently showed a statistically significant positive relationship with perceived stress and a statistically significant negative relationship with the engagement in health promoting behaviors and SOC within the sample of traditional aged U.S. college students.

Mediation analysis is the common standard for testing theories regarding the process by which an independent variable exerts an impact on a dependent variable through mediating variables. The primary goal of this study was to investigate the process by which SOC influences the engagement in health promoting behaviors through the use of emotion-focused and problem-focused coping styles. According to the results of this study, there was sufficient evidence to conclude that emotion-focused and problem-focused coping mediated the relationship between SOC and the engagement in pro-health behaviors using Baron and Kenny's Causal-Steps approach. However, according to Andrew Hayes (2013) the causal steps approach possesses sufficient limitations exclude it as a statistically viable mediation analysis option. Hayes points out 
that the causal steps approach does not formally quantify the indirect effect, it does not require any inferential test about the indirect-effect, it has a propensity to Type II errors, and it requirements large sample sizes to achieve an acceptable minimum statistical power (0.8) (Fritz \& MacKinnon, 2007; Hayes, 2013). Therefore, based on the recommendations of MacKinnon et al. (2007), Preacher and Hayes (2004), and Hayes (2013) mediation analysis was conducted using the bootstrapping resampling method to test for significance (Fritz \& MacKinnon, 2007; Hayes, 2013; MacKinnon, Fairchild, \& Fritz, 2007a; Preacher \& Hayes, 2004). The results of the mediation analysis from the study showed that coping style does act as a statistically significant mediator between SOC and the engagement in pro-health behaviors. When coping styles were factored into the regression model, the effect of SOC on the engagement in health promoting behaviors was diminished to a statistically insignificant level indicating that emotion-focused and problem-focused coping styles act as mediators of their relationship. Therefore based on these results, to better promote the engagement in pro-health behaviors among college students it is important to encourage greater use of problem-focused coping styles while at the same time discouraging the use of emotion-focused coping styles.

In regard to the relationship between SOC and academic performance, SOC had a statistically significant relationship with both term and cumulative GPA $(r=0.151, p<$ 0.01 , and $\mathrm{r}=0.135, \mathrm{p}<0.01$ respectively). Students scoring higher in SOC used fewer emotion-focused coping styles, reported lower perceived stress and had significantly higher term and cumulative GPA's than those students who scored lower SOC. It is important to note that emotion-focused coping was also a statistically significant predictor of cumulative and term GPA $(r=-0.171, p<0.01$, and $r=-0.187, p<0.001)$. 
In fact, emotion-focused coping had a statistically stronger relationship with term and cumulative GPA than SOC $(r=0.151, p<0.01$, and $r=0.135, p<0.01$ respectively). Four out of the six emotion-focused coping styles (denial, substance use, behavioral disengagement, and self-blame) evaluated had statistically significant negative relationships with both the term grade point average and the cumulative grade point average of the students in this sample, while none of the eight problem-focused coping styles were significantly related to cumulative and term grade point average

According to Antonovsky, SOC predicts health through improved coping abilities (A. Antonovsky, 1987c). Based on the results from this study of traditional U.S. college students, SOC had a strong significant negative relationship with emotion-focused coping $(r=-0.544, p<0.001)$, and a smaller statistically significant positive relationship with problem-focused coping $(r=0.105, p<0.05)$ as previous studies have reported. The weak relationship between SOC and problem-focused coping observed may be indicative of the preferred coping strategies used by the current population of traditional aged U.S. college students. Students who scored lower in SOC, scored significantly higher in emotion-focused coping styles including the use of self-distraction, denial, substance use, disengagement, venting, and self-blame. Antonovsky theorized that an individuals' SOC is a product of life experiences. Therefore given the results of the present study showing a statistically significant negative relationship with emotion-focused coping, as a result of life experiences, students in this study population who scored lower in SOC are more likely to enter college with a perception that when faced with threatening, challenging or harmful stressors in life, nothing can be done to alter them than those scoring higher in SOC. This result highlights the importance of identifying low SOC students or students 
who tend to use more emotion-focused coping strategies and designing interventions to aid in the building of a stronger SOC and discouraging the use of emotion-focused coping styles.

The college environment is an ideal environment to apply and test interventions to improve health behaviors and overall academic performance. In fact, colleges spend millions of dollars annually to provide programs and services designed to help student improve their health and academic skills. However, relatively few assess the outcomes of their intervention or report their findings, leaving many to question whether the investment in these programs and services is an effective use of university resources. There is a relative lack of research reporting the outcomes and designs of interventions designed to improve SOC. Examples of the few SOC interventions reported in the literature include one by Vastamaki et al. (2009) and one by Berger et al. (2009). Vastamaki et al. (2009) investigated the temporal stability of SOC in a sample of 74 unemployed Finnish adults ranging in age from 18 to 57 years of age. They found that SOC improved significantly following a six-month intervention designed to boost reemployment (Vastamäki et al., 2009). Within the college setting Berger et al. (2009), evaluated the impact of an academic course designed to provide students with theoretical knowledge of and practical application of cognitive behavioral techniques on individual SOC and situational moods as measured by the Profile of Moods States. The outcomes of their study revealed that the experimental group experienced a statistically significant increase in SOC while the control group did not experience any significant change in SOC (Berger et al., 2009). Given the results of these two studies, there is evidence that SOC is responsive to intervention, however more interventions designed to improve SOC 
are needed to identify the most efficient and practical methods of improving SOC in college students.

Implications:

According to Antonovsky stressors are not our enemy, rather it is our reaction to stress that is the concern. Within the traditional U.S. college student population, stress influences success in and out of the classroom. Administrators throughout higher education are striving to determine best practices in learning experiences that produce higher graduation rates and health promotion professionals in higher education are striving to develop interventions to encourage health promoting behaviors that contribute to a students' success. Based on the results from this study, the use of emotion-focused coping styles are a significant contributor to both poor academic and poor health behavior choices. The results of this study are similar to those reported by Mahmoud et al (2012) who found that emotion-focused coping best predicted depression, anxiety and depression within a college student population. They recommended screening programs designed to reduce the use of emotion-focused coping behaviors (Mahmoud et al., 2012).

The results of the present study indicates that SOC possesses significant potential to predict a students' propensity to choose effective coping styles that encourage more health promoting behaviors and potentially better study habits that lead to better academic outcomes. Additionally there is also evidence that assessing dispositional coping styles may be a more viable option as well. The results of this study show that pro-health behavior engagement and grade point average have a stronger overall relationship with emotion-focused coping than SOC. The main benefit of assessing SOC may be to predict emotion-focused coping using a shorter assessment tool than the 28- 
item Brief COPE. The 13-item Orientation to Life Questionnaire is a relatively short, valid, and reliable assessment of a students' propensity toward the use of effective coping styles and may be a more efficient means to identify students at risk of poor health behavior choices and less successful academic outcomes. It is important to note that Antonovsky's primary purpose of developing the Orientation to Life Questionnaire and the SOC construct was to identify an individual quality/variable that is positively associated with health. He had grown tired of the pathological approach to disease prevention that seeks to identify risk factors for disease. Antonovsky wanted to encourage a salutogenic approach to health promotion that encouraged the identification and promotion of factors that encourage health. The results of the present study could be interpreted to mean that emotion-focused coping should be discouraged, representing a pathogenic approach to health promotion. It could also be interpreted that SOC should be encouraged. These contrasting methods of health promotion represent a research opportunity investigating which intervention approach (salutogenic or pathogenic) is more effective in improving health behaviors. First-year experience courses represent an excellent example of a potential intervention population. College dropout rates are the highest after the first year of college (U.S. Department of Education, 2012). Based on the results of this study and the evidence presented, a course designed to encourage the use of problem-focused coping methods over the use of emotion-coping methods has the potential to improve student academic performance and influence their engagement in health promoting behaviors. 
Limitations:

It is important to note that the results and conclusions from this study are limited by the sampling approach and demographics of the students who participated. The sample student population was generated through a convenience sample of general education courses and therefore lacks the representativeness often associated with the use of random selection techniques. Given the complexity of mediation analysis there are relatively few available resources to aid in the estimation of sample sizes necessary to achieve the minimum acceptable statistical power of 0.8. Statistical power refers to the probability that you will determine that a statistically significant difference exists when once actually exist, thereby avoiding a type II error. Fritz and Mackinnon (2007) provide a reference chart of samples size for simple mediation (one mediator). However, there is no available reference of samples sizes for multiple mediator analyses. Therefore, there was no available means to assess the statistical power of the mediation analysis. Given the relatively small effect size between the variables (see figure 7.) there is a potential that this study does not have a large enough sample size to achieve the minimum recommended statistical power (0.8). Additionally, due to the number of international students who participated in this study and the importance of achieving the largest available sample size, international students were included in the study sample. Therefore, the study sample did not contain all students of U.S. birth and may not be as representative of the traditional U.S. student population as a study that excluded international students.

Another limitation of this study related to the mediation analysis. Often there are multiple variables that contribute to a relationship between a dependent and independent 
variable. In this instance, mediation analysis was limited to coping style. Other variables may play an influential role in determining how SOC relates to the engagement in health promoting behaviors including environmental factors (access, safety, etc.) and socioeconomic factors which were beyond the scope of this study. Therefore it will be necessary to continue to evaluate the causal pathway between SOC and health promoting behaviors. Finally, this study was limited to six health promoting behaviors and the definitions they were assigned. Future studies may need to evaluate the frequency of each behavior (i.e. total number of workout sessions, total number of fruits consumed, etc.) instead of using a dichotomous classification of each health behavior variable as either they did or did not satisfy a defined standard. There is a potential that a dose response exists between health behaviors and SOC.

Conclusion:

In conclusion, the results from this study highlight the potential use of SOC and evaluating dispositional coping styles as a means to identify college students who may be at increased risk for poor health behavior choices and academic difficulties. As Aaron Antonovsky theorized, this study confirmed that within this sample population of traditional U.S. college students, the relationship between SOC and health is mediated by the use of problem and emotion-focused coping styles. Furthermore, the results of this study provide evidence that SOC is a salutary quality that is associated with lower perceived stress levels, the use of fewer emotion-focused coping styles, the engagement in more pro-health behaviors and better overall academic performance. 


\section{REFERENCES}

Abramsohn, Y., Peles, E., Potik, D., Schreiber, S., \& Adelson, M. (2009). Sense of coherence as a stable predictor for methadone maintenance treatment (MMT) outcome. Journal Of Psychoactive Drugs, 41(3), 249-253.

American College Health Association. (2006). National College Health Assessment, from http://www.acha-ncha.org/reports_ACHA-NCHAoriginal.html

American College Health Association. (2012). National College Health Assessment: Spring 2012 Reference Group Executive Summary. Hanover, MD.

American College Health Association. (2013). ACHA-NCHA II Retrieved 10/20/2013, from http://www.acha-ncha.org/docs/ACHA-NCHAII_sample.pdf

American Psychological Association. (2012). Stress in America: Our health at risk. Retrieved 01/10/2013, from http://www.apa.org/news/press/releases/stress/index.aspx Amirkhan, J. H., \& Greaves, H. (2003). Sense of Coherence and Stress: The Mechanics of a Healthy Disposition. [Article]. Psychology \& Health, 18(1), 31-62.

Antonovsky, A. (1979a). Measuring Health on a Continuum Health, Stress, and Coping (pp. 38-69). San Francisco, CA: Jossey-Bass Publishers.

Antonovsky, A. (1979b). Perceiving the world as coherent Health, Stress, and Coping (pp. 123-159). San Francisco, CA: Jossey-Bass Publishers.

Antonovsky, A. (1979c). Prologue: Evolution of a new perspective Health, Stress, and Coping (pp. 1-11). San Francisco, CA: Jossey-Bass Publishers.

Antonovsky, A. (1979d). Stressors, Tension, and Stress Health, Stress, and Coping (pp. 70-97). San Francisco, CA: Jossey-Bass Publishers.

Antonovsky, A. (1979). Tension Managment and Resources for Resistance Health, Stress and Coping (pp. 98-122). San Francisco, CA: Jossey-Bass Publishers.

Antonovsky, A. (1987a). The "Sense of Coherence" Concept Unraveling the Mystery of Health: How people manage stress and stay well. (pp. 15-32). San Francisco, CA: JoeseyBass Publishers. 
Antonovsky, A. (1987a). The "Sense of Coherence" Concept Unraveling the mystery of health: How people manage stress and stay well. (pp. 19). San Francisco, CA US: JosseyBass.

Antonovsky, A. (1987b). Similarities of the concept to other views of health Unraveling the mysteries of health: How people manage stress and stay well (pp. 33-62). San Francisco, CA: Jossy-Bass Publishers.

Antonovsky, A. (1987b). Toward a new view of health and illness Unraveling the mystery of health (pp. 1-14). San Francisco, CA: Jossey-Bass Publishers.

Antonovsky, A. (1987c). Unraveling the Mystery of Health: How people manage stress and stay well. San Francisco, CA: Jossey-Bass Publishers.

Antonovsky, A. (1993). The structure and properties of the Sense of Coherence scale. Social Science \& Medicine, 36(6), 725-733.

Antonovsky, A. (1996). The salutogenic model as a theory to guide health promotion. Health Promotion International, 11(1), 11-18.

Antonovsky, H., \& Sagy, S. (1986). The Development of a Sense of Coherence and Its Impact on Responses to Stress Situations. [Article]. Journal of Social Psychology, 126(2), 213.

Barry, L. M., Hudley, C., Kelly, M., \& Cho, S. (2009). Differences in self-reported disclosure of college experiences by first-generation college student status. Adolescence, 44(173), 55-68.

Ben-Zur, H. (2002). Monitoring/blunting and social support: Associations with coping and affect. International Journal of Stress Management, 9(4), 357-373. doi:

10.1023/a:1019990518144

Berger, R., Sarid, O., Hurvitz, N., \& Anson, O. (2009). Sense of Coherence and Mood States: Exploring the Causal Relationships. [Article]. Journal of Applied Social Psychology, 39(1), 82-94. doi: 10.1111/j.1559-1816.2008.00430.x

Bernabé, E., Tsakos, G., Watt, R. G., Suominen-Taipale, A. L., Uutela, A., Vahtera, J., \& Kivimäki, M. (2009a). Structure of the sense of coherence scale in a nationally representative sample: the Finnish Health 2000 survey. Quality Of Life Research: An International Journal Of Quality Of Life Aspects Of Treatment, Care And Rehabilitation, 18(5), 629-636. 
Bernabé, E., Tsakos, G., Watt, R. G., Suominen-Taipale, A. L., Uutela, A., Vahtera, J., \& Kivimäki, M. (2009b). Structure of the sense of coherence scale in a nationally representative sample: the Finnish Health 2000 survey. [Article]. Quality of Life Research, 18(5), 629-636. doi: 10.1007/s11136-009-9469-z

Binkowska-Bury, M., \& Januszewicz, P. (2010). Sense of Coherence and Health-Related Behavior among University Students - A Questionnaire Survey. Central European Journal of Public Health, 18(3), 145-150.

Bland, H. W., Melton, B. F., Welle, P., \& Bigham, L. (2012). Stress Tolerance: New Challenges for Millennial College Students. [Article]. College Student Journal, 46(2), 362-375.

Bray, S. R., \& Born, H. A. (2004). Transition to University and Vigorous Physical Activity: Implications for Health and Psychological Well-Being. Journal of American College Health, 52(4), 181-188.

Britton, P. C. (2004). The relation of coping strategies to alcohol consumption and alcohol-related consequences in a college sample. [Article]. Addiction Research \& Theory, 12(2), 103-114. doi: 10.1080/16066350310001613062

Brougham, R., Zail, C., Mendoza, C., \& Miller, J. (2009). Stress, Sex Differences, and Coping Strategies Among College Students. [Article]. Current Psychology, 28(2), 85-97. doi: 10.1007/s12144-009-9047-0

Carver, C. S. (1997). You want to measure coping but your protocol's too long: Consider the Brief COPE. International Journal of Behavioral Medicine, 4, 92-100.

Carver, C. S., Pozo, C., Harris, S. D., Noriega, V., Scheier, M. E., Robinson, D. S., . . Clark, K. C. (1993). How Coping Mediates the Effect of Optimism on Distress: A Study of Women With Early Stage Breast Cancer. Journal of Personality and Social Psychology, 65(2), 375-390.

Carver, C. S., Scheier, M. F., \& Segerstrom, S. C. (2010). Optimism. Clinical Psychology Review, 30(7), 879-889. doi: http://dx.doi.org/10.1016/j.cpr.2010.01.006

Cohen, J. (1960). A coefficient of agreement for nominal scales. Educational and Psychological Measurement, 20, 37-46. doi: 10.1177/001316446002000104

Cohen, M., Ben-Zur, H., \& Rosenfeld, M. J. (2008). Sense of coherence, coping strategies, and test anxiety as predictors of test performance among college students. International Journal of Stress Management, 15(3), 289-303. doi: 10.1037/10725245.15.3.289 
Cohen, M., \& Kanter, Y. (2004). Relation between sense of coherence and glycemic control in type 1 and type 2 diabetes. Behavioral Medicine, 29(4), 175-183. doi: 10.3200/bmed.29.4.175-185

Cohen, S., Kamarck, T., \& Mermelstein, R. (1983). A global measure of perceived stress. Journal of Health and Social Behavior, 24, 385-396.

Cohen, S., \& Williamson, G. (1988). The social psychology of health: Claremont Symposium on Applied Social Psychology. Newbury Park, CA: Sage.

Dallman, M. F., Pecoraro, N., Akana, S. F., La Fleur, S. E., Gomez, F., Houshyar, H., . . . Manalo, S. (2003). Chronic stress and obesity: a new view of "comfort food". Proceedings Of The National Academy Of Sciences Of The United States Of America, 100(20), 11696-11701.

Darling, C. A., McWey, L. M., Howard, S. N., \& Olmstead, S. B. (2007). College student stress: the influence of interpersonal relationships on sense of coherence. Stress \& Health: Journal of the International Society for the Investigation of Stress, 23(4), 215229.

Davidson, O. B., Feldman, D. B., \& Margalit, M. (2012). A Focused Intervention for 1stYear College Students: Promoting Hope, Sense of Coherence, and Self-Efficacy. [Article]. Journal of Psychology, 146(3), 333-352. doi: 10.1080/00223980.2011.634862

Devonport, T. J., \& Lane, A. M. (2006). Relationships between self-efficacy, coping and student retention. [Article]. Social Behavior \& Personality: An International Journal, 34(2), 127-138.

Dusselier, L., Dunn, B., Wang, Y., II, M. C. S., \& Whalen, D. F. (2005). Personal, health, academic, and environmental predictors of stress for residence hall students/. Journal of American College Health, 54(1), 15-24.

Economos, C. D., Hildebrandt, M. L., \& Hyatt, R. R. (2008). College Freshman Stress and Weight Change: Differences by Gender. [Article]. American Journal of Health Behavior, 32(1), 16-25.

Eriksson, M., \& Lindstrom, B. (2005). Validity of Antonovsky's sense of coherence scale: a systematic review. Journal of Epidemiology \& Community Health, 59, 460-466. doi: $10.1136 /$ jech.2003.018085

Filaire, E., Treuve, P., \& Toumi, H. (2012). Relationship Between Eating-Behavior Disorders and Psychological Parameters in Male First-Year Physical Education Students. 
[Article]. International Journal of Sport Nutrition \& Exercise Metabolism, 22(5), 383391.

Frenz, A. W., Carey, M. P., \& Jorgensen, R. S. (1993). Psychometric evaluation of Antonovsky's Sense of Coherence Scale. Psychological Assessment, 5(2), 145-153. doi: 10.1037/1040-3590.5.2.145

Friedlander, L. J., Reid, G. J., Shupak, N., \& Cribbie, R. (2007). Social Support, SelfEsteem, and Stress as Predictors of Adjustment to University Among First-Year Undergraduates. Journal of College Student Development, 48(3), 259-274. doi: $10.1353 /$ csd.2007.0024

Fritz, M. S., \& MacKinnon, D. P. (2007). Required sample size to detect the mediated effect. Psychological Science, 18(3), 233 - 239.

Grayson, J. (2008). Sense of coherence and academic achievement of domestic and international students: a comparative analysis. [Article]. Higher Education, 56(4), 473492. doi: 10.1007/s10734-007-9106-0

Grayson, J. P. (2007). Sense of Coherence, Problem Freedom and Academic Outcomes of Canadian Domestic and International Students. [Article]. Quality in Higher Education, 13(3), 215-236. doi: 10.1080/13538320701800134

Grota, B. L. (2006). The relationship among coping strategies, perceived stress, and sense of coherence. 66, ProQuest Information \& Learning, US. Retrieved from http://search.ebscohost.com/login. aspx?direct=true \&db=psyh\&AN=2006-99002$102 \&$ site $=$ ehost-live Available from EBSCOhost psyh database.

Gustavsson-Lilius, M., Julkunen, J., Keskivaara, P., Lipsanen, J., \& Hietanen, P. (2012). Predictors of distress in cancer patients and their partners: The role of optimism in the sense of coherence construct. Psychology \& Health, 27(2), 178-195. doi: $10.1080 / 08870446.2010 .484064$

Hakanen, J. J., Feldt, T., \& Leskinen, E. (2007). Change and stability of sense of coherence in adulthood: Longitudinal evidence from the Healthy Child study. Journal of Research in Personality, 41(3), 602-617. doi: 10.1016/j.jrp.2006.07.001

Hayes, A. F. (2013). Introduction to mediation, moderation, and conditional process analysis: A regression-based approach. New York, NY: The Guilford Press.

Heiman, T. (2004). Examination of the Salutogenic Model, Support Resources, Coping Style, and Stressors among Israeli university students. Journal of Psychology, 138(6), 505-520. 
Hicks, T., \& Heastie, S. (2008). High school to college transition: A profile of the stressors, physical and psychological health issues that affect the first-year on-campus college student. Journal of Cultural Diversity, 15(3), 143-147.

Hover, P. A. (2014). Perceived stress, mindfulness and sense of coherence: a comparison between first generation and non-first generation clinical psychology doctoral trainees. 3602985 Psy.D., The Chicago School of Professional Psychology, Ann Arbor. Retrieved from

http://echo.louisville.edu/login?url=http://search.proquest.com/docview/1468958473?acc ountid $=14665$

http://findit.library.louisville.edu:9003/sfx_local?url_ver=Z39.88-

2004\&rft_val_fmt=info:ofi/fmt:kev:mtx:dissertation\&genre=dissertations+\%26+theses\& sid=ProQ:ProQuest + Dissertations $+\% 26+$ Theses + Full + Text $\&$ atitle $=\&$ title $=$ Perceived + str ess $\% 2 \mathrm{C}+$ mindfulness+and+sense + of + coherence $\% 3 \mathrm{~A}+\mathrm{a}+$ comparison+between+first + gen eration+and+non-

first+generation+clinical+psychology+doctoral+trainees\&issn=\&date $=2014-01$ $01 \&$ volume $=\&$ issue $=\&$ spage $=\&$ au $=$ Hover $\% 2 C+$ Paige + Amber $\&$ isbn $=9781303570599 \& j$ title $=\& b$ title $=\& r f t \_i d=i n f o: e r i c /$ ProQuest Dissertations $\&$ Theses Full Text database.

Hsieh, P.-H., Sullivan, J. R., Sass, D. A., \& Guerra, N. S. (2012). Undergraduate Engineering Students' Beliefs, Coping Strategies, and Academic Performance: An Evaluation of Theoretical Models. [Article]. Journal of Experimental Education, 80(2), 196-218. doi: 10.1080/00220973.2011.596853

Hudd, S. S., Dumlao, J., Erdmann-Sager, D., Murray, D., Phan, E., Soukas, N., \& Yokozuka, N. (2000). Stress at college: Effects on health habits, health status and selfesteem. [Article]. College Student Journal, 34(2), 217.

Ievers-Landis, C. E., Burant, C. J., \& Hazen, R. (2011). The Concept of Bootstrapping of Structural Equation Models with Smaller Samples: An Illustration Using Mealtime Rituals in Diabetes Management. Journal of Developmental and Behavioral Pediatrics, 32(8), 619-626.

Innocents Abroad? Student Health Behaviors Overseas. (2004). [Article]. National OnCampus Report, 32(19), 1-2.

James, L. R., Mulaik, S. A., \& Brett, J. M. (2006). A Tale of Two Methods.

Organizational Research Methods, 9(2), 233-244.

Johnsen, G. A. (1992a). Sense of coherence, perceived health, and the performance of health-promoting behaviors. Ph.D., Boston College. Retrieved from 
http://search.ebscohost.com/login.aspx?direct=true \&db=c8h\&AN=1995002131\&site=eh ost-live Available from EBSCOhost c8h database.

Johnsen, G. A. (1992b). Sense of coherence, perceived health, and the performance of health-promoting behaviors. Ph.D., Boston College. Retrieved from http://search.ebscohost.com/login.aspx?direct=true \&db=cin20\&AN=1995002131\&site=e host-live Available from EBSCOhost cin20 database.

Johnson, N., Oliff, P., \& Williams, E. (2011). An Update on State Budget Cuts Retrieved 10/20/2012, from http://www.cbpp.org/cms/index.cfm?fa=view\&id=1214

Julal, F. S. (2013). Use of student support services among university students: associations with problem-focused coping, experience of personal difficulty and psychological distress. [Article]. British Journal of Guidance \& Counselling, 41(4), 414425. doi: 10.1080/03069885.2012.741680

Keeling, R. P., \& Hersh, R. H. (2011). We're Losing our Minds: Rethinking American Higher Education. New York, NY: Palgrave Macmillan.

Kobasa, S. C. (1979). Stressful life events, personality, and health: An inquiry into hardiness. Journal of Personality and Social Psychology, 37(1), 1-11.

Lazarus, R. S., \& Folkman, S. (1984a). The Coping Process: An alternative to Traditional Formulations Stress, Appraisal, and Coping (pp. 141-180). New York, NY: Springer Publishing Compnay.

Lazarus, R. S., \& Folkman, S. (1984b). The Stress Concept in the Life Sciences Stress, appraisal, and coping (pp. 19). New York: Springer Publishing Company.

Lazarus, R. S., \& Folkman, S. (1984c). Stress, Appraisal, and Coping. New York, NY: Springer Publishing Company.

MacKinnon, D. P., Fairchild, A. J., \& Fritz, M. S. (2007a). Mediation analysis. Annual Review of Psychology, 58(593), 1-19. doi: 10.1146/annurev.psych.58.110405.085542

MacKinnon, D. P., Fairchild, A. J., \& Fritz, M. S. (2007b). Mediation Analysis. Annual Review of Psychology, 58(593), 1-22. doi: 10.1146/annurev.psych.58.110405.085542

Mahmoud, J. S. R., Staten, R., Hall, L. A., \& Lennie, T. A. (2012). The relationship among young adult college students' depression, anxiety, stress, demographics, life satisfaction, and coping styles. Issues in Mental Health Nursing, 33(3), 149-156. doi: 10.3109/01612840.2011.632708 
Mattila, M. L., Rautava, P., Honkinen, P. L., Ojanlatva, A., Jaakkola, S., Aromaa, M., . . . Sillanpää, M. (2011). Sense of coherence and health behaviour in adolescence. Acta Paediatrica, 100(12), 1590-1595. doi: 10.1111/j.1651-2227.2011.02376.x

McAlister, A. L., Perry, C. L., \& Parcel, G. S. (2008). How individuals, environments, and health behaviors interact: Social Cognitive Theory. In K. Glanz, B. K. Rimer \& K. Viswanath (Eds.), Health Behavior and Health Education: Theory, Research, and Practice (4th ed., pp. 167-188). San Francisco, CA.: Jossey-Bass Publishers.

McSherry, W. C., \& Holm, J. E. (1994). Sense of coherence: Its effects on psychological and physiological processes prior to, during, and after a stressful situation. [Article]. Journal of Clinical Psychology, 50(4), 476-487.

Merriam-Webster. (2013). Merriam-Webster Dictionary Retrieved 11/25/2013, from http://www.merriam-webster.com/dictionary/resilience

National Center for Education Statistics. (2011). Table 200. Total fall enrollment in degree-granting institutions, by attendance status, sex, and age: Selected years, 1970 through 2020. Digest of Education Statistics Retrieved 12/14/2013, from http://nces.ed.gov/programs/digest/d11/tables/dt11_200.asp

National Center for Education Statistics. (2012a). Fast Facts: Enrollment. Digest of Education Statistics: 2011. Retrieved from http://nces.ed.gov/fastfacts/display.asp?id=98

National Center for Education Statistics. (2012b). Table 376. Percentage of first-time full-time bachelor's degree-seeking students at 4-year institutions who completed a bachelor's degree, by race/ethnicity, time to completion, sex, and control of institution: Selected cohort entry years, 1996 through 2005. Digest of Education Statistics Retrieved 12/14/2013, from http://nces.ed.gov/programs/digest/d12/tables/dt12_376.asp

Nilsson, K. W., Leppert, J., Simonsson, B., \& Starrin, B. (2010). Sense of coherence and psychological well-being: improvement with age. Journal Of Epidemiology And Community Health, 64(4), 347-352. doi: 10.1136/jech.2008.081174

Pallant, J. F., \& Lae, L. (2002). Sense of coherence, well-being, coping and personality factors: further evaluation of the sense of coherence scale. [Article]. Personality \& Individual Differences, 33(1), 39.

Palmer, L. K. (2013). The Relationship Between Stress, Fatigue, and Cognitive Functioning [Article]. College Student Journal, 47(2), 312-325. 
Patterson, F., Lerman, C., Kaufmann, V. G., Neuner, G. A., \& Audrain-McGovern, J. (2004). CIgarette Smoking Practices Among American College Students: Review and Future Directions. [Article]. Journal of American College Health, 52(5), 203-210.

Patterson, F., Lerman, C., Kaufmann, V. G., Neuner, G. A., \& Audrain-McGovern, J. (2004). Cigarette smoking practices among American college students: review and future directions. [Review] [52 refs]. Journal of American College Health, 52(5), 203-210.

Posadzki, P., Stockl, A., Musonda, P., \& Tsouroufli, M. (2010). A mixed-method approach to sense of coherence, health behaviors, self-efficacy and optimism: Towards the operationalization of positive health attitudes. Scandinavian Journal of Psychology, 51, 246-252. doi: 10.1111/j.1467-9450.2009.00764.x

Preacher, K. J., \& Hayes, A. F. (2004). SPSS and SAS procedures for estimating indirect effects in simple mediation models. Behavior Research Methods, 36(4), 717-731.

Preacher, K. J., \& Hayes, A. F. (2008). Asymptotic and resampling strategies for assessing and comparing indirect effects in multiple mediator models. Behavior Research Methods, 40(3), 879-891. doi: 10.3758/BRM.40.3.879

Preacher, K. J., Rucker, D. D., \& Hayes, A. F. (2007). Addressing moderated mediation hypotheses: Theory, methods, and prescriptions. Multivariate Behavioral Research, 42, $185-227$.

Pritchard, M. E., Wilson, G. S., \& Yamnitz, B. (2007a). What predicts adjustment among college students? A longitudinal panel study. Journal Of American College Health: J Of $\mathrm{ACH}, 56(1), 15-21$.

Pritchard, M. E., Wilson, G. S., \& Yamnitz, B. (2007b). What predicts adjustment among college students? A longitudinal panel study. Journal of American College Health, 56(1), $15-21$.

Pryor, J. H., Hurtado, S., DeAngelo, L., Palucki, Blake, L., \& Tran, S. (2010). The American freshman: National norms fall 2010. Los Angeles, CA: Higher Education Research Institute, UCLA.

Ptacek, J. T., Smith, R. E., Raffety, B. D., \& Lindgren, K. P. (2008). Coherence and transituational generality in coping: The unity and the diversity. [Article]. Anxiety, Stress \& Coping, 21(2), 155-172. doi: 10.1080/10615800701466467

Quick, J. C., Wright, T. A., Adkins, J. A., Nelson, D. L., \& Quick, J. D. (2013). Stress in Organizations Preventive Stress Management in Organizations (pp. 11-25). Washington, D.C.: American Psychological Association. 
Rice, K. G., \& Van Arsdale, A. C. (2010). Perfectionism, Perceived Stress, Drinking to Cope, and Alcohol-Related Problems among College Students. Journal of Counseling Psychology, 57(4), 439-450.

Richardson, C. G., \& Ratner, P. A. (2005). Sense of coherence as a moderator of the effects of stressful life events on health. Journal of Epidemiology \& Community Health, 59(11), 979-984.

Roberti, J. W., Harrington, L. N., \& Storch, E. A. (2006). Further Psychometric Support for the 10-Item Version of the Perceived Stress Scale. Journal of College Counseling, $9(2), 135$.

Rod, N. H., Grønbaek, M., Schnohr, P., Prescott, E., \& Kristensen, T. S. (2009).

Perceived stress as a risk factor for changes in health behaviour and cardiac risk profile: a longitudinal study. Journal Of Internal Medicine, 266(5), 467-475. doi: 10.1111/j.13652796.2009.02124.x

Rutter, M. (1985). Resilience in the face of adversity: Protective factors and resistance to psychiatric disorder. British Journal of Psychiatry, 147(6), 598-611. doi:

10.1192/bjp.147.6.598

Sarenmalm, E. K., Browall, M., Persson, L. O., Fall-Dickson, J., \& Gaston-Johansson, F. (2013). Relationship of sense of coherence to stressful events, coping strategies, health status, and quality of life in women with breast cancer. Psycho-Oncology, 22(1), 20-27. doi: 10.1002/pon.2053

Seligman, M., \& Csikszentmihalyi, M. (2000). Positive Psychology: An Introduction. American Psychologist, 55(1), 5-14.

Seligman, M. E. P., \& Csikszentmihalyi, M. (2000). Positive psychology: An introduction. American Psychologist, 55(1), 5-14. doi: 10.1037/0003-066x.55.1.5

Selye, H. (1950). Stress and the general adaptation sundrome. British Medical Journal, 1(4667), 1383-1392.

Selye, H. (1976a). The birth of the G.A.S. The Stress of Life (Revised ed., pp. 29-56). New York/St Louis/San Francisco/London/Toronto: McGraw-Hill Book Company.

Selye, H. (1976b). Blueprint for dissection The Stress of Life (Revised Edition ed., pp. 57-95). New York/ St. Louis/ San Francisco/ London/ Toronto: McGraw-Hill Book Compnay. 
Selye, H. (1976c). The discovery of stress The Stress of Life (Revised Edition ed., pp. 114). New York/ St. Louis/ San Francisco/ London/ Toronto: McGraw-Hill Book Company.

Skirka, N. (2000). The relationship of hardiness, sense of coherence, sports participation, and gender to perceived stress and psychological symptoms among college students. The Journal Of Sports Medicine And Physical Fitness, 40(1), 63-70.

Smith, T. L., \& Meyers, L. S. (1997). The Sense of Coherence: Its Relationship to Personality, Stress, and Health Measures. [Article]. Journal of Social Behavior \& Personality, 12(2), 513-526.

Snell, D. L., Siegert, R. J., Jean, E., Hay-Smith, C., \& Surgenor, L. J. (2011). Factor Structure of the Brief COPE in People With Mild Traumatic Brain Injury. Journal of Head Trauma Rehabilitation, 26(6), 468-477. doi: 10.1097/HTR.0b013e3181fc5e1e

Sullivan, G. C. (1993). Towards clarification of convergent concepts: sense of coherence, will to meaning, locus of control, learned helplessness and hardiness. Journal Of Advanced Nursing, 18(11), 1772-1778.

Suominen, S., Blomberg, H., Helenius, H., \& Koskenvuo, M. (1999). Sense of coherence and health - Does the association depend on resistance resources? A study of 3115 adults in Finland. Psychology \& Health, 14(5), 937-948. doi: 10.1080/08870449908407358

Suraj, S., \& Singh, A. (2011). Study of sense of coherence health promoting behavior in north Indian students. The Indian Journal Of Medical Research, 134(5), 645-652. doi: 10.4103/0971-5916.90989

Tobamidanik, L., \& Zabkiewicz, D. (2009). Indicators of sense of coherence and alcohol consumption-related problems: the 2000 U.S. National alcohol survey. Substance Use \& Misuse, 44(3), 357-373. doi: 10.1080/10826080802347511

Tomaka, J., Morales-Monks, S., \& Shamaley, A. G. (2013). Stress and coping mediate relationships between contingent and global self-esteem and alcohol-related problems among college drinkers. Stress and Health: Journal of the International Society for the Investigation of Stress, 29(3), 205-213.

U.S. Department of Education. (2012). Strategic Plan for Fiscal Years 2011-2014. Washington D.C.: Retrieved from http://www2.ed.gov/about/reports/strat/plan201114/plan-2011.pdf. 
Vaez, M., \& Laflamme, L. (2008). Experienced stress, psychological symptoms, selfrated health and academic acheivement: A longitudinal study of Swedish university students. Social Behavior \& Personality: An International Journal, 36(2), 183-195.

Vastamäki, J., Moser, K., \& Paul, K. I. (2009). How stable is sense of coherence? Changes following an intervention for unemployed individuals. Scandinavian Journal Of Psychology, 50(2), 161-171.

Viera, A. J., \& Garrett, J. M. (2005). Understanding Interobserver Agreement: The Kappa Statistic. Family Medicine, 37(5), 360-363.

Wainwright, N. W. J., Surtees, P. G., Welch, A. A., Luben, R. N., Khaw, K.-T., \& Bingham, S. A. (2007). Healthy lifestyle choices: Could sense of coherence aid health promotion. Journal Of Epidemiology And Community Health, 61(10), 871-876. doi: 10.1136/jech.2006.056275

Welle, P. D., \& Graf, H. M. (2011). Effective Lifestyle Habits and Coping Strategies for Stress Tolerance among College Students. American Journal of Health Education, 42(2), 96-105.

Wichianson, J. R., Bughi, S. A., Unger, J. B., Spruijt-Metz, D., \& Nguyen-Rodriguez, S. T. (2009). Perceived stress, coping and night-eating in college students. [Article]. Stress $\&$ Health: Journal of the International Society for the Investigation of Stress, 25(3), 235240. doi: $10.1002 / \mathrm{smi} .1242$

Wilburn, V. R., \& Smith, D. E. (2005). Stress, self-esteem, and suicidal tendencies in late adolescence. [Article]. Adolescence, 40(157), 33-45.

WKU Office of Institutional Research. (2013). Fact Book 2013, from https://www.wku.edu/instres/documents/2013_fact_book.pdf 
Appendix A

Subject Informed Consent Document: Reliability Assessment

Investigator: D. Todd Misener

Site: Western Kentucky

University

Phone number if you have questions: (270) 745-6531

\section{Introduction:}

You are invited to participate in a research study by answering the attached survey about your health habits and experience of stress in your life. Approximately 40 subjects will be invited to participate. The purpose of this study is to assess the inter-rater reliability of the survey questions. You will be asked to complete this survey a total of two times. The second administration of the survey will be conducted 7 days following the first administration.

\section{Procedures:}

In this study, you will be asked to complete the enclosed survey. It will take approximately 10 minutes to complete. As part of this research you will be asked to generate a unique identifying number using the year you were born, the last 2 digits of your phone number, and the date in the month you were born (i.e. 91-93-04). Using the unique identifying number, your surveys will be matched up to compare their responses on both questionnaires.

\section{Potential Risks:}

The risks associated with your participation in this study are minimal. You will not be asked to provide any individually identifying information on the survey, and the results of this study will only be reported in aggregate.

\section{Voluntary Participation:}

Taking part in this study is voluntary. By completing this survey you agree to take part in the research study. You do not have to answer any questions that make you uncomfortable. You may choose not to take part at all. If you decide to be in this study you may stop taking part at any time. If you decide not to be in the study or if you stop taking part at any time, you will not lose any benefits for which you may qualify. Your completion of this survey means that this study has been discussed with you, that your questions have been answered, and that you are voluntarily choosing to take part in the study. This informed consent document is not a contract. You are not giving up any legal rights by agreeing to this informed consent document. You will be provided a copy of this page for your records. Individuals from the University of Louisville School of Public Health \& Information Sciences, the Institutional Review Board (IRB), the Human Subjects Protection Program Office (HSPPO), the Western Kentucky University IRB and other regulatory agencies may inspect these records. In all other respects, however, the data will be held in confidence to the extent permitted by law. Should the data be published, your identity will not be disclosed.

If you have any questions, concerns, or complaints about the research study, please contact me, Todd Misener at (270) 745-6531. If you have any questions about your 
rights as a research subject, you may call the Human Subjects Protection Program Office at 502-852-5188. You can discuss any questions about your rights as a research subject, in private, with a member of the Institutional Review Board (IRB).

You may also call this number if you have other questions about the research, and you cannot reach the research staff, or you want to talk to someone else. The IRB is an independent committee made up of people from the University community, staff of the institutions, as well as people from the community not connected with these issues. The IRB has reviewed this research study.

If you have concerns or complaints about the research or research staff and you do not wish to give your name, you may call 1-877-852-1167. This is a 24-hour hotline answered by people who do not work at the University of Louisville or Western Kentucky University.

\author{
THIS PROJECT HAS BEEN REVIEWED AND APPROVED BY THE \\ WKU AND UNIVERSITY OF LOUISVILLE INSTITUATIONAL REVIEW BOARD (IRB) \\ Paul Mooney, WKU Human Protections Administrator \& \\ Rebecca H. Higgins, Director, Human Subjects Protection Program, University of Louisville.
}


Appendix B

Student Reliability Survey

Using the boxes provided, please generate at unique identifying number using the following information specific to you:

Birth Year (i.e. 1991):

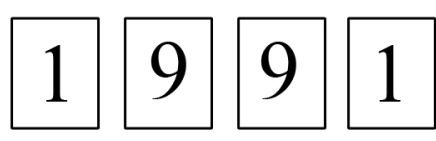

Last Two Digits of your phone number (i.e. 290-1234 ): 3

Birth Year:

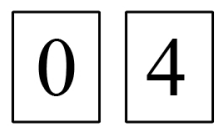

Day In Month You Were Born ( i.e. born on 4th of July): 04

Last two digits of your phone number:
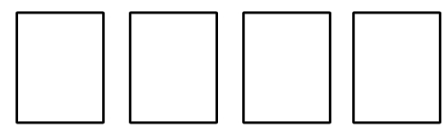

Day in month your were born:
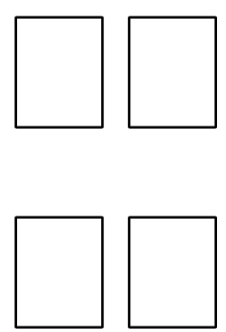
SURVEY\#: 00 Provide only one answer to each question.

1. Within the last 30 days, on how many days did you use: cigarettes, cigars, little cigars, clove cigarettes, and/or tobacco from a water pipe (hookah)

2. Over the past 2 weeks, rounded to the nearest hour, on average how many hours of sleep did you get each night?

3. How many servings of fruits and vegetables do you usually have per day? $(1$ serving $=$ 1 medium piece of fruit; $1 / 2$ fresh, frozen or canned fruits/vegetables; $3 / 4$ cup fruit/vegetable juice; 1 cup salad greens; or $1 / 4$ cup dried fruit).

4. Within the last 30 days, on how many days did you use: alcohol (beer, wine, liquor)?

IF you drink alcohol answer 5a and 5b. If you don't drink alcohol go to question 6.

5a. Over the last two weeks, how many times have you had five or more drinks of alcohol in a sitting?

$5 b$. The last time you "partied"/socialized how many drinks of alcohol did you have? ? (One drink of alcohol is defined as one 12oz. can or bottle of beer or wine cooler, a $4 \mathrm{oz}$. glass of wine, or a shot of liquor straight or in a mixed drink.)

6. On how many of the past seven days did you do moderate-intensity cardio or aerobic exercise (caused a noticeable increase in heart-rate, such as a brisk walk) for at least 30 minutes?

7. On how many of the past seven days did you do vigorous-intensity cardio or aerobic exercise (caused large increases in breathing or heart rate, such as jogging) for at least 20 minutes?

8. On how many of the past seven days did you do 8-10 strength training exercises (such as resistance weight machines) for $8-12$ repetitions each?

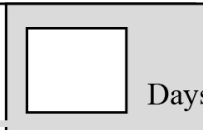

Days

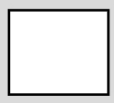

Hours per night

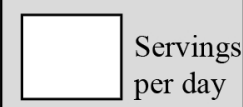

per day

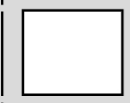

Days

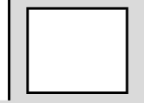

Times

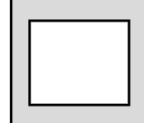

Drinks

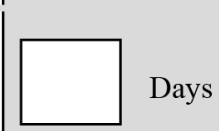

ays

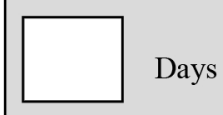

Days

Days

Next is a series of 13 questions relating to various aspects of your lives. Each question has seven possible answers. Please mark the number which expresses your answer, with numbers 1 and 7 being the extreme answers. If the words under 1 are right for you, circle 1 ; if the words under 7 are right for you, circle 7 . If you feel differently, CIRCLE the number which best expresses your feeling. Please give only one answer to each question.

9. Do you have the feeling that you don't really care about what goes on around you?

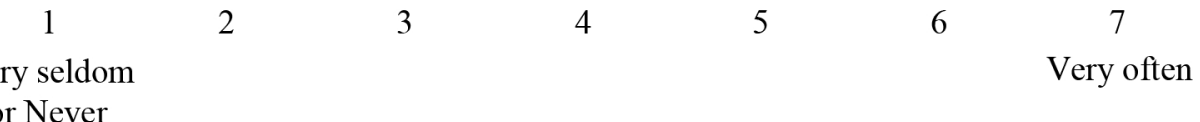

10. Has it happened in the past that you were surprised by the behavior of people whom you thought you knew well?

3

4

5

6

7

Never

Always

Happened

happened

11. Has it happened that people whom you counted on disappointed you?

$\begin{array}{ccccccc}1 & 2 & 3 & 4 & 5 & 6 & \begin{array}{c}7 \\ \text { Always } \\ \text { hever } \\ \text { happened }\end{array}\end{array}$


12. Until now your life has had:

$\begin{array}{ccccccc}1 & 2 & 3 & 4 & 5 & 6 & 7 \\ \begin{array}{c}\text { No clear goals } \\ \text { or purpose at all }\end{array} & & & & & & \begin{array}{c}\text { Very clear goals } \\ \text { and purpose }\end{array}\end{array}$

13. Do you have the feeling that you're being treated unfairly?
1
2
3
4
5

6

7

Very often
Very seldom or never

14. Do you have the feeling that you are in an unfamiliar situation and don't know what to do?

$\begin{array}{cllllcc}1 & 2 & 3 & 4 & 5 & 6 & \begin{array}{c}7 \\ \text { Very seldom } \\ \text { or never }\end{array}\end{array}$

15. Doing the things you do every day is:

$\begin{array}{ccccccc}1 & 2 & 3 & 4 & 5 & 6 & 7 \\ \begin{array}{c}\text { A source of } \\ \text { deep pleasure }\end{array} & & & & & \begin{array}{c}\text { A source of pain } \\ \text { and boredom }\end{array}\end{array}$

16. Do you have very mixed-up feelings and ideas?

$\begin{array}{ccccccc}1 & 2 & 3 & 4 & 5 & 6 & 7 \\ \text { Very seldo }\end{array}$

Very often

or never

17. Does it happen that you have feelings inside you would rather not feel?
1
2
3
4
5
6
7
Very seldom or never

Very often

18. Many people - even those with a strong character - sometimes feel like sad sacks (losers) in certain situations. How often have you felt this way in the past?

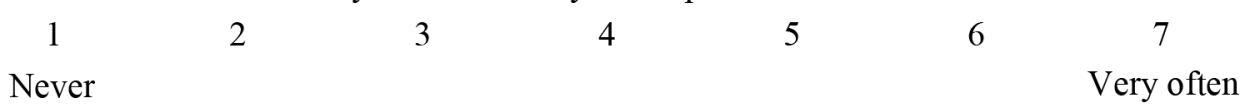

19. When something happened, have you generally found that:

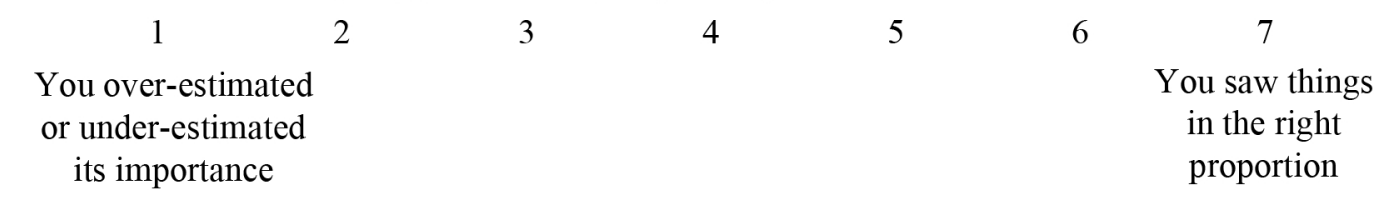

20. How often do you have the feeling that there's little meaning in the things you do in your daily life?

$\begin{array}{ccccccc}1 & 2 & 3 & 4 & 5 & 6 & 7 \\ \text { Very often } & & & & & & \begin{array}{c}\text { Very seldom } \\ \text { or never }\end{array}\end{array}$

21. How often do you have feelings that you're not sure you can keep under control?

$\begin{array}{ccccccc}1 & 2 & 3 & 4 & 5 & 6 & \begin{array}{c}7 \\ \text { Very seldom } \\ \text { or never }\end{array}\end{array}$


The next 10 questions ask about your feelings and thoughts during the last month. In each case, please select the response that best represents how often you felt or thought a certain way.

22. In the last month, how often have you been upset because of something that happened unexpectedly?

23. In the last month, how often have you felt that you were unable to control the important things in your life?

24. In the last month, how often have you felt nervous and "stressed"?

25. In the last month, how often have you felt confident about your ability to handle your personal problems?

26. In the last month, how often have you felt that things were going your way?

27. In the last month, how often have you found that you could not cope with all the things that you had to do?

28. In the last month, how often have you been able to control irritations in your life?

29. In the last month, how often have you felt that you were on top of things?

30. In the last month, how often have you been angered because of things that were outside your control?

31. In the last month, how often have you felt difficulties were piling up so high that you could not overcome them?

One more section to go 
The next 28 questions deal with ways you've been coping with the stress in your life since classes began this semester. There are many ways to try to deal with problems. These items ask what you've been doing to cope with stress in your life since class began this semester.

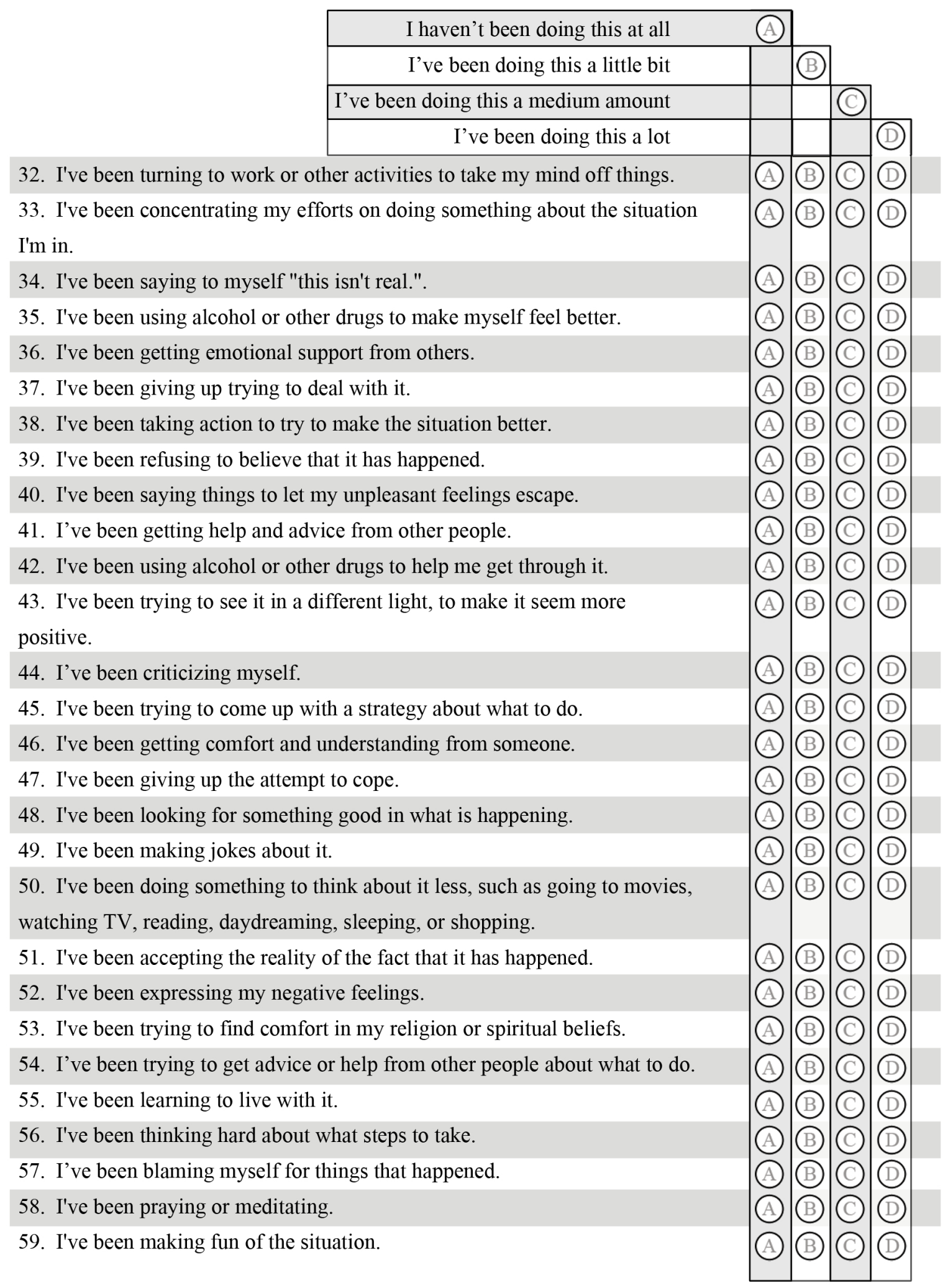




\title{
Appendix C
}

\section{Invitation to Participate}

\author{
D. Todd Misener, MPH, CHES \\ 1906 College Heights Blvd. \\ Western Kentucky University \\ Bowling Green, KY 42101 \\ todd.misener@wku.edu
}

February $26^{\text {th }}, 2014$

\section{Dear WKU Colleagues:}

I am a doctoral student at the University of Louisville and am seeking your assistance with my survey administration. My goal is to have a minimum of 372 students aged 1824 years complete the survey and I am asking for your permission to administer the paper survey to your class during your class time. The survey will take 10-15 minutes to complete. The purpose of this study is to investigate the relationship between sense of coherence, the engagement in health behaviors, and individual coping styles of U.S. college students aged 18-24 years.

As part of this research your students will be asked to provide on a separate form from the survey their survey number, student ID (800\#) and signature signifying their permission to access the following data from their academic records: age, gender, ethnicity, housing status, international status, current hours enrolled, cumulative grade point average and enrollment status. Please know that all student identifiers will be removed from the academic information prior to merging their academic and survey data. As an incentive to participate, all those who participate in this survey will be entered into a drawing for one of five $\$ 100$ gift-cards.

Your assistance with this process is very much appreciated. If you decide to grant me permission to survey your class please let me know the day, time and location of your class.

Sincerely,

D. Todd Misener

IRB approval \# 
Appendix D

Student Stress \& Coping Survey

Thank you for your willingness to complete this survey. Please read the instructions for each section carefully and answer the questions honestly. Please note the survey number at the top left of the next page. This is the number you will need to include on the form requesting access to your student records. Please know that your academic information will not include any personally identifying information when added to the survey data, and that all information will be confidential. Please know that you may choose to halt your participation in this survey at any time with no penalty. Also, as a thank you for your willingness to complete this survey, your name will be added to a drawing for one of $5 \$ 100$ scholarships.

Please turn the page and begin... 
SURVEY\#: 00 Provide only one answer to each question.

1. Within the last 30 days, on how many days did you use: cigarettes, cigars, little cigars, clove cigarettes, and/or tobacco from a water pipe (hookah)

2. Over the past 2 weeks, rounded to the nearest hour, on average how many hours of sleep did you get each night?

3. How many servings of fruits and vegetables do you usually have per day? $(1$ serving $=$ 1 medium piece of fruit; $1 / 2$ fresh, frozen or canned fruits/vegetables; $3 / 4$ cup fruit/vegetable juice; 1 cup salad greens; or $1 / 4$ cup dried fruit).

4. Within the last 30 days, on how many days did you use: alcohol (beer, wine, liquor)?

IF you drink alcohol answer 5a and 5b. If you don't drink alcohol go to question 6.

5a. Over the last two weeks, how many times have you had five or more drinks of alcohol in a sitting?

$5 b$. The last time you "partied"/socialized how many drinks of alcohol did you have? ? (One drink of alcohol is defined as one 12oz. can or bottle of beer or wine cooler, a $4 \mathrm{oz}$. glass of wine, or a shot of liquor straight or in a mixed drink.)

6. On how many of the past seven days did you do moderate-intensity cardio or aerobic exercise (caused a noticeable increase in heart-rate, such as a brisk walk) for at least 30 minutes?

7. On how many of the past seven days did you do vigorous-intensity cardio or aerobic exercise (caused large increases in breathing or heart rate, such as jogging) for at least 20 minutes?

8. On how many of the past seven days did you do 8-10 strength training exercises (such as resistance weight machines) for $8-12$ repetitions each?

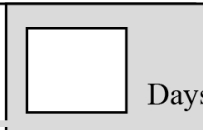

Days

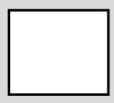

Hours per night

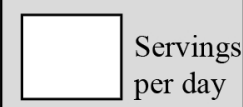

per day

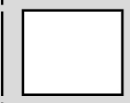

Days

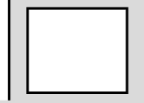

Times

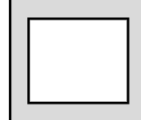

Drinks

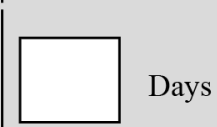

ays

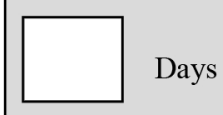

Days

Days

Next is a series of 13 questions relating to various aspects of your lives. Each question has seven possible answers. Please mark the number which expresses your answer, with numbers 1 and 7 being the extreme answers. If the words under 1 are right for you, circle 1 ; if the words under 7 are right for you, circle 7 . If you feel differently, CIRCLE the number which best expresses your feeling. Please give only one answer to each question.

9. Do you have the feeling that you don't really care about what goes on around you?

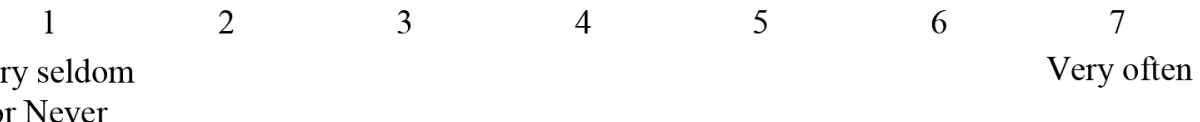

10. Has it happened in the past that you were surprised by the behavior of people whom you thought you knew well?

3

4

5

6

7

Never

Always

Happened

happened

11. Has it happened that people whom you counted on disappointed you?

$\begin{array}{ccccccc}1 & 2 & 3 & 4 & 5 & 6 & \begin{array}{c}7 \\ \text { Always } \\ \text { hever } \\ \text { happened }\end{array}\end{array}$


12. Until now your life has had:

$\begin{array}{ccccccc}1 & 2 & 3 & 4 & 5 & 6 & 7 \\ \begin{array}{c}\text { No clear goals } \\ \text { or purpose at all }\end{array} & & & & & & \begin{array}{c}\text { Very clear goals } \\ \text { and purpose }\end{array}\end{array}$

13. Do you have the feeling that you're being treated unfairly?
1
2
3
4
5

6

7

Very often
Very seldom or never

14. Do you have the feeling that you are in an unfamiliar situation and don't know what to do?

$\begin{array}{cllllcc}1 & 2 & 3 & 4 & 5 & 6 & \begin{array}{c}7 \\ \text { Very seldom } \\ \text { or never }\end{array}\end{array}$

15. Doing the things you do every day is:

$\begin{array}{ccccccc}1 & 2 & 3 & 4 & 5 & 6 & 7 \\ \begin{array}{c}\text { A source of } \\ \text { deep pleasure }\end{array} & & & & & \begin{array}{c}\text { A source of pain } \\ \text { and boredom }\end{array}\end{array}$

16. Do you have very mixed-up feelings and ideas?
1
2
3
4
5
$6 \quad 7$

Very often

Very seldom

or never

17. Does it happen that you have feelings inside you would rather not feel?
1
2
3
4
5
6
7
Very seldom or never

Very often

18. Many people - even those with a strong character - sometimes feel like sad sacks (losers) in certain situations. How often have you felt this way in the past?

$\begin{array}{ccccccc}1 & 2 & 3 & 4 & 5 & 6 & \begin{array}{c}7 \\ \text { Never }\end{array} \\ & & & & & & \text { Very often }\end{array}$

19. When something happened, have you generally found that:

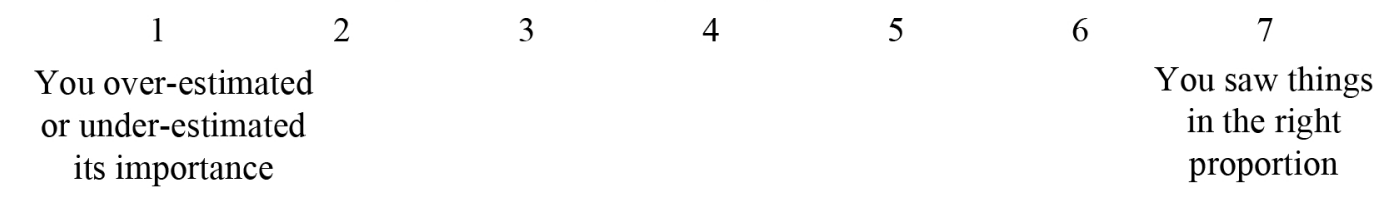

20. How often do you have the feeling that there's little meaning in the things you do in your daily life?

$\begin{array}{ccccccc}1 & 2 & 3 & 4 & 5 & 6 & 7 \\ \text { Very often } & & & & & & \begin{array}{c}\text { Very seldom } \\ \text { or never }\end{array}\end{array}$

21. How often do you have feelings that you're not sure you can keep under control?

$\begin{array}{ccccccc}1 & 2 & 3 & 4 & 5 & 6 & \begin{array}{c}7 \\ \text { Very seldom } \\ \text { or never }\end{array}\end{array}$


The next 10 questions ask about your feelings and thoughts during the last month. In each case, please select the response that best represents how often you felt or thought a certain way.

22. In the last month, how often have you been upset because of something that happened unexpectedly?

23. In the last month, how often have you felt that you were unable to control the important things in your life?

24. In the last month, how often have you felt nervous and "stressed"?

25. In the last month, how often have you felt confident about your ability to handle your personal problems?

26. In the last month, how often have you felt that things were going your way?

27. In the last month, how often have you found that you could not cope with all the things that you had to do?

28. In the last month, how often have you been able to control irritations in your life?

29. In the last month, how often have you felt that you were on top of things?

30. In the last month, how often have you been angered because of things that were outside your control?

31. In the last month, how often have you felt difficulties were piling up so high that you could not overcome them?

One more section to go 
The next 28 questions deal with ways you've been coping with the stress in your life since classes began this semester. There are many ways to try to deal with problems. These items ask what you've been doing to cope with stress in your life since class began this semester.

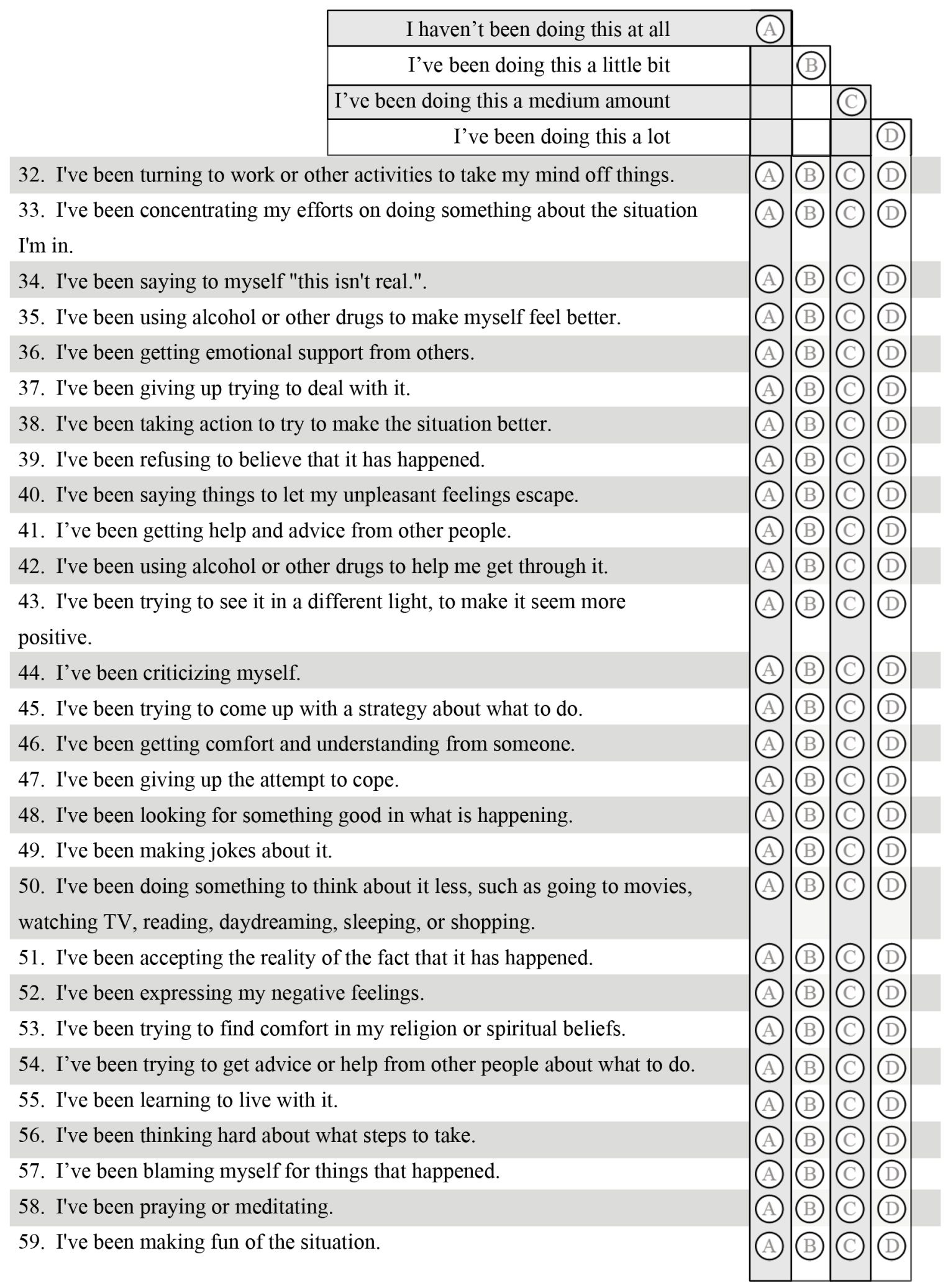


Appendix E

Subject Informed Consent Document

Investigator: D. Todd Misener

Site: Western Kentucky University

Phone number if you have questions: (270) 745-6531

Introduction:

You are invited to participate in a research study by answering the attached questionnaire about your health habits and experience of stress in your life. Approximately 372 subjects will be invited to participate. The purpose of this study is to investigate the relationship between sense of coherence, the engagement in health behaviors, and individual coping styles of college students aged 18-24 years.

Procedures:

In this study, you will be asked to complete the enclosed questionnaire. It will take approximately 10 minutes to complete. As part of this research you will be asked to provide on a separate form from the survey your survey number, student ID (800\#) and signature signifying your permission to access the following data from your academic records: age, gender, ethnicity, housing status, international status, current hours enrolled, and cumulative grade point average. All those who participate in this survey will be entered into a drawing for one of five \$100 gift-cards.

Potential Risks:

The risks associated with your participation in this study are minimal. Your student ID and any identifier will be deleted from the data set prior to analysis to maintain your anonymity. You will not be asked to provide any individually identifying information on the survey and no individually identifying information will be reported.

Voluntary Participation:

Taking part in this study is voluntary. By completing this survey you agree to take part in the research study. You do not have to answer any questions that make you uncomfortable. You may choose not to take part at all. If you decide to be in this study you may stop taking part at any time. If you decide not to be in the study or if you stop taking part at any time, you will not lose any benefits for which you may qualify. Your completion of this survey means that this study has been discussed with you, that your questions have been answered, and that you are voluntarily choosing to take part in the study. This informed consent document is not a contract. You are not giving up any legal rights by agreeing to this informed consent document. You will be provided a copy of this page for your records. Individuals from the University of Louisville School of Public Health \& Information Sciences, the Institutional Review Board (IRB), the Human Subjects Protection Program Office (HSPPO), the Western Kentucky University IRB and other regulatory agencies may inspect these records. In all other respects, however, the data will be held in confidence to the extent permitted by law. Should the data be published, your identity will not be disclosed.

If you have any questions, concerns, or complaints about the research study, please contact me, Todd Misener at (270) 745-6531. If you have any questions about your 
rights as a research subject, you may call the Human Subjects Protection Program Office at 502-852-5188. You can discuss any questions about your rights as a research subject, in private, with a member of the Institutional Review Board (IRB).

You may also call this number if you have other questions about the research, and you cannot reach the research staff, or you want to talk to someone else. The IRB is an independent committee made up of people from the University community, staff of the institutions, as well as people from the community not connected with these issues. The IRB has reviewed this research study.

If you have concerns or complaints about the research or research staff and you do not wish to give your name, you may call 1-877-852-1167. This is a 24-hour hotline answered by people who do not work at the University of Louisville or Western Kentucky University.

\author{
THIS PROJECT HAS BEEN REVIEWED AND APPROVED BY THE \\ WKU AND UNIVERSITY OF LOUISVILLE INSTITUATIONAL REVIEW BOARD (IRB) \\ Paul Mooney, WKU Human Protections Administrator \& \\ Rebecca H. Higgins, Director, Human Subjects Protections Program, University of Louisville.
}




\section{Appendix F}

\section{Academic Data Permission Form}

In this study, you will be asked to complete the survey and you will be asked to provide your survey number, student ID (800\#) and signature signifying your permission to access the following data from your academic records: age, gender, ethnicity, housing status, international status, current hours enrolled, and cumulative grade point average. All those who participate in this survey will be entered into a drawing for one of five $\$ 100$ gift-cards.

The risks associated with your participation in this study are minimal. Your student ID and any identifier will be deleted from the data set prior to analysis to maintain your anonymity. You will not be asked to provide any individually identifying information on the survey and no individually identifying information will be reported.

Taking part in this study is voluntary. By providing your student ID (800\#), your survey number, and signature on the line provided you are granting permission for the primary investigator (Todd Misener) to retrieve and use the following data from your WKU academic records: gender, ethnicity, international status, hours enrolled, student classification, age, housing status, and cumulative grade point average. You are also acknowledging that you have read and agree to voluntarily participate in all aspects of the study that were listed in the Subject Informed Consent document you were provided.

\begin{tabular}{|c|c|c|}
\hline $\begin{array}{c}\text { Survey \# } \\
\text { Student ID } \\
(800 \#)\end{array}$ & Signature \\
\hline 00 & 800123456 & gaku Smith \\
\hline & & \\
\hline & & \\
\hline & & \\
\hline & & \\
\hline & & \\
\hline & & \\
\hline & & \\
\hline
\end{tabular}


Appendix G

Permission to use ACHA-NCHA Survey Questions

Hi Todd,

You have permission to use the 11 ACHA-NCHA questions you identified below in the instrument you are developing for implementation with 400 students at Western Kentucky University through May 31, 2014. Any further use of these items would require submission of a new request.

Best of luck with your research!

Mary Hoban

Mary T Hoban, PhD, MCHES

Director, ACHA-NCHA Program Office

American College Health Association

1362 Mellon Road, Suite 180

Hanover, MD 21076

443-270-4558

410-859-1510 (fax)

mhoban@acha.org

www.acha.org

www.acha-ncha.org

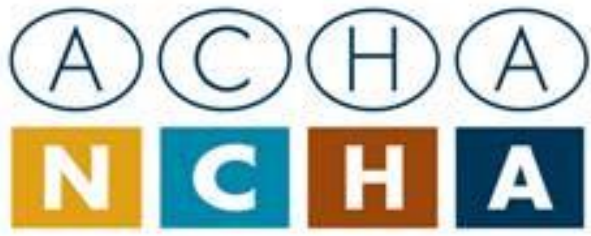

American College Health Association National College Health Assessment 


\section{CURRICULUM VITA}

NAME: D. Todd Misener

ADDRESS: Bowling Green, KY 42104

DOB: January 4, 1973

EDUCATION:

Bachelor of Science, Physical Education

University of Saskatchewan

Masters of Public Health, Health Education

Western Kentucky University

Doctor of Philosophy, Health Promotion

University of Louisville

PROFESSIONAL EXPERIENCE:

Assistant Director, Health \& Fitness July 2001 - Present Intramural-Recreational Sports Department, Western Kentucky University

Assistant Director, Health \& Fitness responsibilities include:

- Responsible for overall vision and planning for campus fitness and wellness programs, services and facilities.

- Manage operations of the Health \& Fitness Lab, including the oversight of all health and fitness services, massage therapy services, group fitness, instructional programs, special events, fitness center, and overall assessment of programs and services.

- Directly supervise 3 professional staff members (Fitness Coordinator, Registered Dietitian, and Office Associate) and the indirect supervision of their direct reports including 3 graduate assistants and approx. 50 student and part-time staff members.

- Manage multiple departmental budgets, including the generation of regular budget reports detailing monthly and yearly revenues and expenditures. 
- Serve as the webmaster for the Intramural-Recreational Sports department which involves the development, management, and maintenance of all eight departmental websites.

- Oversee the management and maintenance of fitness equipment and facilities including the fitness center, dance studio, Health \& Fitness Lab and open fitness areas.

- Manage marketing and promotions efforts for all areas in the IntramuralRecreational Sports department including the supervision of a graduate assistant in marketing, a part-time graphic design worker, and student videographers.

- Oversee data collection, analysis, and reporting for the department.

- Conduct health and fitness promotion seminars and presentations to campus and community groups as requested.

- Coordinate collaborative health promotion programs and events with various departments on campus.

Additional Role: Director of WKU Student Wellness Program responsibilities include:

- Oversee the J. Clifford Todd, Professor in Longevity \& Healthful Living Fund valued at over $\$ 1.2$ million, including budget management, stewardship, program vision, and development.

- Supervise the Student Wellness Coordinator who is the professional staff member responsible for coordinating the day to day operations of the program and who supervises the Student Wellness Program Graduate Assistant.

- Oversee the development of an evidence-based online health promotion program, database, and portal.

- Develop and implement policies and procedures necessary to comply with HIPPA standards.

- Conduct Institution Review Board approved research and assessment of student health behaviors and program participation.

- Complete detailed semi-annual and annual program and budget reports for program donor, sponsors and WKU administrators.

- Solicit additional funding through the WKU Development Office and the College Heights Foundation.

\section{PROFESSIONAL ACCOMPLISHMENTS:}

- Successfully petitioned WKU's College Heights Foundation for endowed funding to support the development of a campus Student Wellness program (\$1.2 million, J. Clifford Todd Professor in Longevity and Healthful Living Fund).

- Responsible for the vision, overall development and funding for the WellU® program. Beginning in 2007 and in collaboration with the WKU College Heights 
Foundation, WKU Health Services, and the Health \& Fitness Lab, I oversaw the development and design of WKU's Student Wellness Program titled "WellUß". Over the past 6 years program funding has increased from $\$ 0.00$ to over $\$ 100,000$ annually at no expense to students or the university and student participation has risen from 302 in its first year to 8, 995 students in 2013/2014.

- Since 2008, raised over $\$ 250,000$ in additional program funding beyond what the J. Clifford Todd Professor in Longevity and Healthful Living Fund provides.

- Led the successful development and registration of the WellUß program with the United States Patent and Trademark office. Officially registered August, $3^{\text {rd }}$ 2010.

- Designed an integrated online student registration/participation tracking/reporting system.

- Targeted funding for, developed and filled the Student Wellness Coordinator position to directly coordinate the day to day operations of the WellUß program.

- In collaboration with the WKU College of Health \& Human Services, gained funding, developed and filled a graduate assistant position to assist the Student Wellness Coordinator.

- Currently leading the grant funded development of an online wellness education portal to provide health and wellness promotion programming to WKU's satellite campuses.

- Coordinated WKU's annual Faculty \& Staff Health Fair beginning in 2001 and delegated to the Employee Wellness Manager in 2005.

- Served as the WKU Employee Wellness Advisory Committee Chair, 2002 2005.

- In collaboration with WKU Health Services successfully petitioned WKU's benefits committee for funding to conduct annual Health Risk Appraisals for all benefits eligible staff. The funding was awarded in 2003.

- In collaboration with WKU Health Services, developed WKU's employee wellness program, including gaining full university funding for and hiring a fulltime Employee Wellness Manager position. 2004 - 2005

- Supervised and mentored WKU Employee Wellness Program Manager, 2005 2008.

\section{TEACHING EXPERIENCE:}

Part-time Instructor,

August 2012 - Present

WKU College of Health \& Human Services

Personal Health (PH 100) (teach 1-2 sections per semester)

Purpose: Examines behaviors and environmental conditions that enhance or hinder an individual's health status. In addition to exploring social and environmental factors, 
students are encouraged to think critically about behavioral choices that impact ones' health. Students assess their individual behavior in the light of current scientific knowledge concerning mental health; drugs alcohol and tobacco; health care; selection of health products; prevention of disease; nutrition; exercise, and stress management

Part-time Instructor, August 2001 - May 2008

WKU College of Health \& Human Services

PH 390, Fitness \& Wellness Assessment:( taught 1-2 sections per semester)

Purpose: To familiarize allied health students with the basic skills of adult wellness and fitness assessment and to foster the appreciation of the role of regular exercise in disease prevention and health promotion. Practical (hands-on) clinical skill development was emphasized.

\section{RESEARCH:}

- Dissertation: An examination of the relationship between sense of coherence, engagement in health behaviors, and individual coping styles. Successfully defended in August 2014. Presently working on publication submission to the Journal of American College Health.

- Beginning in 2002, I have served as a co-investigator involved with the administration and evaluation of the American College Health Associations, National College Health Assessment administration at WKU.

- Currently oversee the research and assessment efforts for the IntramuralRecreational Sports program.

- Currently engaged in an IRB approved joint research project between WellU® and WKU Health Services investigating associations between individual health, engagement in recreational and wellness programs and student success and retention using ACHA-NCHA data, WellU® participation data and institutional data.

- Serving as the Chair for NIRSA's Research \& Assessment Committee (2013 2015)

\section{NATIONAL MEETING PRESENTATIONS:}

"Don't forget those closest to you: Using MAP-Works to connect with your student employees"

2014 Mastering MAP-Works and Benchmarking Conference, Indianapolis IN, June, 2014.

"Expanding your engagement partners to reach at risk students: Campus Recreation/Wellness" 
2014 Mastering MAP-Works and Benchmarking Conference.

Indianapolis IN, June, 2014.

"Research \& Assessment Roundtable"

Co-presenting with Stacey Hall, University of New Hampshire, and Nicole Olmeda, University of Texas, at 2014 NIRSA Annual Conference.

Nashville TN, April, 2014.

"Retention and Assessment Strategies for Collegiate Recreation"

Presented at NIRSA's Region II Conference.

Biloxi Mississippi, October 2013.

"Pre-conference on Assessment"

Co-presenting with Tina Clawson, Oregon State University; Doug Franklin, Ohio

University; Tamara Jarrett, CREW/Solutions; and Nicole Olmeda, University of Texas at NIRSA's 2013 National Conference.

Las Vegas NV, March 2013.

"Developing a Healthy Campus Ecology"

Developed and moderated a session discussing innovative health promotion programs and services on college campuses at the American Public Health Associations national conference in 2012.

San Francisco, CA, October 2012.

"Development and Integration of a Comprehensive Student Wellness Program on a College Campus."

Presented a poster presentation at the American Public Health Associations national conference in 2011.

Washington, D.C., October 2011.

"Making room for health promotion in student learning outcomes and accountability measures"

Presented at the American College Health Associations annual meeting in 2011.

Phoenix, AZ, June 2011.

CERTIFICATIONS \& AWARDS:

Certified Health Education Specialist - National Commission of Health Education Credentialing

CPR/First Aid for the professional rescuer - American Red Cross

2002 Outstanding Graduate Student Award - WKU College of Public Health

2014 WKU Intramural Recreational Sports Alumni of the Year Award Recipient

2014 WKU Staff Excellence Award Recipient - Professional Staff Category 


\section{SKILLS \& COMPETENSIES:}

- An innovator

- An active collaborator

- Excellent communication and organizational skills.

- Proficient in the application of student development theory in higher education.

- Well versed in the application and assessment of the CAS standards.

- Knowledgeable in current and emerging wellness and recreation industry trends.

- Strong leadership skills, and strong history of developing staff.

- Advanced skills with Microsoft Office products.

- Proficient in program assessment, statistical analysis, and strategic planning.

- Skilled in website development, management and design (CMS, Dreamweaver, html).

- Proficient in HIPPA compliance regulations and student health insurance.

- Graphic Designer (Adobe Illustrator, Photoshop, InDesign, Adobe Professional).

\section{PROFESSIONAL MEMBERSHIPS:}

- National Intramural Recreational Sports Association (NIRSA)

- American College Personnel Association (ACPA)

- American College Health Association (ACHA)

- Mid-Atlantic College Health Association (MACHA)

- Member of NIRSA's Wellness Commission

- Member of NIRSA's Research \& Assessment Committee (Chair) 